$P N L-4642$

$1-$

NUREG/CR-3176

PNL-4642

\title{
Crack Growth Evaluation for Small Cracks in Reactor Coolant Piping
}

Prepared by F. A. Simonen, M. E. Mayfield, T. P. Forte, D. Jones

Pacific Northwest Laboratory

Operated by

Battelle Memorial Institute

Prepared for

U.S. Nuclear Regulatory

Commission 


\section{NOTICE}

This report was prepared as an account of work sponsored by an agency of the United States Government. Neither the United States Government nor any agency thereof, or any of their employees, makes any warranty, expressed or implied, or assumes any legal liability of responsibility for any third party's use, or the results of such use, of any information, apparatus, product or process disclosed in this report, or represents that its use by such third party would not infringe privately owned rights.

\section{Availability of Reference Materials Cited in NRC Publications}

Most documents cited in NRC publications will be available from one of the following sources:

1. The NRC Public Document Room, 1717 H Street, N.W. Washington, DC 20555

2. The NRC/GPO Sales Program, U.S. Nuclear Regulatory Commission, Washington, DC 20555

3. The National Technical Information Service, Springfield, VA 22161

Although the listing that follows represents the majority of documents cited in NRC publications, it is not intended to be exhaustive.

Referenced documents available for inspection and copying for a fee from the NRC Public Document Room include NRC correspondence and ir.ternal NRC memoranda; NRC Office of Inspection and Enforcement bulletins, circulars, information notices, inspection and investigation notices; Licensee Event Reports; vendor reports and correspondence; Commission papers; and applicant and licensee documents and correspondence.

The following documents in the NUREG series are available for purchase from the NRC/GPO Sales Program: formal NRC staff and contractor reports, NRC-sponsored conference proceedings, and NRC booklets and brochures. Also available are Regulatory Guides, NRC regulations in the Code of Federal Regulations, and Nuclear Regulatory Commission Issuances.

Documents available from the National Technical Information Service include NUREG series reports and technical reports prepared by other federal agencies and reports prepared by the Atomic Energy Commission, forerunner agency to the Nuclear Regulatory Commission.

Documents available from public and special technical libraries include all open literature items, such as books, journal and periodical articles, and transactions. Federal Register notices, federal and state legislation, and congressional reports can usually be obtained from these libraries.

Documents such as theses, dissertations, foreign reports and translations, and non-NRC conference proceedings are available for purchase trom the organization sponsoring the publication cited.

Single copies of NRC draft reports are available free upon written request to the Division of Technical Information and Document Control, U.S. Nuclear Regulatory Commission, Washington, DC 20555 .

Copies of industry codes and standards used in a substantive manner in the NRC regulatory process are maintained at the NRC Library, 7920 Norfolk Avenue, Bethesda, Maryland, and are available there for reference use by the public. Codes and standards are usually copyrighted and may be purchased from the originating organization or, if they are American National Standards, from the American National Standards Institute, 1430 Broadway, New York, NY 10018. 
NUREG/CR-3176

PNL-4642

R5

\section{Crack Growth Evaluation for Small Cracks in Reactor Coolant Piping}

Manuscript Completed: January 1983

Date Published: April 1983

Prepared by

F. A. Simonen, M. E. Mayfield*, T. P. Forte*, D. Jones*

Pacific Northwest Laboratory

Richland, WA 99352

*Battelle Columbus Laboratories

Prepared for

Division of Engineering Technology

Office of Nuclear Regulatory Research

U.S. Nuclear Regulatory Commission

Washington, D.C. 20555

NRC FIN B2289 


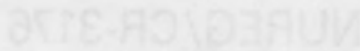

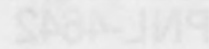 \\ c.p.}

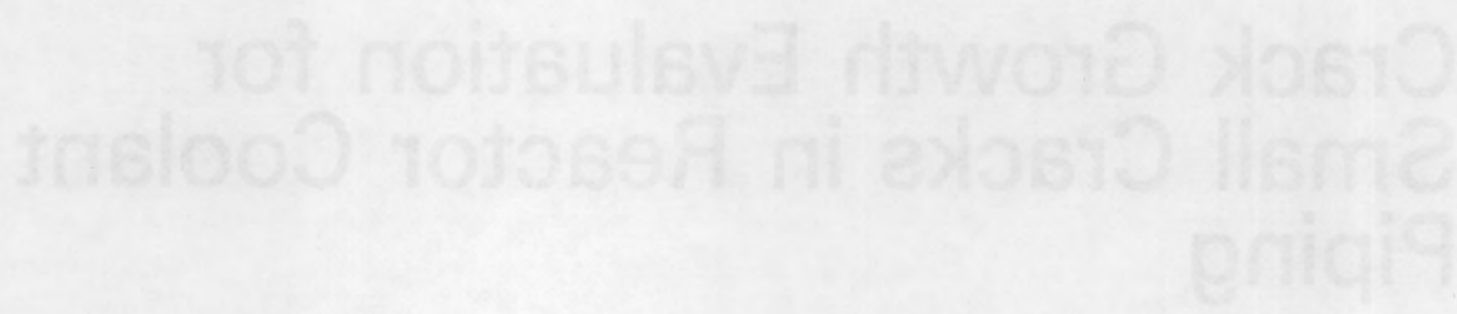




\section{ABSTRACT}

This report describes an evaluation of fatigue crack growth in Pressurized Water Reactor (PWR) piping. The results provide supporting data to a research program for the U.S. Nuclear Regulatory Commission (NRC) at the Pacific Northwest Laboratory which has the objective of evaluating the effectiveness and reliability of inservice inspection of primary coolant piping. The crack growth calculations described here were performed after a review and refinement of input parameters to a previous study entitled "Cold Leg Integrity Evaluation." Less conservative estimates of initial flaw size, crack growth rate curves, and stress transients resulted in a significant increase in predicted life for flawed piping over the results of the original study. Except for the charging inlet nozzle analysis, all locations of postulated cracking had predicted lives well in excess of the 40-year design life. A detailed comparison is made with published probabilistic fracture mechanics calculations. The deterministic predictions of long fatigue life are shown to be consistent with predicted low failure probabilities for PWR primary coolant piping. The two analysis approaches together indicate that present inspection rules are adequate to detect in primary coolant piping the fatigue crack growth caused by design stress transients. 


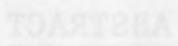

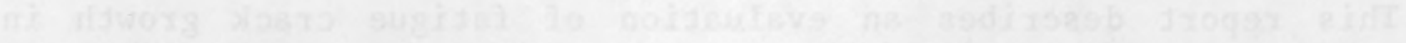

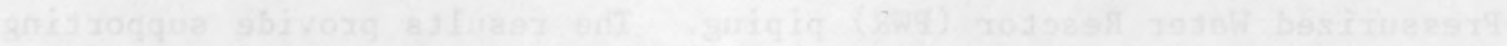

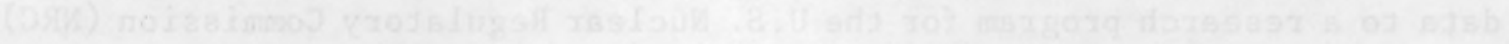

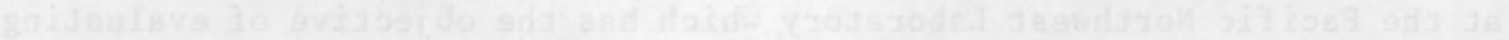

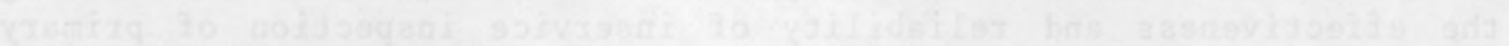

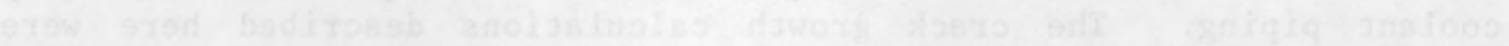

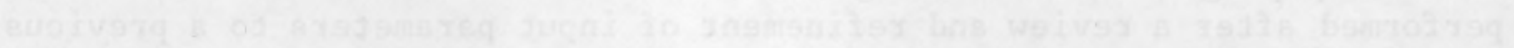

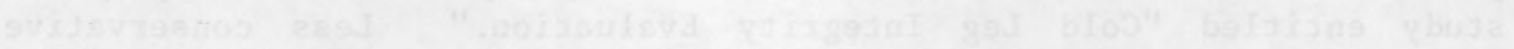

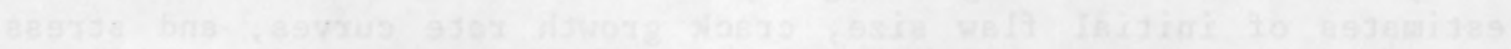

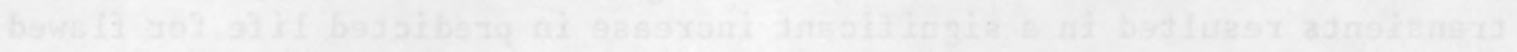

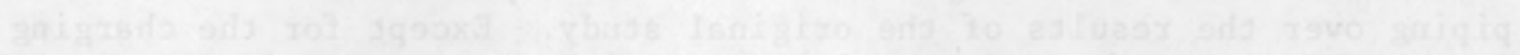

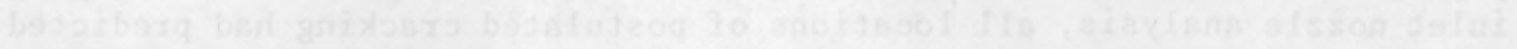

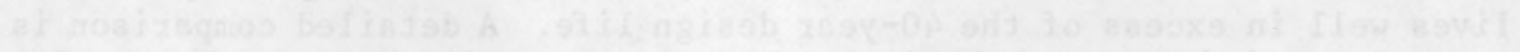

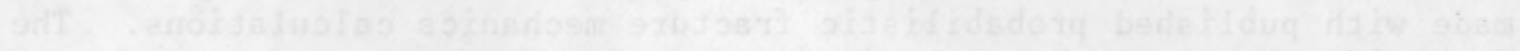

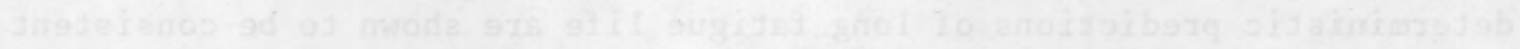

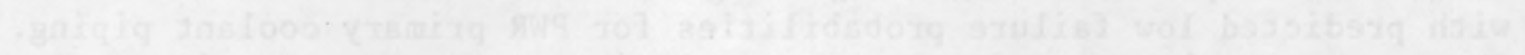

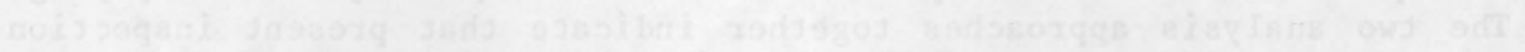

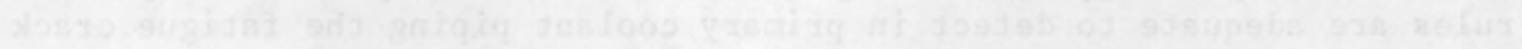

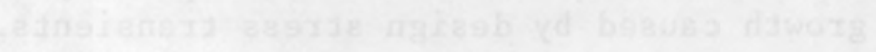




\section{CONTENTS}

ABSTRACT

iii

1.0 INTRODUCTION

2.0 SUMMARY

3.0 TECHNICAL DISCUSSION.

3.1 ANALYSIS PROCEDURE .

3.2 ANALYSIS INPUTS.

3.2.1 Description of Component Geometry. . . . 8

3.2.2 Stress Levels and Stress History . . . . 16

3.2.3 Fracture Mechanics Model . . . . . 20

3.2.4 Material Properties . . . . . . 20

3.2.5 Crack Shape and Depth . . . . . . . 24

3.3 COMPUTATIONAL PROCEDURE . . . . . . . . . 27

3.3.1 Stress Intensity Factor. . . . . . 27

3.3 .2 Input to CRACKS . . . . . . . . 27

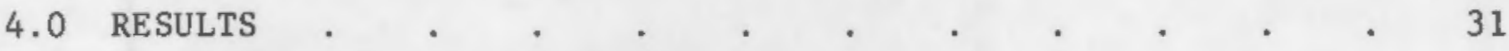

4.1 STRAIGHT PIPE $. \quad . \quad . \quad . \quad . \quad . \quad . \quad . \quad . \quad$. 31

4.2 SENSITIVITY STUDY . . . . . . . . . . . 35

4.3 DISSIMILAR METAL WELDS . . . . . . . . 37

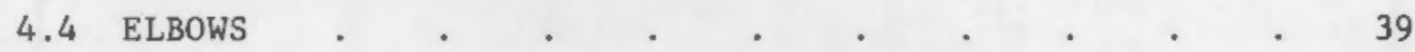

4.5 NOZZLES . . . . . . . . . . . . 41

4.6 VIBRATIONAL STRESS EVALUATION . . . . . . 42

4.6.1 Effect of Vibrational Frequency and Flaw Aspect Ratio. . . . . . . 42

4.6.2 Critical Flaw Sizes . . . . . . . 44

5.0 COMPARISON TO PROBABILISTIC ANALYSIS . . . . . . 47

5.1 DISCUSSION OF INPUT PARAMETERS. $\quad . \quad$. . . . . 47

5.1.1 Description of Component Geometry. . . . 47

5.1.2 Stress Levels and Stress History. . . . 49

5.1.3 Fracture Mechanics Model . . . . . 50

5.1 .4 Material Properties . . . . . . 50

5.1.5 Initial Crack Size and Shape. . . . . 51

5.2 QUANTITATIVE COMPARISON . . . . . . . . 51

5.2.1 Initial Flaw Probability . . . . . 52

5.2.2 Growth Rate Probability . . . . . 52

5.2 .3 Leak Probability. . . . . . 55

6.0 CONCLUSIONS . . . . . . . . . . . . . . 59

REFERENCES . . . . . . . . . . . . . . 61 


\section{FIGURES}

1. General Trend of Fatigue Crack Growth Rate Data . . 7

2. Crack Growth Rate Data Where the Environment has a

Significant Influence • . . . . . . . 7

3. St. Lucie, Primary Coolant Loop . . . . . . 99

4. St. Lucie-1, Cold Legs P5 and P14 . . . . . . 9

5. St. Lucie-1, Cold Legs P9 and P18 . . . . . . 10

6. St. Lucie-1, Safe-Ends Connecting Cold Legs to Pumps . . 10

7. Farley-1 Primary Coolant Piping . . . . . . 11

8. Farley-1, Cold Leg . . . . . . . . . . 11

9. Approximate Details of Pipe Junctures to Pump and Pressure 12

10. Location of Crack Considered in Analysis of Point D in

Farley-1 . . . . . . . . . . . . . 14

11. Location of Cracks Considered in St. Lucie-1 Analyses
$180 \mathrm{~TB} / 170 \mathrm{~T}$, and $165 \mathrm{~B} / 170 \mathrm{TR}-\mathrm{E}$ bow.

12. Location of Cracks Considered in St. Lucie-1 Analyses

13. Location of Cracks Considered in St. Lucie-1 Analyses $453 \mathrm{TR}$ and $154 \mathrm{TR}$. . . . . . . . . 15

14. Location of Crack Considered in St. Lucie-1 Analysis $155 \mathrm{~T}$ of Charging Inlet Nozzle . . . . . . 16

15. Fatigue Crack Growth Rate for Carbon Steels . . . . 25

16. Fatigue Crack Growth Rate for Stainless Steels . . . 25

17. Fatigue Crack Growth Rate Data for Stainless Steels -Conditions of Low and High R, Laboratory Air, and Simulated PWR Environment . . . . . . . . 26

18. Results of the Circumferential Crack Growth Analysis for Straight Pipe, St. Lucie-1, Points 180TBP, 180TB/170T, $479 \mathrm{TBP}$, and $479 \mathrm{TR} / 465 \mathrm{~B}$

19. Results of Circumferential Crack Growth Analysis for Straight Pipe, St. Lucie-1, Points 180TB/170T, 165B/170TR, $165 \mathrm{BR} / 170 \mathrm{~T}, 154 \mathrm{~T}, 465 \mathrm{BR} / 460 \mathrm{~T}$, and $545 \mathrm{~T}$

20. Comparison of Growth Rates for Axial and Circumferential Cracks in Straight Pipe, St. Lucie-1, Point $180 \mathrm{~TB} / 170 \mathrm{~T}$.

21. Results of the Sensitivity Analysis for Straight Pipe, St. Lucie-1 (Curve Numbers Refer to the Run Numbers of Table 9), Point 165B/170TR 


\section{FIGURES (Cont'd)}

22. Results of the Crack Growth Analysis for Stainless Steel Straight Pipe, Farley-1 (Point D -- Ref. 2, Point 13 --

Ref. 1) . . . . . . . . . . 38

23. Results of the Crack Growth Analysis for Dissimilar Metal Welds, St. Lucie-1, Points $154 \mathrm{TR}$ and 453TR . . . . 38

24. Results of the Crack Growth Analysis for Circumferentially Flawed St. Lucie-1 Points 165B/170TR, 165BR/160T, 479 TR/465B. 40

25. Comparison of Growth Rates for Axial and Circumferential Cracks in Elbow, St. Lucie-1 Point 165B/170TR . . . 40

26. Results of the Crack Growth Analysis of the Charging Inlet Nozzle, St. Lucie-1 Point 155T . . . . . . 41

27. Effect of Vibrational Frequency on Critical Flaw Size . . 45

28. Effect of the Aspect Ratio of an ID Surface Flaw on Critical Flaw Size. . . . . . . . 45

29. Comparison of Critical Flaw Sizes for Ferritic and Stainless Steels Under Vibrational Stress . . . . . . 46

30. Diagram of Primary Piping of Zion-1 Showing Locations of Welds Considered (Ref. 1) . . . . . . . 48

31. Conditional Probability of Crack Existing in Various Regions of State Space. . . . . . . . . . . 53

32. Probability Distribution on Crack Growth Rate Coefficient C . 54 
1. Joint Locations for Revised Cold Leg Crack Growth Analyses . 13

2. Stress Cycle Make-Up for Point 453TR in St. Lucie-1 . . 17

3. Axial Stresses for Dissimilar Metal Welds in St. Lucie-1 . 18

4. Stress History Used in Analyzing Straight Pipe, Elbows, and Dissimilar Metal Welds in St. Lucie-1 . . . . 21

5. Stress History Used in Analyzing Nozzle in St. Lucie-1 . . 22

6. Stress History Used in Analyzing Points A and D in Farley-1 . 23

7. Library of Correction Factors, $B_{i}$. $\quad . \quad$. $\quad . \quad$. 28

8. Results of the Fracture Mechanics Analyses Using the
Revised Input Data. . . . . . . 32

9. Results of Sensitivity Studies of Initial Crack Size, Spectrum, Vibration, and Crack Growth Rate Equation on Life (Location 165B/170TR - Straight Pipe, Circumferential Crack, $a / 2 C=0.1$ ).

10. Results of a Sensitivity Study to Evaluate the Effect of Including a Through-Wall Stress Gradient for the Dissimilar Metal Welds (Initial Crack Size - 10\% t, Final Crack Size = $50 \%$ t

11. Assessment of Crack Growth Rates and Vibrational Frequencies. 43

12. Dimensions and Materials Used in the Straight Pipe Sections of the cold Legs in Farley-1 and Zion-1.

13. Probabilities Associated with Inputs to Deterministic 



\subsection{INTRODUCTION}

This report describes the efforts and results of a study performed to evaluate the growth by fatigue of relatively small cracks in nuclear reactor piping. The research described herein was performed to provide supporting data to a research program concerning the adequacy and reliability of nondestructive inspection (NDI) techniques for nuclear reactor piping. The Pacific Northwest Laboratory, operated for the Department of Energy by Battelle Memorial Institute, is conducting the research program for the Nuclear Regulatory Commission. The depths of the small cracks were taken to be one-tenth of the pipe wall thickness to be consistent with flaw acceptance standards of Section XI of the ASME Boiler and Pressure Vessel Code which defines the NDI requirements.

The objectives of this study were 1) to evaluate the growth of relatively small cracks in the cold leg piping system of a Pressurized Water Reactor (PWR) and 2) to compare the results of these calculations to the results of the probabilistic analysis reported by Harris et al. (Ref. 1).

The calculations were performed at Battelle Columbus Laboratories and were based on procedures developed in an earlier study (Ref. 2) to evaluate the integrity of the cold leg piping system in three different PWRs. In addition to the computational procedures, this study drew on the stress analysis and plant descriptions prepared as part of the original study. There are, however, significant differences in the two studies, most notably in terms of the stress history, postulated initial flaw sizes and material properties used in the analyses.

The original study was a deliberately conservative assessment of the cold leg integrity. As such, it took the form of a worst-case analysis. The present study was concerned with avoiding excessive conservatism and emphasized crack growth under conditions typical of "normal operation". Thus, operational transients with a low probability of occurrence (earthquakes for example) were eliminated from the stress history. Further, the crack growth rate curves used were the recently revised curves given in Section XI of the ASME Boiler and Pressure Vessel Code (Ref. 3), rather than the upper bound curve used in Reference 2. Other areas where the conservatism in the original study has been lessened for this work are discussed in Section 3.0, Technical Discussion.

One of the three plants examined in Reference 2 was designed by Westinghouse (Farley-1). The cold leg design was similar to the cold leg piping in the Zion-l plant examined by Harris (Ref. 1). Thus, one weld joint was selected from the Farley-l plant and re-analyzed for comparison to a similar joint in the $\mathrm{Zion-1}$ plant. 



\subsection{SUMMARY}

The objectives of this study were 1) to evaluate the growth by fatigue of small cracks in the cold leg piping system of a pressurized water reactor, and 2) to compare the results of these calculations to the results of the probabilistic analysis reported by Harris (Ref. 1).

In meeting the first objective, seventeen distinct points in the cold leg piping system of the St. Lucie-1 PWR were analyzed. In meeting the second objective, the Harris report (Ref. 1) was reviewed and three points in the Farley-1 PWR were analyzed for comparison to the results of Harris for the Zion-1 PWR.

The calculations performed here were based on a previous study of the integrity of the cold leg piping systems (Ref. 2) of three PWRs, including St. Lucie-1 and Farley-1. This study differs from that original study in that less conservative assumptions were used and the "cracks" were allowed to "grow" from an initial depth of a 0.25 inches $(\sim 10$ percent of the wall thickness) to a final depth of 50 percent of the wall thickness. In contrast, the original study allowed the cracks to grow from 25 percent (typically) of the wall thickness to all the way through the wall.

The initial crack geometry studied was a semi-elliptical, innersurface crack with an initial depth of 0.250 inches and an aspect ratio (depth divided by length) of 0.1. This aspect ratio was kept constant as the crack was "grown" to a depth of 50 percent of the pipe wall thickness. Both circumferential and axial flaws were considered.

The results of the study are reported in terms of the number of 40year design lives required to propagate the crack from the initial depth to the final depth. These "lives" are contrasted to the results of the original study reported in Reference 2.

In general, the results indicated that the calculated crack growth life could be increased significantly from the worst-case predictions reported in Reference 2 by changing the input parameters. The calculated life of the charging inlet nozzle in St. Lucie-l was still less than one design life, indicating that this is a fatigue-critical location for normal operating stresses. Predicted lives for piping with circumferential cracks ranged from 13 to 100 design lives. For piping with axial flaws, the predicted lives ranged from 4 to 50 design lives. Predicted lives for dissimilar metal welds do not differ markably from other circumferential welds. 
Results of the present deterministic analyses are consistent with the low failure probabilities estimated by Harris (Ref. 1). Both studies show that present NDI requirements ( $f l$ aw detection capability and inspection intervals) are adequate to detect the fatigue-caused growth of fabrication flaws in PWR primary coolant piping.

The present study indicates that the relatively short predicted lives in the original study (Ref. 2) was due largely to a combination of the relatively large initial flaw sizes and the assumed level and number of vibrational stress cycles ( $2.1 \times 10^{10}$ cycles/40 years). Changes in crack growth rate curves ( $\mathrm{da} / \mathrm{dN}$ versus $\Delta \mathrm{K}$ ) had a noticable but lesser impact on predicted fatigue life. The deletion of low-probability transients had a relatively small effect on the time to failure.

A review of the probabilistic results of Reference 1 in 1 ight of the deterministic calculations reported here suggests that apparent differences in conclusions between References 1 and 2 can be resolved. A comparison is made by estimating probabilities for the conservative inputs to the present deterministic calculations. 


\subsection{TECHNICAL DISCUSSION}

This section discusses the basics of the analysis procedure, the input parameters, computational procedures, and points in the piping system considered. The discussion of the procedures draws heavily on the original study (Ref. 2) and is therefore brief. The reader is directed to Reference 2 for a detailed description of the analysis procedures.

\subsection{ANALYSIS PROCEDURE}

The analysis procedure was identical to the procedure detailed in Reference 2. Briefly, the analys is involves integrating an equation of the form

$$
N=\int_{a_{1}}^{a_{2}} \frac{d a}{(d a / d N)}=\int_{a_{1}}^{a_{2}} \frac{d a}{f(\Delta K, R, \text { material, environment })}
$$

This equation is based on the concepts of Linear Elastic Fracture Mechanics (LEFM). A basic tenet of LEFM is that the stress intensity factor (SIF), $\mathrm{K}$, completely describes the stress field ahead of a crack. Further, empirical observation has shown that the change in SIF, $\Delta K$, provides a measure of the crack driving force for fatigue crack growth. Thus, if one can describe $\mathrm{K}$ and the loading for a complex structure, the rate of fatigue crack growth can be predicted based on crack growth rates measured in simple laboratory specimens. The key factors in evaluating Equation (1) are the stress intensity factor for the structure of interest and the form of the function $f$.

In general, the stress intensity factor $c$ an be expressed as

$$
K=\beta \sigma \sqrt{\pi a}
$$

where

$$
\begin{aligned}
& \beta=\text { a correction factor describing both structure and crack geometry } \\
& \sigma=\text { the applied stress } \\
& a=\text { the crack depth. }
\end{aligned}
$$

Correction factors $\left(\beta_{\mathrm{T}} \mathrm{s}\right)$ for circumferential cracks in pipe were described in Reference 2. Those corrections were also used in this study. However, this study included an additional correction when the dissimilar metal 
welds (DMWs) were analyzed to account for the steep through-wall stress gradient at those locations. The implementation of these corrections and numerical integration scheme are discussed in Section 3.3.

The form of the function $\mathrm{f}$ in Equation (1) is determined by the crack growth rate data for the material and environment of interest. In general, fatigue crack growth rate data take on a sigmoidal shape when plotted on a $\log -\log$ scale. Figure 1 depicts this general trend. In region $I$, the growth rate increases sharply once $\Delta \mathrm{K}$ rises above a threshold $\Delta \mathrm{K}$ value. In region II, there is a linear relationship between $\log (\mathrm{da} / \mathrm{dN})$ and $\log \Delta \mathrm{K}$. Thus, in this region $\mathrm{da} / \mathrm{dN}$ can be expressed as a power law function of $\Delta \mathrm{K}$. In region III, the growth rate again increases sharply as $\mathrm{K}_{\max }$ approaches a critical value described by the fracture toughness of the material.

For many applications, the crack growth rate is adequately described by the linear portion of the general curve, i.e., region II. Thus, the crack growth rate is simply given by

$$
\frac{d a}{d N}=c(\Delta K)^{n}
$$

where $\mathrm{C}$ and $\mathrm{n}$ are constants dependent on the material and environment.

For some environments, the general shape of the crack growth rate curve is distinctly different from that depicted in Figure 1. Figure 2 depicts crack growth rate data for which the environment has a significant influence. Crack growth rates for carbon steels exposed to nuclear reactor environments often exhibit this type of behavior. This type of behavior can be conveniently described by a multilinear curve which is the type of curve presently included in Section XI of the ASME Boiler and Pressure Vessel Code (Ref. 3).

The analysis procedure involves the integration of Equation (1). Inputs to the analysis include:

- descriptions of the component geometry

- stress levels and stress history

- a fracture mechanics model (the correction factors)

- material properties

- the depth and shape of the initial and final crack.

\subsection{ANALYSIS INPUTS}

As already noted, analyses were performed for seventeen points in the St. Lucie-1 plant and for three points in the Farley-1 plant. The following discussion details the inputs to the analyses for these points. 


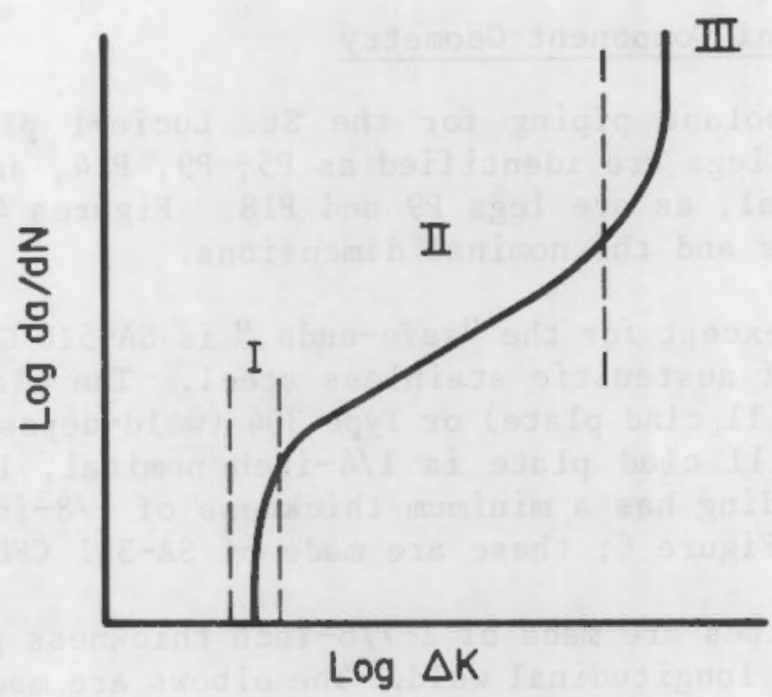

FIGURE 1. General Trend of Fatigue Crack Growth Rate Data

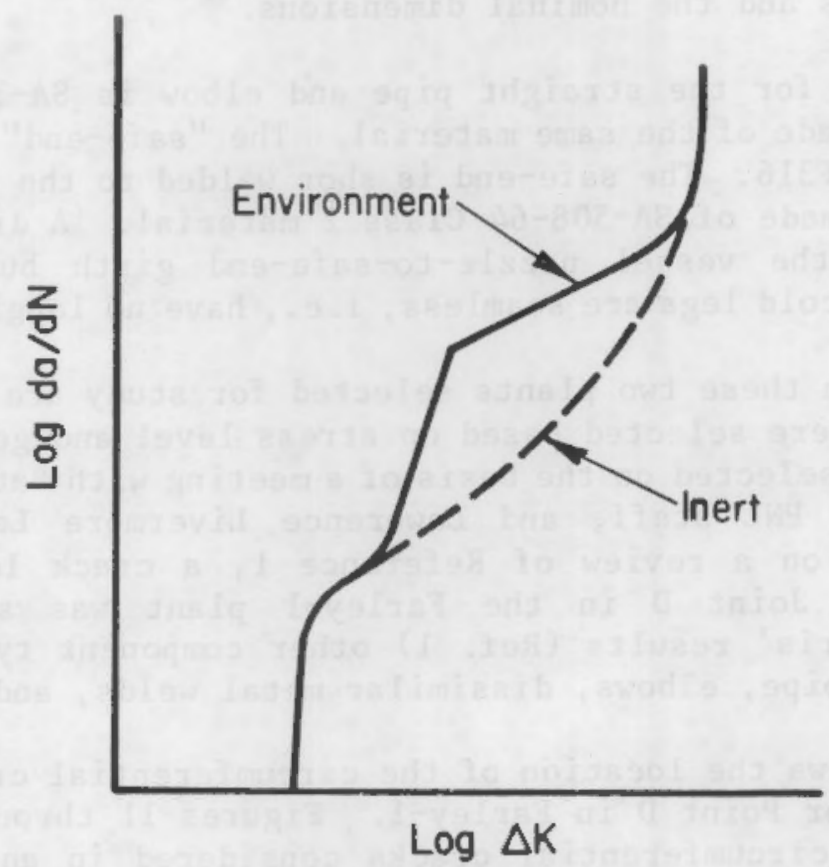

FIGURE 2. Crack Growth Rate Data Where the Environment Has a Significant Influence 


\subsubsection{Description of Component Geometry}

The primary coolant piping for the St. Lucie-l plant is shown in Figure 3. The cold legs are identified as P5, P9, P14, and P18. Legs P5 and P14 are identical, as are legs P9 and P18. Figures 4 and 5 show the layout of these legs and the nominal dimensions.

The material, except for the "safe-ends," is SA-516 Grade 70, with an internal cladding of austenitic stainless steel. The cladding is either SA-240 Type 304L (mill clad plate) or Type 304 (weld-deposited clad). The thickness of the mill clad plate is $1 / 4-i$ nch nominal, 1/8-inch minium. Weld-deposited cladding has a minimum thickness of 1/8-inch. The "safeends" are shown in Figure 6; these are made of SA-351 CF8M.

The straight pipes are made of $2-7 / 8$-inch thickness plate rolled and welded with a single longitudinal weld. The elbows are made of $3-5 / 8$-inch thickness plate with longitudinal welds along the crotch and back. The "safe-ends" are 4 inches long, presumably seamless.

The primary coolant piping for the Farley-1 plant is shown in Figure 7. All three cold legs are identical. Figure 8 shows the layout of the Farley-1 cold legs and the nominal dimensions.

The material for the straight pipe and elbow is SA-351 Grade CF8A. The pump body is made of the same material. The "safe-end" (see Figure 9) is made of SA-182 F316. The safe-end is shop welded to the pressure vesse1 nozzle, which is made of SA-508-64 Class 2 material. A dissimilar metal joint exists at the vessel nozzle-to-safe-end girth butt weld. All portions of these cold legs are seamless, i.e., have no longitudinal welds.

The points in these two plants selected for study are given in Table 1. These points were selected based on stress level and geometry. Point D in Farley-1 was selected on the basis of a meeting with Battelle-Columbus Laboratory staff, PNL staff, and Lawerence Livermore Laboratories/SAI staff(a). Based on a review of Reference 1 , a crack location in the straight pipe at Joint D in the Farley-1 plant was selected. For comparison to Harris' results (Ref. 1) other component types considered include straight pipe, elbows, dissimilar metal welds, and a nozzle.

Figure 10 shows the location of the circumferential crack considered in the analysis for Point D in Farley-1. Figures 11 through 14 show the locations of the circumferential cracks considered in analyses for St. Lucie-1. The axial cracks considered were taken as remote from the girth welds yet in the general vicinity of the locations listed.

(a) This meeting was held on April 15, 1981, at Lawrence Livermore Laboratories. 


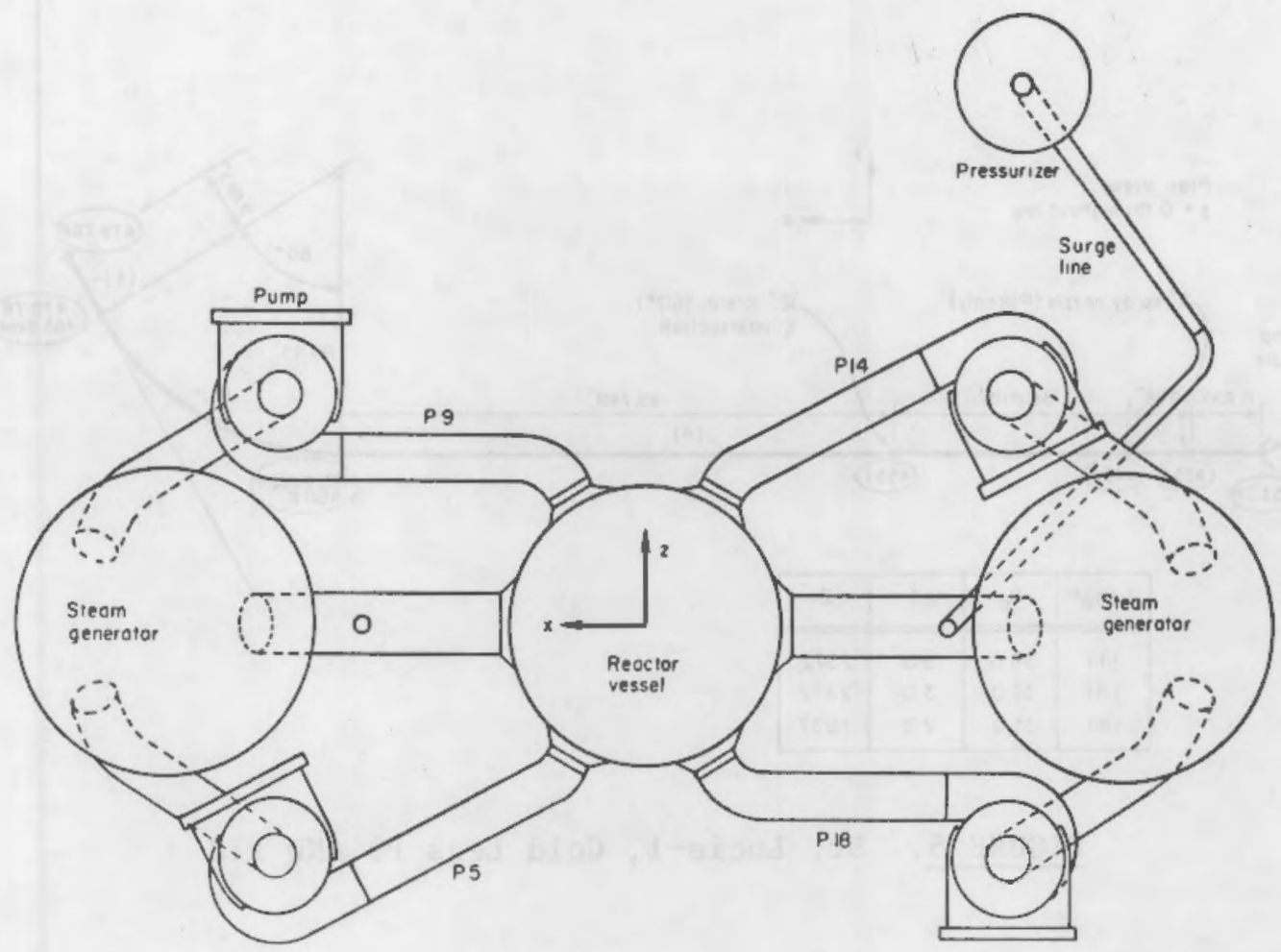

FIGURE 3. St. Lucie-1, Primary Coolant Loop

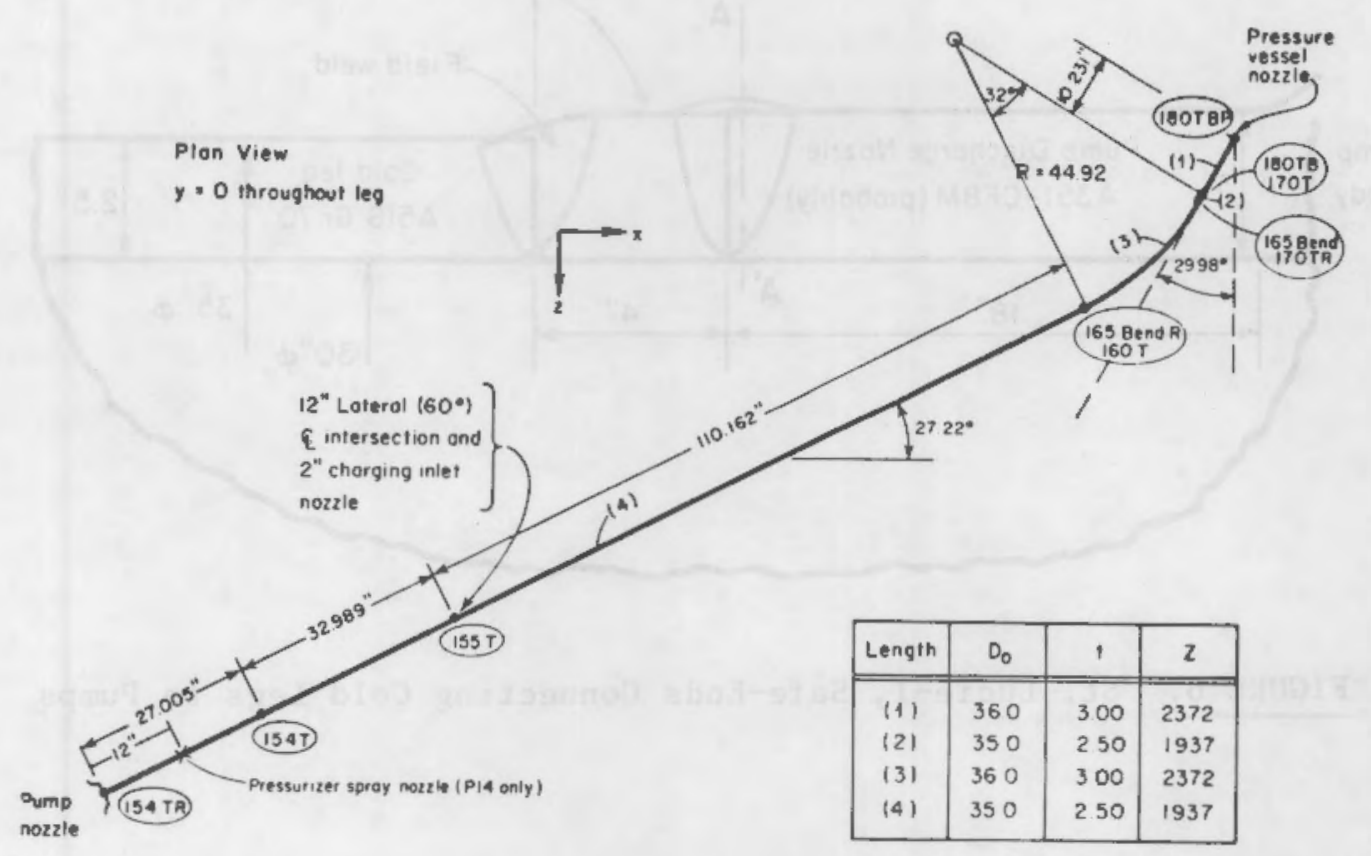

FIGURE 4. St. Lucie-1, Cold Legs P5 AND P14 


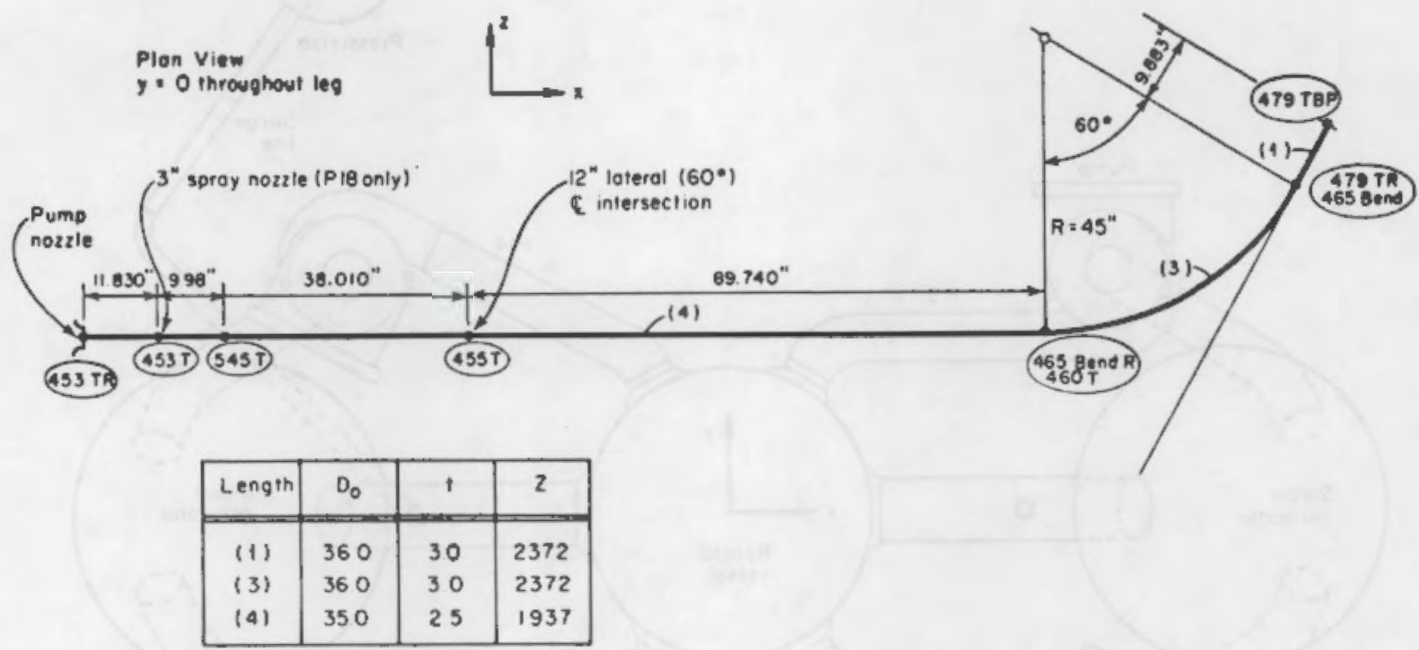

FIGURE 5. St. Lucie-1, Cold Legs P9 AND P18

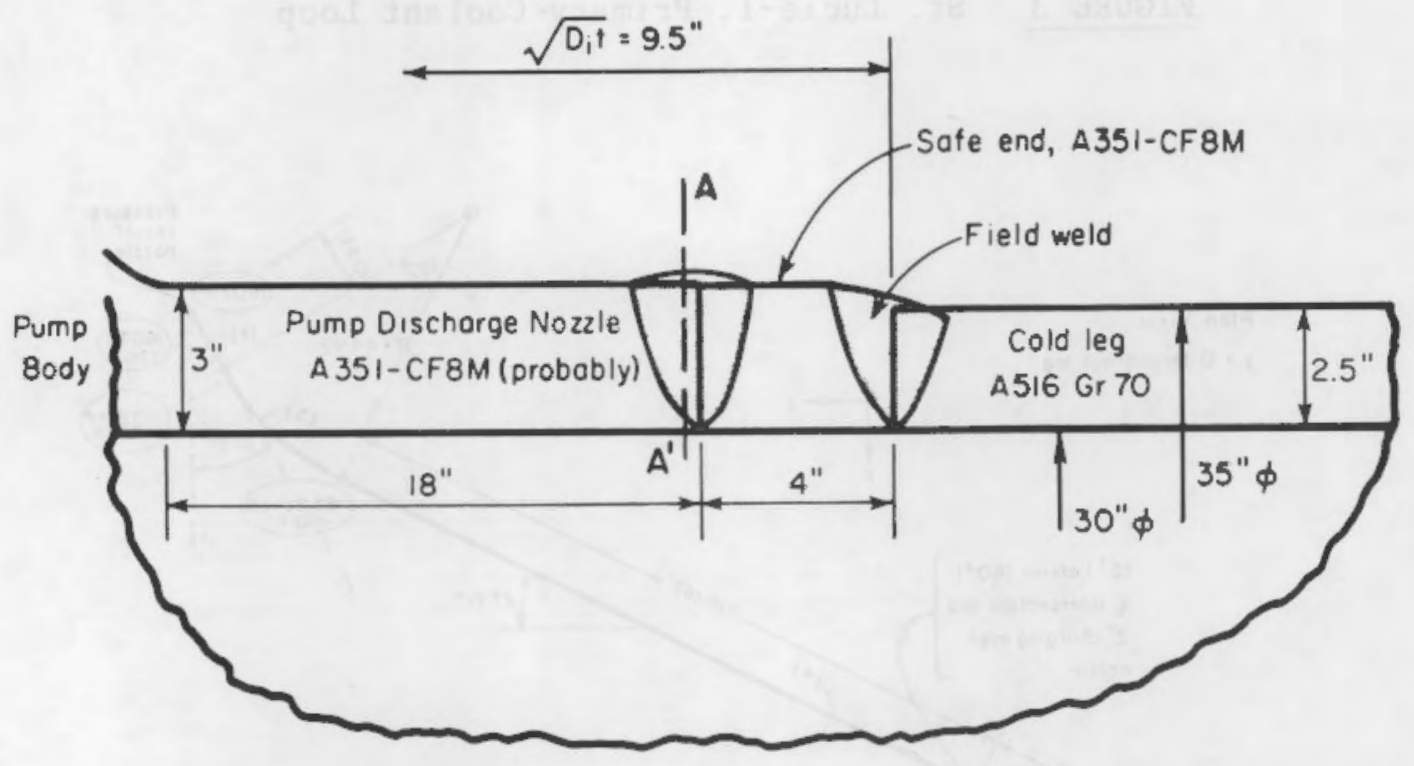

FIGURE 6. St. Lucie-1, Safe-Ends Connecting Cold Legs to Pumps 


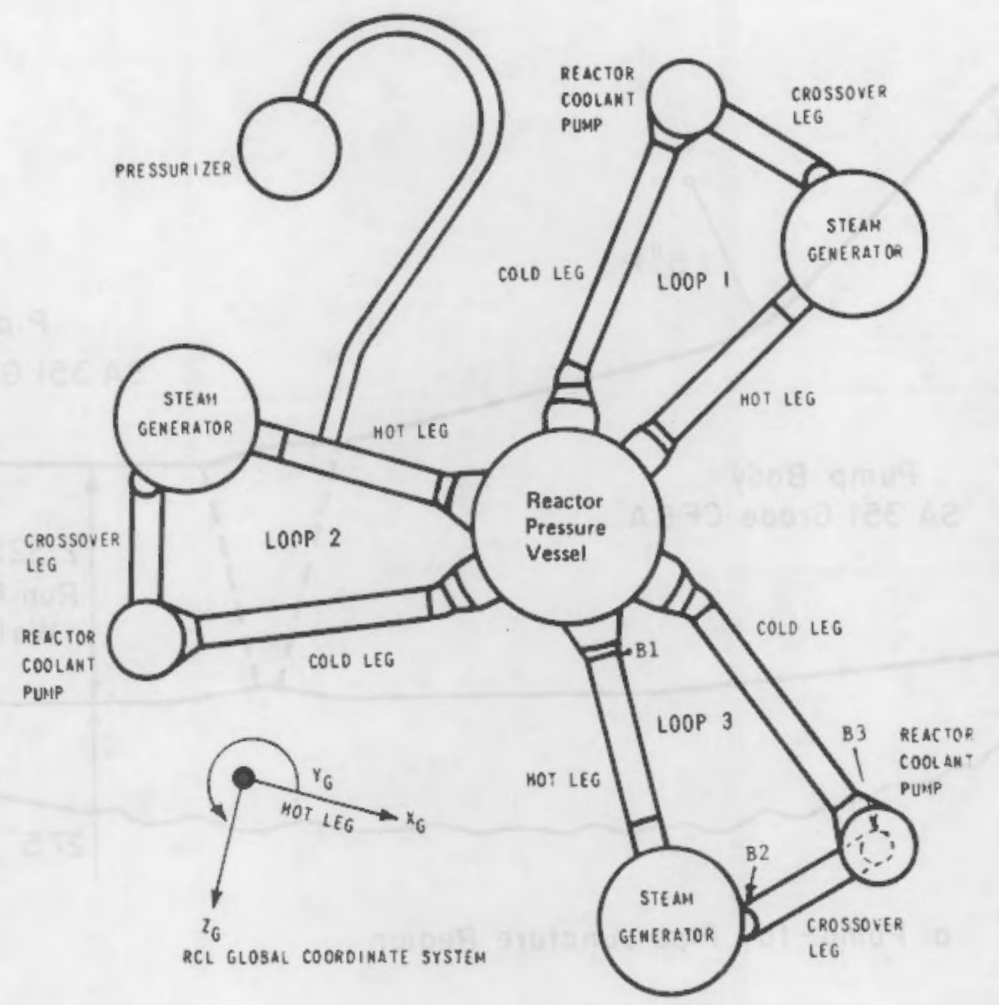

FIGURE 7. Farley-1 Primary Coolant Piping
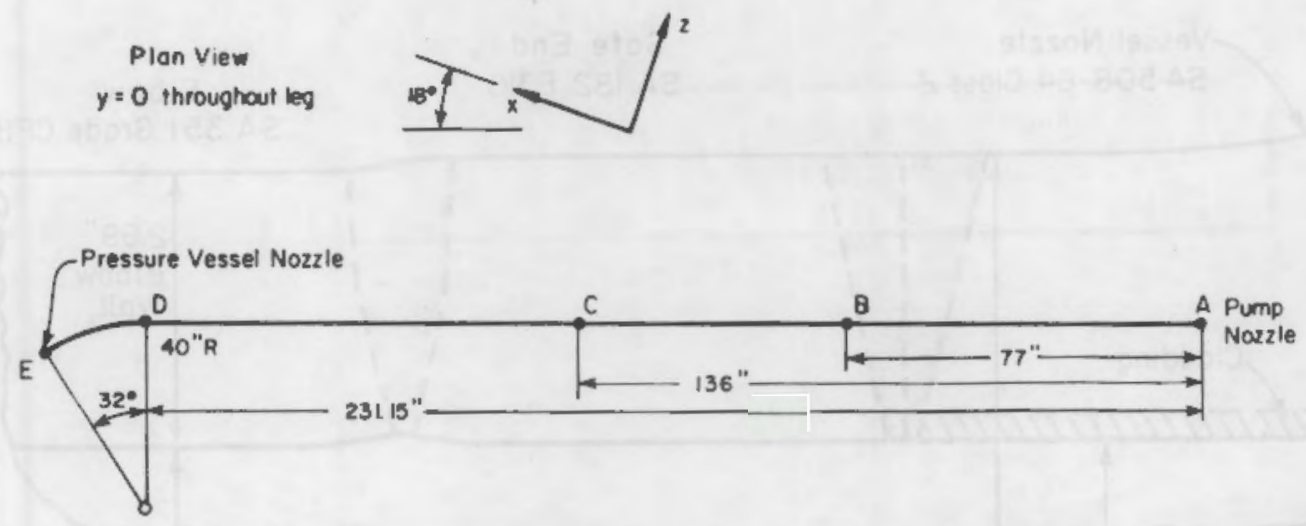

\begin{tabular}{|l|l|l|l|}
\hline \multirow{2}{*}{ Length } & \multicolumn{3}{|c|}{ Nominal Dimensions, inch } \\
\cline { 2 - 4 } & \multicolumn{1}{|c|}{$D$} & \multicolumn{1}{|c|}{1} & \multicolumn{1}{|c|}{2} \\
\hline A to D & 32.19 & 2.325 & 1520 \\
$D$ to E & 32.89 & 2.69 & 1782 \\
\hline
\end{tabular}

FIGURE 8. Farley-1, Cold Leg 


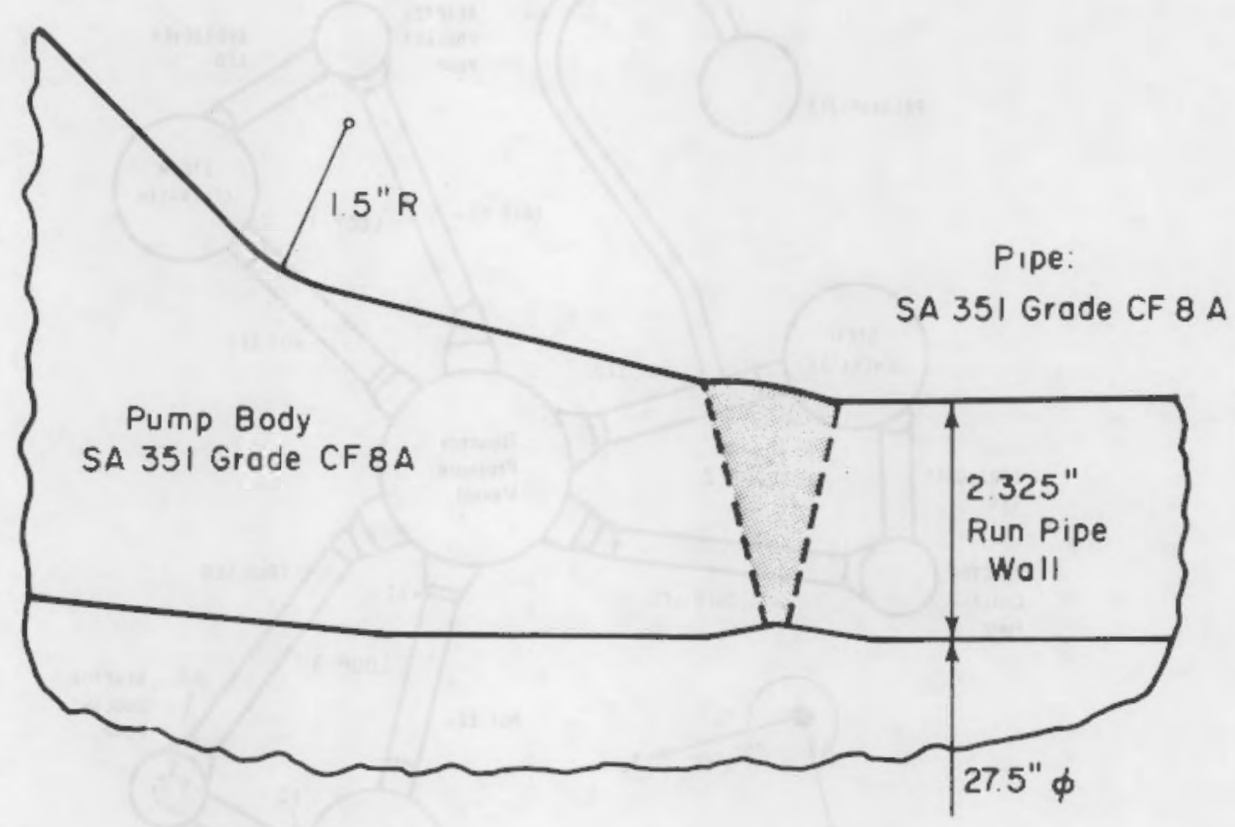

a. Pump-10-Pipe Juncture Region

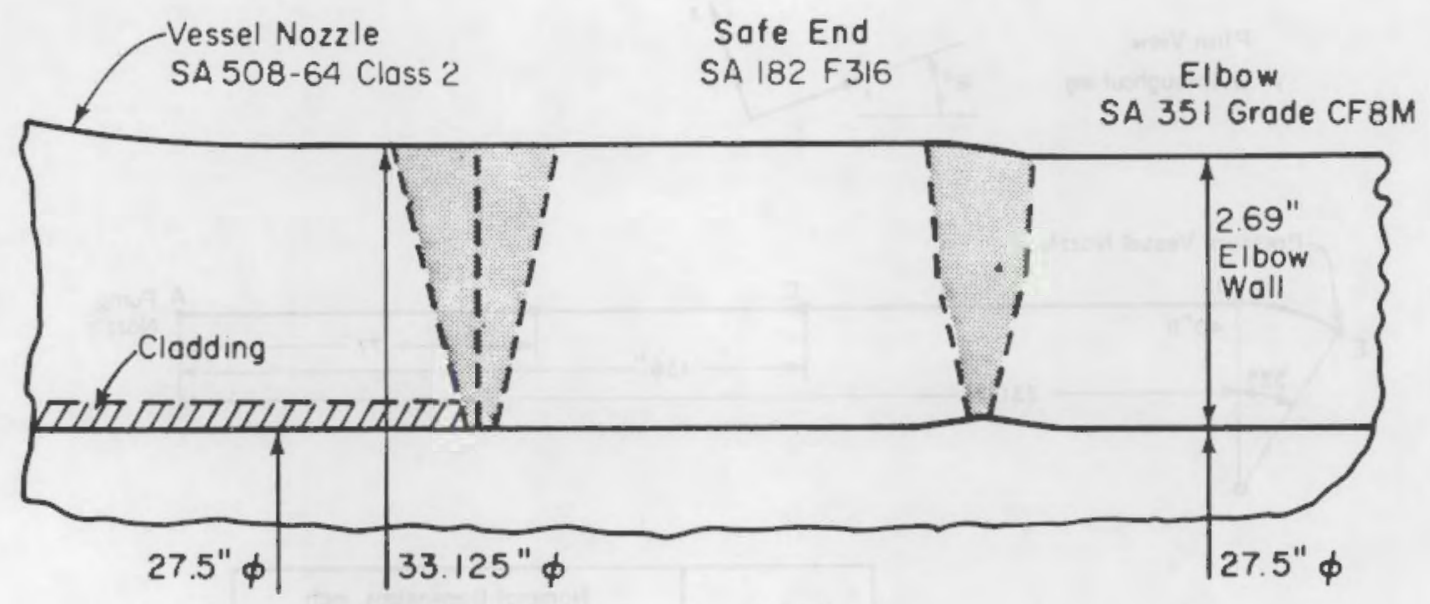

b. Pressure Vessel-to-Pipe Juncture Region

FIGURE 9. Approximate Details of Pipe Junctures to Pump and Pressure Vessel for Farley-1 
TABLE 1. Joint Locations for Revised Cold Leg Crack Growth Analyses

\begin{tabular}{|c|c|c|c|c|}
\hline Plant & Joint Location & Component Type & $\begin{array}{l}\text { Detail } \\
\text { Drawin }\end{array}$ & \\
\hline Farley-1 & A & Straight Pipe (2.325") & & \\
\hline Farley-1 & $\begin{array}{l}\text { D (BCL Model) } \\
\text { Joint } 13 \text { (LLL Model) }\end{array}$ & $\begin{array}{l}\text { Straight pipe to elbow } \\
\text { joint - straight pipe } \\
\text { side }\end{array}$ & Figure & 10 \\
\hline Farley-1 & D (e1bow) & $\begin{array}{l}\text { Straight pipe to elbow } \\
\text { joint - elbow side }\end{array}$ & Figure & 10 \\
\hline St. Lucie-1 & 180 TВР & Straight pipe (3.0") & & \\
\hline St. Lucie-1 & $180 \mathrm{~TB} / 170 \mathrm{~T}$ & Straight pipe (3.0") & Figure & 11 \\
\hline St. Lucie-1 & 479TBP & $\begin{array}{l}\text { Straight pipe (weld to } \\
\text { vessel nozzle) }\end{array}$ & Figure & 12 \\
\hline St. Lucie-1 & $479 \mathrm{TR} / 465 \mathrm{~B}$ & Straight pipe (3.0") & Figure & 12 \\
\hline St. Lucie-1 & $180 \mathrm{~TB} / 170 \mathrm{~T}$ & Straight pipe (2.5") & & \\
\hline St. Lucie-1 & $165 \mathrm{~B} / 170 \mathrm{TR}$ & Straight pipe (2.5") & Figure & 11 \\
\hline St. Lucie-1 & $154 \mathrm{~T}$ & Straight Pipe (2.5") & & \\
\hline St. Lucie-1 & $165 \mathrm{BR} / 170 \mathrm{TR}$ & Straight pipe (2.5") & & \\
\hline St. Lucie-1 & $465 \mathrm{BR} / 460 \mathrm{~T}$ & Straight pipe (2.5") & & \\
\hline St. Lucie-1 & $545 \mathrm{~T}$ & Straight pipe (2.5") & & \\
\hline St. Lucie-1 & $165 \mathrm{~B} / 170 \mathrm{TR}$ & E1bow $\left(3.0^{\prime \prime}\right)$ & Figure & 11 \\
\hline St. Lucie-1 & $165 \mathrm{BR} / 160 \mathrm{~T}$ & Elbow $\left(3.0^{\prime \prime}\right)$ & & \\
\hline St. Lucie-1 & $479 \mathrm{TR} / 465 \mathrm{~B}$ & Elbow $\left(3.0^{\prime \prime}\right)$ & & \\
\hline St. Lucie-1 & $465 \mathrm{~B} / 460 \mathrm{~T}$ & Elbow $\left(3.0^{\prime \prime}\right)$ & & \\
\hline St. Lucie-1 & $154 \mathrm{TR}$ & $\begin{array}{l}\text { Dissimilar metal weld } \\
\text { (at coolant pump) }\end{array}$ & Figure & 13 \\
\hline St. Lucie-1 & 453TR & $\begin{array}{l}\text { Dissimilar metal weld } \\
\text { (at coolant pump) }\end{array}$ & Figure & 13 \\
\hline St. Lucie-1 & $155 \mathrm{~T}$ & Charging inlet nozzle & Figure & 14 \\
\hline
\end{tabular}


Pipe:

SA 351 Grode CF 8 A

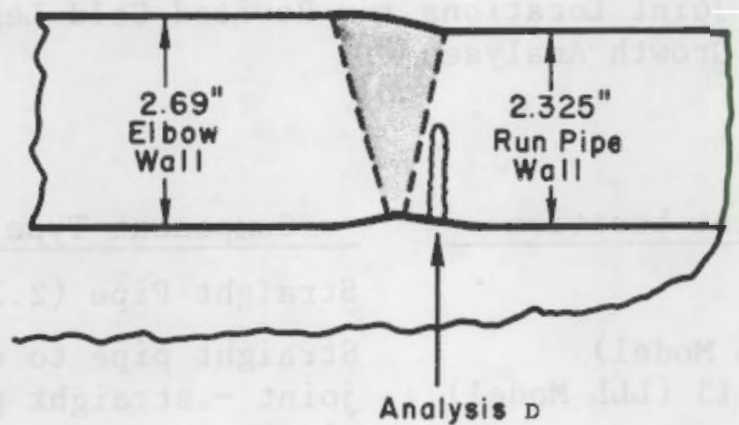

FIGURE 10. Location of Crack Considered in Analysis of Point D in Farley-1

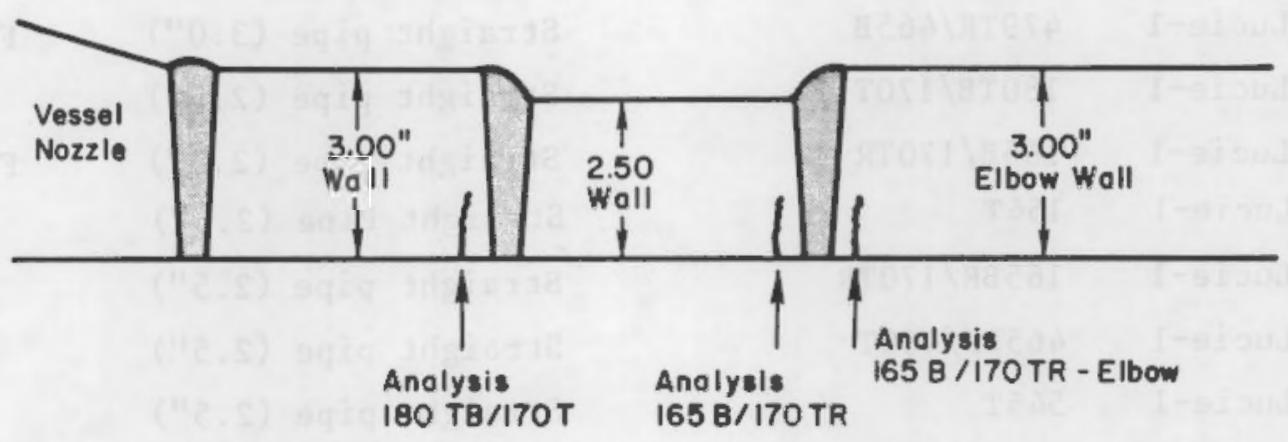

FIGURE 11. Location of Cracks Considered in St. Lucie-1 Analyses $180 \mathrm{~TB} / 170 \mathrm{~T}, 165 \mathrm{~B} / 170 \mathrm{TR}$, AND 165B/170TR - ELBOW 


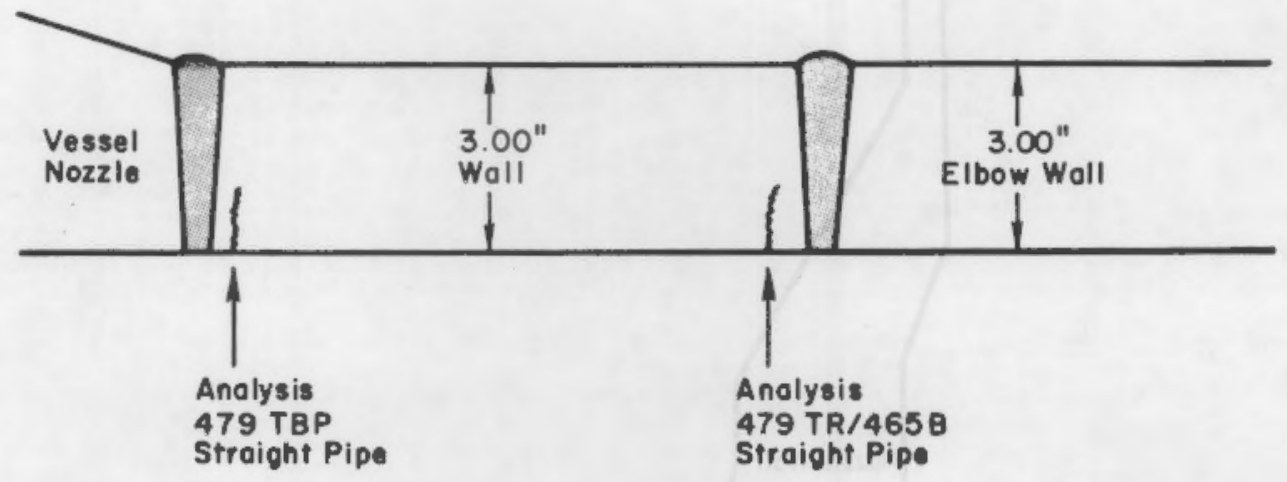

FIGURE 12. Location of Cracks Considered in St. Lucie-1 Analyses 479TBP AND 470TR/465B

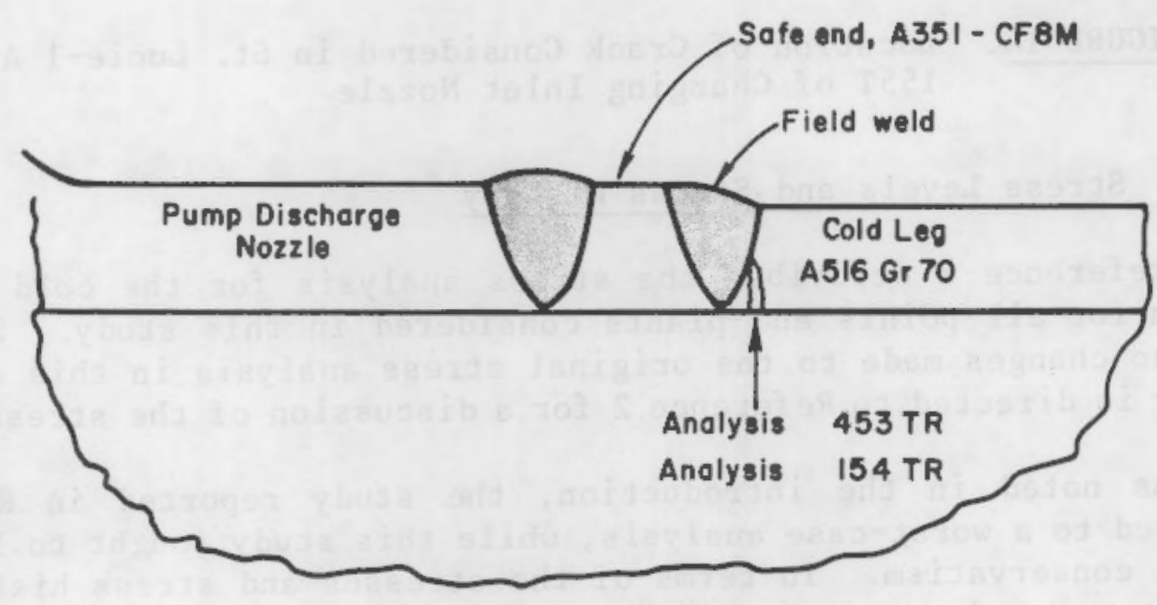

FIGURE 13. Location of Cracks Considered in St. Lucie-1 Analyses 453TR AND 154TR 


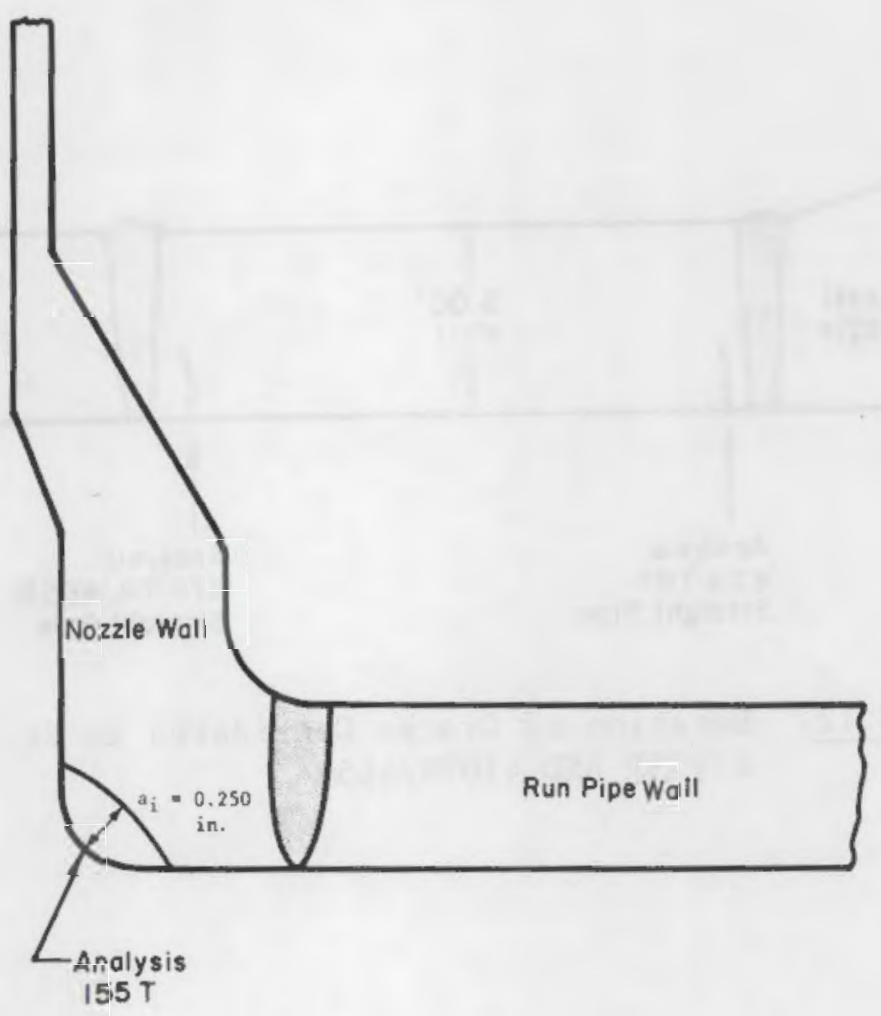

FIGURE 14. Location of Crack Considered in St. Lucie-1 Analysis $155 \mathrm{~T}$ of Charging Inlet Nozzle

\subsubsection{Stress Levels and Stress History}

Reference 2 describes the stress analysis for the cold leg piping system for all points and plants considered in this study. Since there were no changes made to the original stress analysis in this study, the reader is directed to Reference 2 for a discussion of the stress analysis.

As noted in the introduction, the study reported in Reference 2 amounted to a worst-case analysis, while this study sought to lessen some of the conservatism. In terms of the stresses and stress history, there are two areas where conservatisms were reduced. The first pertains to the the Dissimilar Metal Welds (DMWs) and the through-wall stress gradient at those locations. In the original study, the DMW stresses were included in the combined stress cycle ${ }^{(a)}$ by calculating the maximum tensile stress on the inner surface of the carbon steel pipe and taking this as constant through the thickness.

\footnotetext{
(a) The "combined stress cycle" is the stress cycle $\left(\sigma_{\min }\right.$ and $\sigma_{\max }$ ) obtained by the elastic superposition of pressure, moment and thermal stresses.
} 
For the present study, the DMW stresses were treated as a gradient and included in the evaluation of the stress cycle for the inner and outer surfaces. Table 2 illustrates how the DMW stresses were included in forming the stress cycle for Point $453 \mathrm{TR}$ in St. Lucie-1 for the startup/shutdown transient and loading/unloading transient. The static stress in Table 2 includes the pressure, moment, and $\Delta T$, terms for the startup/shutdown transient. The DMW stress was included as a total stress for each transient by simply multiplying the DMW stress for the startup/shutdown transient by the quantity ( 1 + temperature ratio) where the temperature ratio is the change in temperature for the transient divided by the temperature change for the start-up/shutdown transient; e.g., for the loading/unloading transient the temperature ratio is $50 / 480$.

TABLE 2. Stress Cycle Make-Up for Point 453TR in

St. Lucie-1

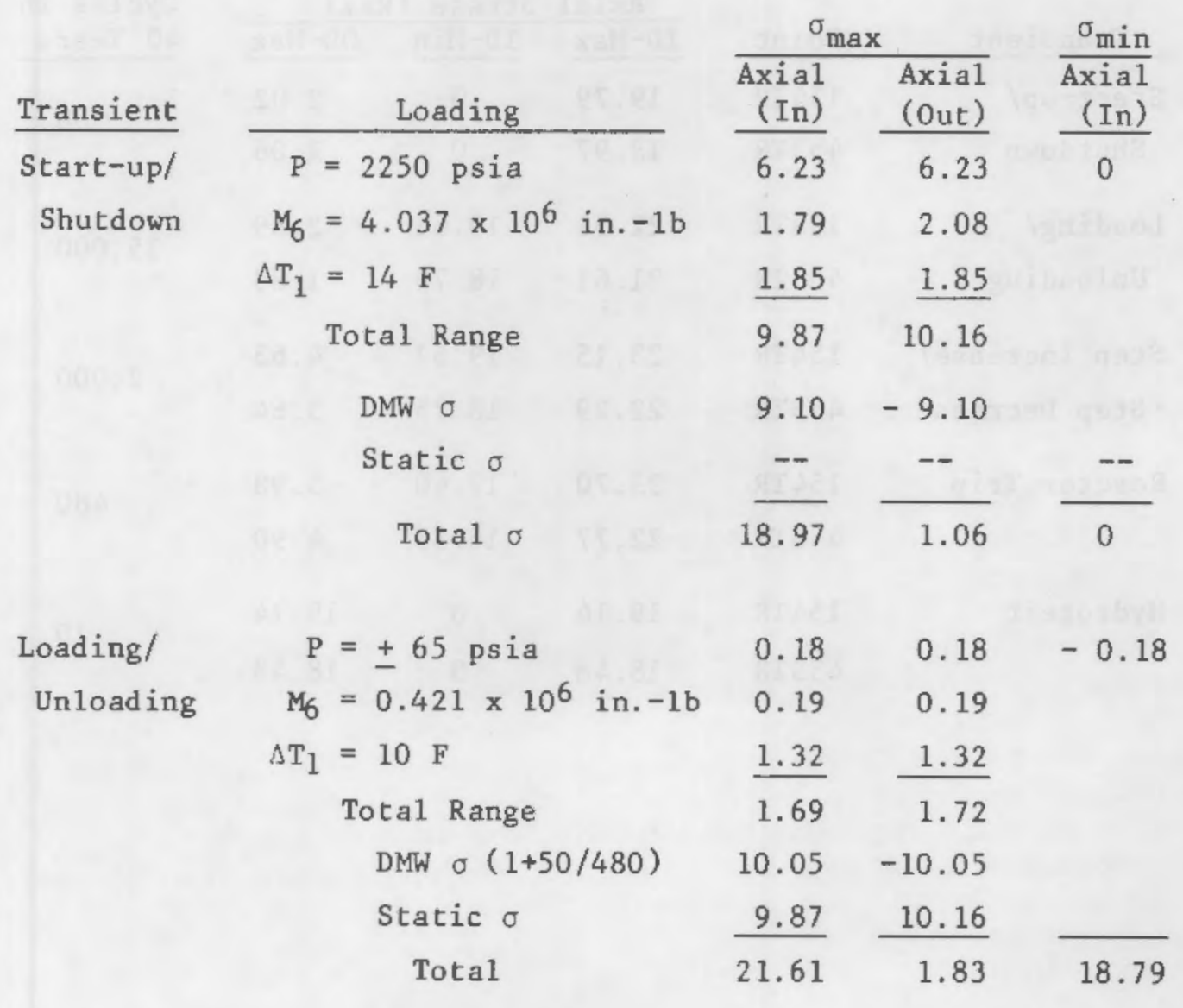


Table 3 lists the stress cycles formed for each of the DMWs in St. Lucie-l for each of the design transients considered in this analysis. Note that only those transients included in the present fatigue analysis are presented.

The stress gradient from I.D. to O.D. is different for each transient. However, the computer code used in the fatigue analysis cannot accommodate gradients that change cycle by cycle. Therefore, a weighted average gradient was calculated for Points $453 \mathrm{TR}$ and $154 \mathrm{TR}$. This is the same procedure used in Reference 2 to average the stress gradient for the nozzles.

TABLE 3. Axial Stresses for the Dissimilar Metal We1ds in St. Lucie-1

\begin{tabular}{|c|c|c|c|c|c|}
\hline \multirow[b]{2}{*}{ Transient } & \multirow[b]{2}{*}{ Point } & \multicolumn{3}{|c|}{ Axial Stress (ksi) } & \multirow{2}{*}{$\begin{array}{l}\text { Number of } \\
\text { Cycles in } \\
40 \text { Years } \\
\end{array}$} \\
\hline & & ID-Max & ID-Min & OD-Max & \\
\hline Start-up/ & $154 \mathrm{TR}$ & 19.79 & 0 & 2.02 & \multirow{2}{*}{500} \\
\hline Shutdown & 453TR & 18.97 & 0 & 1.06 & \\
\hline Loading/ & $154 \mathrm{TR}$ & 22.51 & 19.61 & 2.89 & \multirow{2}{*}{15,000} \\
\hline Unloading & 453TR & 21.61 & 18.79 & 1.83 & \\
\hline Step Increase/ & $154 \mathrm{TR}$ & 23.15 & 19.57 & 4.63 & \multirow{2}{*}{2,000} \\
\hline Step Decrease & $453 \mathrm{TR}$ & 22.29 & 18.75 & 3.64 & \\
\hline \multirow[t]{2}{*}{ Reactor Trip } & $154 \mathrm{TR}$ & 23.70 & 17.40 & 5.98 & \multirow{2}{*}{480} \\
\hline & $453 \mathrm{TR}$ & 22.77 & 16.58 & 4.90 & \\
\hline \multirow[t]{2}{*}{ Hydrotest } & $154 \mathrm{TR}$ & 19.14 & 0 & 19.14 & \multirow{2}{*}{10} \\
\hline & $453 \mathrm{TR}$ & 18.48 & 0 & 18.48 & \\
\hline
\end{tabular}


The gradient average is weighted by the number of cycles in 40 years for each transient. This can be expressed as

$$
\Delta \sigma_{w t}=\frac{\sum_{i=1}^{n} \Delta \sigma_{i} N_{i}}{\sum_{i=1}^{n} N_{i}}
$$

The change in stress from I.D. to O.D. determined in this fashion $\left(\Delta \sigma_{w t}\right)$ can be used to determine the average gradient, expressed in terms of a stress concentration factor $\mathrm{k}_{\mathrm{t}}$, which is a function of position through the wal1 thickness. To put this in a form convenient for the computer code requires that the stress cycle be formed for the inner surface and the stress concentration reflect the change (decrease in this case) in stress with position through the pipe wall. Thus, $k_{t}$ is taken as 1.0 at the inner surface. The $k_{t}$ at the outer surface can be evaluated by

$$
k_{t}(\text { O.D. })=1-\frac{\Delta \sigma_{w t}(\text { gradient })}{\Delta \sigma_{w t}(\text { I.D. })}
$$

where $\sigma_{w t}$ (I.D.) is the weighted average of the maximum stress on the inner surface of the pipe. Using Equations (4) and (5) with the stress data in Table 3 gives $k_{t}(154 \mathrm{TR})=0.139$ and $k_{t}(453 \mathrm{TR})=0.1213$. The manner in which these values of $k_{t}$ were used in the crack growth analysis will be discussed in Section 4.

Another area where the conservatism of the original study has been reduced is the stress history used in the analysis. The history used in Reference 2 considered all of the postulated design transients, which included both normal and abnormal operation. The emphasis of this study was crack growth under normal operating transients, and the consequences of this crack growth on inservice inspection requirements. Accordingly, it was decided to eliminate the low probability abnormal transients from the stress history used in this study.

The decision to delete the low-probability transients was, in part, based on the results of the probabilistic calculations of Harris et al. (Ref. 1). These calculations showed that the main contributor to leak probability was the start-up/shut-down transient, and the earthquake stresses have little impact on failure probability in primary coolant piping. Furthermore, the occurrence of the low-probability transients may result in an inspection of piping before putting the plant back on-line. Therefore, the consideration of these transients would likely fall outside the normal code-type inspection plans of interest in the present study. 
Deletion of seismic stresses was in part due to the very high level of conservatism known to exist in the vendors seismic calculations. However, sensitivity calculations performed late in this study indicated that inclusion of the abnormal transients gave little increase in fatigue crack growth rates. In some of the subsequent calculations, the abnormal transients were included along with the normal transients. These calculations are noted in the results section of this report.

The postulated vibrational stresses of 1,000 psi were deleted from the transients of the original study (Ref. 2). A vibrational stress of this level had been included as a possible rather than a probable condition. The net effect in Ref. 2 was that flaws of depth corresponding to roughly one-half the wall thickness grew very rapidly, since limits for threshold $\Delta K$ were then exceeded. In certain cases of deep initial flaws the fatigue 1 ife was dominated by vibrational stresses, and the effect of the normal and high-probability operation transients was not clear. In a later section of this report, the effect of vibration stresses is studied in a parametric fashion. These results allow the effect of postulated vibration stresses on fatigue life to be considered as a separate issue. In effect, a vibration stress reduces the end of life or critical flaw size and thereby reduces the predicted fatigue life.

Table 4 shows the stress transients from normal operation used for straight pipe, elbows, and DMWs in the St. Lucie-1 plant. It should be noted that the occurrence or distribution with respect to time of transients during the history has been made more uniform as an improvement over the distribution of transients used in Reference 2. Table 5 shows the stress history used for the nozzle in St. Lucie-1. Table 6 shows the stress history used for Points A and D in Farley-1.

\subsubsection{Fracture Mechanics Model}

The fracture mechanics model used in this study is identical to the model used in Reference 2 and will not be discussed here.

\subsubsection{Material Properties}

of the material properties of interest to this study, only the fatigue crack growth rates for carbon and stainless steels were different from that used in Reference 2. Recently published data were used to modify the curves. In this regard, Reference 1 gives crack growth rate data and curves for the stainless steels, and Reference 4 gives the currently accepted "code" curves for carbon steels. 
TABLE 4. Stress History Used in Analyzing Straight Pipe, Elbows, and Dissimilar Metal Welds in St. Lucie-1

\begin{tabular}{l} 
List of Transients \\
\hline Start-up/Shutdown \\
Plant Loading/Plant Unloading \\
Step Increase/Step Decrease \\
Reactor Trip \\
Hydrotest
\end{tabular}

\begin{tabular}{cr} 
Identifier & $\begin{array}{r}\text { No. Cycles/ } \\
40 \text { Years }\end{array}$ \\
\cline { 2 - 2 } a,b & 500 \\
$c, d$ & 15,000 \\
e,f & 2,000 \\
$g$ & 480 \\
h & 10
\end{tabular}

\section{STRESS HISTORY}

\begin{tabular}{|c|c|c|c|}
\hline $\begin{array}{l}\text { Mission } \\
\text { Number }\end{array}$ & $\begin{array}{l}\text { Layer } \\
\text { Number }\end{array}$ & Transient & $\begin{array}{c}\text { Cycles/ } \\
\text { Layer } \\
\end{array}$ \\
\hline \multirow[t]{10}{*}{1} & 1 & $a, b$ & 1 \\
\hline & 2 & $c, d$ & 7 \\
\hline & 3 & $e, f$ & 1 \\
\hline & 4 & $c, d$ & 8 \\
\hline & 5 & $e, f$ & 1 \\
\hline & 6 & g & 1 \\
\hline & 7 & $c, d$ & 8 \\
\hline & 8 & $e, f$ & 1 \\
\hline & 9 & $c, d$ & 7 \\
\hline & 10 & $e, f$ & 1 \\
\hline 2 & 1 & $\mathrm{~h}$ & 1 \\
\hline
\end{tabular}

$\left.\begin{array}{lll}\begin{array}{l}\text { Mission } \\ \text { Number }\end{array} & \begin{array}{c}\text { Number } \\ \text { of Repeats }\end{array} & \\ 1 & 50 & 1\end{array}\right\} \begin{aligned} & \text { Sequence repeats } 10 \\ & \text { times for } 40 \text { years. }\end{aligned}$


TABLE 5. Stress History Used in Analyzing Nozzle in St. Lucie-1

\section{List of Transients}

Heat-up/Cool-doun

Steady-state

Reactor Trip

Plant Unloading

Step Decrease

Plant Loading/Step Increase

Purification

Boric Acid Dilution

Hydrotest

\begin{tabular}{c} 
Identifier \\
\hline A, C \\
B \\
D \\
E \\
F \\
H \\
I \\
J \\
U
\end{tabular}

No. Cycles/

40 Years

500

1,000

480

15,000

2,000

19,000

1,000

8,000

10

\section{STRESS HISTORY}

$\begin{array}{cc}\begin{array}{c}\text { Mission } \\ \text { Number }\end{array} & \begin{array}{c}\text { Layer } \\ \text { Number }\end{array} \\ & 1 \\ & 2 \\ & 3 \\ & 4 \\ & 5 \\ & 6 \\ & 7 \\ & 8 \\ & 9 \\ & 10 \\ & 11 \\ 12 \\ 13 \\ 14 \\ 15 \\ 16\end{array}$

2

Trans

Cycles/

Layer

A, C 1

F 2

B 1

E 1

H 13

J 8

H 13

I 1

J 8

E 1

H 13

F 2

$\begin{array}{rcr}\text { 1 } & \text { A,C } & 1 \\ 2 & \text { F } & 2 \\ 3 & \text { B } & 1 \\ 4 & \text { E } & 1 \\ 5 & \text { H } & 13 \\ 6 & \text { I } & 1 \\ 7 & \text { J } & 8 \\ 8 & \text { E } & 1 \\ 9 & \text { H } & 13 \\ 10 & \text { I } & 1 \\ 11 & \text { J } & 8 \\ 12 & \text { E } & 1 \\ 13 & \text { H } & 13 \\ 14 & \text { B } & 1 \\ 15 & \text { F } & 2\end{array}$

3

1

U

1

\begin{tabular}{|c|c|}
\hline $\begin{array}{l}\text { Mission } \\
\text { Number }\end{array}$ & $\begin{array}{c}\text { Number } \\
\text { of Repeats }\end{array}$ \\
\hline 1 & 24 \\
\hline 2 & 1 \\
\hline 1 & 24 \\
\hline 2 & 1 \\
\hline 3 & 1 \\
\hline
\end{tabular}

Sequence repeats 10 times for 40 years. 
TABLE 6. Stress History Used in Analyzing Points A and D in Farley-1

\begin{tabular}{l} 
List of Transients \\
\hline Start-up/Shutdown \\
Loading/Unloading \\
Step Increase/Step Decrease \\
Large Step Decrease With Steam Dump \\
Loss of Load \\
Loss of Power \\
Loss of Flow, One Pump \\
Reactor Trip \\
Hydrotest
\end{tabular}

\begin{tabular}{cr} 
Identifier & $\begin{array}{c}\text { No. Cycles/ } \\
40 \text { Years }\end{array}$ \\
\cline { 2 - 2 } 1 & 200 \\
2 & 18,300 \\
3 & 2,000 \\
4 & 200 \\
5 & 80 \\
6 & 40 \\
7 & 80 \\
8 & 400 \\
$10 \mathrm{~b}$ & 50
\end{tabular}

\section{STRESS HISTORY}

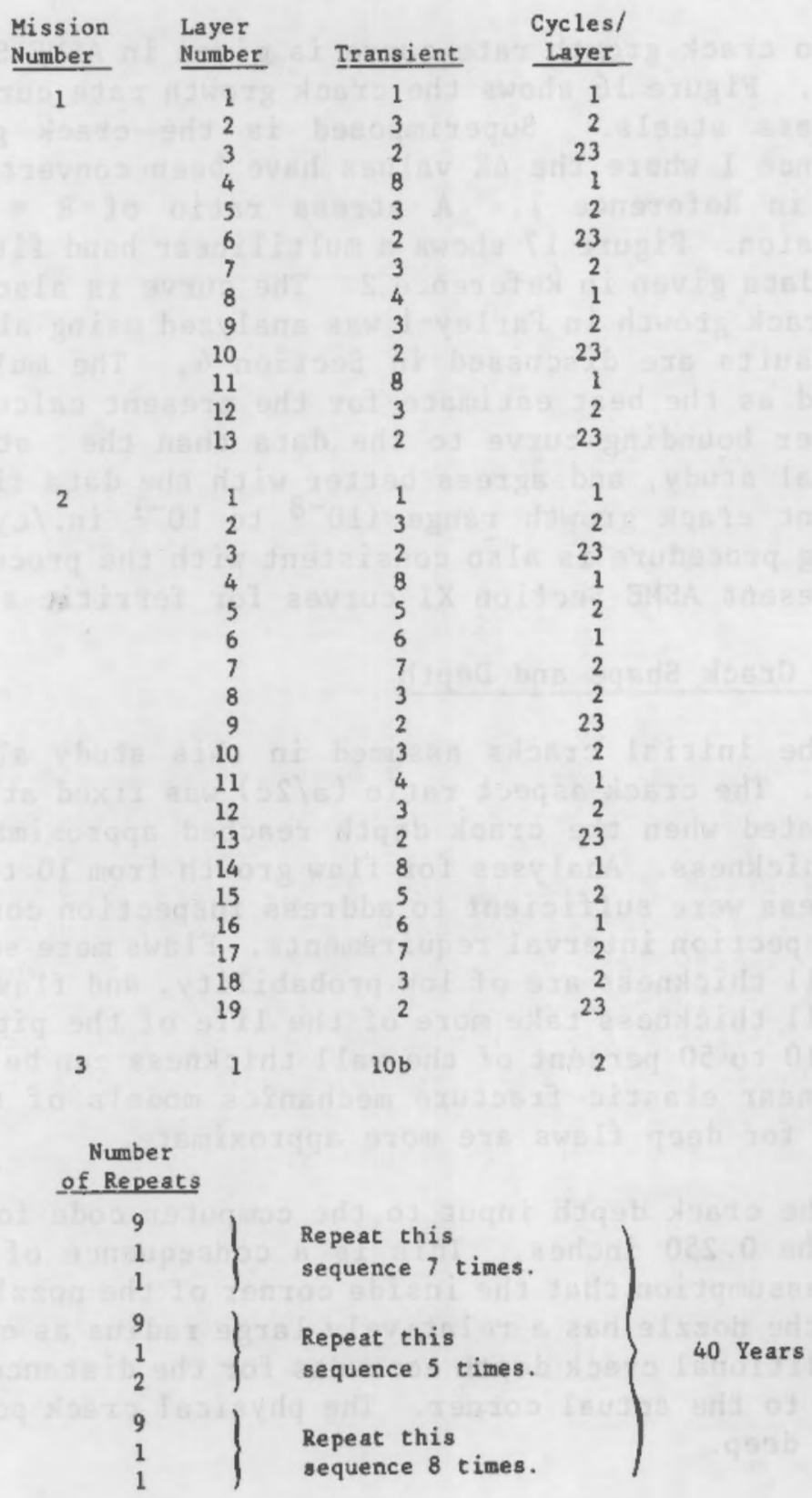


Figure 15 shows the upper bound curve used in Reference 2 for the carbon steels. Superimposed on this curve is the ASME Code curve from Reference 4. The code curve is somewhat less conservative than the upper bound curve. The relative difference between these two curves in terms of the life predictions is discussed in Section 4. The code curve was used for all of the St. Lucie-1 analyses, in order to base calculations on a documented fit of da/dN data. The data fits of references 2 and 4 were based on essentially the same test data. The Bamford curve (Ref. 4) is a statistically based fit of the mean of upper bound crack growth rate data, whereas the curve of the original cold leg study (Ref. 2) is a hand-fit upper bound to the data. Each curve is believed to be a conservative basis for predicting crack growth rates in piping.

No crack growth rate curve is given in ASME Section XI for stainless steels. Figure 16 shows the crack growth rate curve from Reference 2 for stainless steela. Superimposed is the crack growth rate curve from Reference 1 where the $\Delta K$ values have been converted from the $K_{e f f}$ values given in Reference 1. A stress ratio of $R=0.7$ was used in this conversion. Figure 17 shows a multilinear hand fit to all of the stainless steel data given in Reference 2. The curve is also superimposed on Figure 16. Crack growth in Farley-1 was analyzed using all three of these curves. The results are discussed in Section 4. The multi-linear hand fit was adopted as the best estimate for the present calculations. This curve is a better bounding curve to the data than the straight line fit of the original study, and agrees better with the data fit of Reference 1 in the relevant crack growth range $\left(10^{-8}\right.$ to $10^{-1}$ in./cycle). The multilinear fitting procedure is also consistent with the procedure used in developing the present ASME Section XI curves for ferritic steels.

\subsubsection{Crack Shape and Depth}

The initial cracks assumed in this study all had a depth of 0.250 inches. The crack aspect ratio $(a / 2 c)$ was fixed at 0.1 . The analyses were terminated when the crack depth reached approximately 50 percent of the wall thickness. Analyses for flaw growth from 10 to 50 percent of the wall thickness were sufficient to address inspection concerns of flaw detection and inspection interval requirements. Flaws more severe than 10 percent of the wall thickness are of low probability, and flaw growth to 50 percent of the wall thickness take more of the life of the pipe. Also, the growth of flaws 10 to 50 percent of the wall thickness can be reasonably predicted by the linear elastic fracture mechanics models of this study, whereas the models for deep flaws are more approximate.

The crack depth input to the computer cade for the nozzle was deeper than the 0.250 inches. This is a consequence of the fracture mechanics model assumption that the inside corner of the nozzle is a sharp corner. In fact, the nozzle has a relatively large radius as can be seen in Figure 14 . The additional crack depth accounts for the distance from the assumed sharp corner to the actual corner. The physical crack postulated was still 0.25 inches deep. 


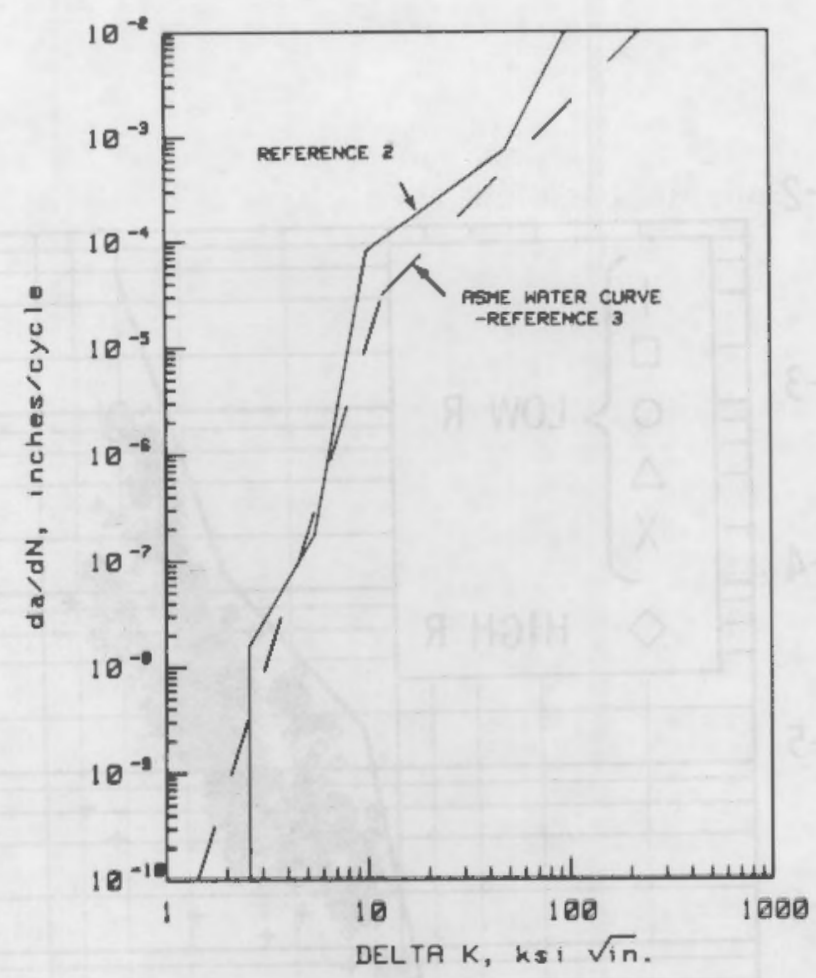

FIGURE 15. Fatigue Crack Growth Rate for Carbon Steels

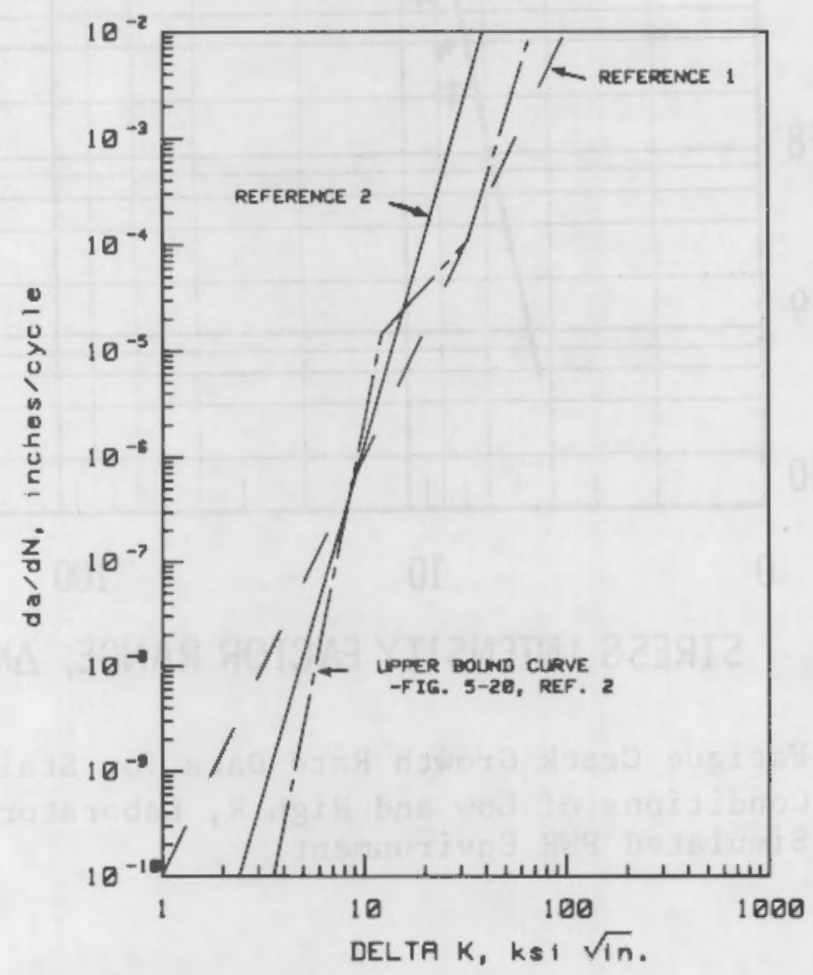

FIGURE 16. Fatigue Crack Growth Rate for Stainless Steels 


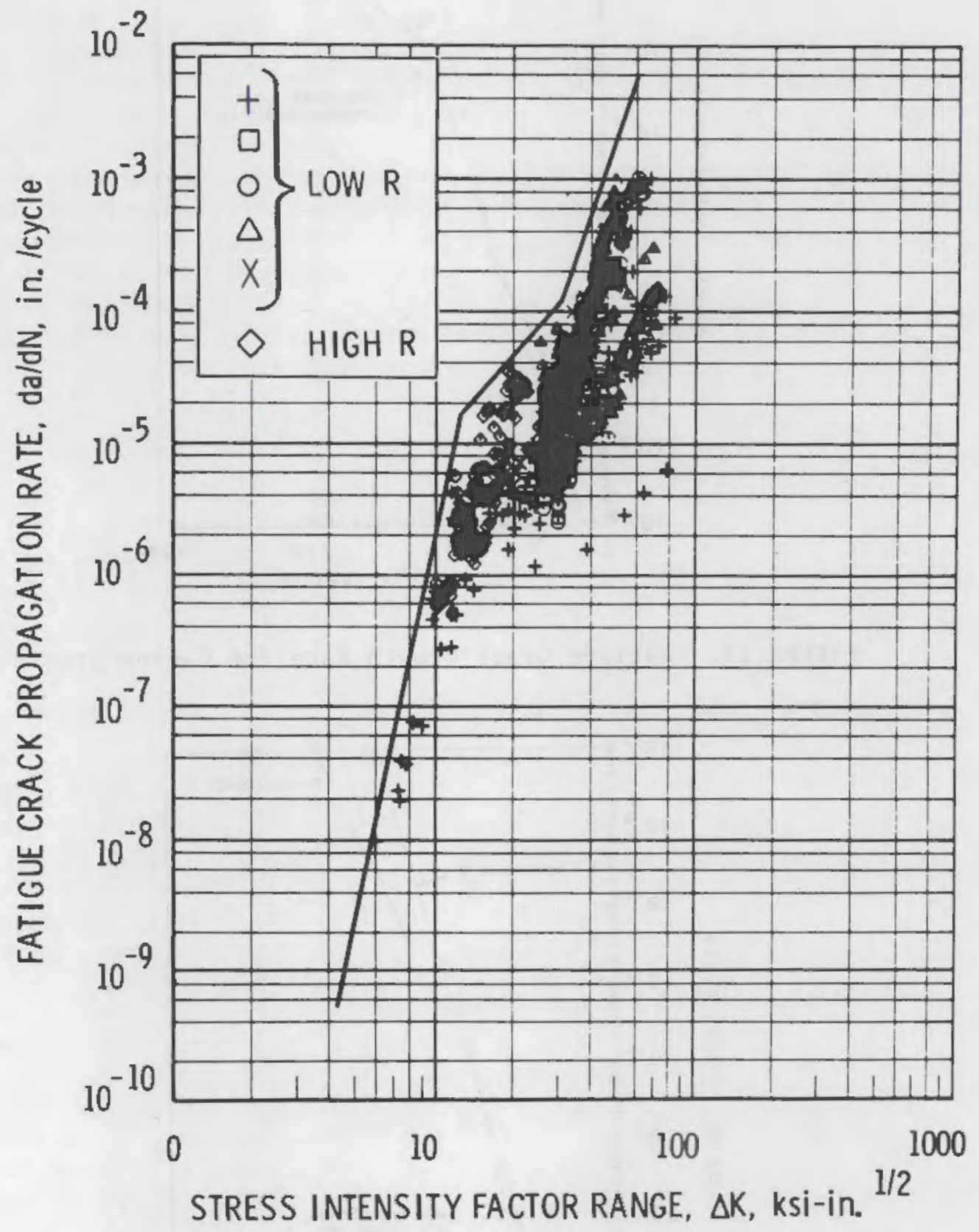

FIGURE 17. Fatigue Crack Growth Rate Data for Stainless Steels -Conditions of Low and High R, Laboratory Air, and Simulated PWR Environment 


\subsection{COMPUTATIONAL PROCEDURE}

The fatigue crack growth calculations were made using a modified version of the CRACKS III computer code (here referred to as CRACKS). CRACKS (Ref. 5) was originally developed by the Air Force Flight Dynamics Laboratory for use in aircraft damage tolerance evaluations. As such, the code was not directly applicable to crack growth in piping components, and therefore had to be modified. The modifications consisted mainly of including stress intensity factors for cracks in piping components and the different failure criteria needed for these components but not needed for aircraft structures. All the modifications which were made to CRACKS were made as part of the original Cold Leg study. The basic features of the program will be briefly highlighted in the following subsections. A complete discussion of the operation of CRACKS can be found in Reference 2.

\subsubsection{Stress Intensity Eactor}

The mathematical form of the stress intensity factor used by CRACKS is identical to Equation (2). The formulation of the CRACKS program takes full advantage of Equation (2) by defining $B T$ as

$$
B_{T}=\prod_{i=1}^{n} \beta_{i}
$$

The CRACKS program has in internal library of $B_{i}$ values covering a wide range of useful cases, as 1 isted in Table 7 . The advantage of specifying BT as given in Equation (6) can best be illustrated by an example of how this feature was used in the present investigation. Consider the dissimilar metal weld; in this case the total correction factor, $\beta_{\mathrm{T}}$, was composed of a correction $\left(B_{11}\right)$ describing the circumferential surface crack in the pipe, and another correction factor $\left(B_{3}\right)$ to describe the through-wall stress gradient. The advantage is that the individual correction factors can be easily combined with only minor additions to the input information. This latter correction factor, $\beta_{3}$, is one of the tabular correction factors available in CRACKS. With the tabular format, as many as 100 data points can be used to specify the shape of a stress gradient as a function of crack length. For the linear through-wall stress gradient used with the dissimilar metal we1d examined here, the gradient was completely specified with two data points.

\subsubsection{Input to CRACKS}

The input information required for using CRACKS is organized into a number of discrete units. The following is an abbreviated list of that information. 
TABLE 7. Library of Correction Factors, $B_{i}$

\begin{tabular}{|c|c|}
\hline i & Description of $\beta_{i}$ \\
\hline 1 & Constant \\
\hline 2 & Finite width correction \\
\hline 3 & $\begin{array}{l}\text { User defined tabular correction, } \\
\text { a function of crack length }\end{array}$ \\
\hline 4 & $\begin{array}{l}\text { User defined tabular correction, } \\
\text { a function of crack length }\end{array}$ \\
\hline 5 & $\begin{array}{l}\text { Bowie solution for a single crack } \\
\text { emanating from a circular hole }\end{array}$ \\
\hline 6 & $\begin{array}{l}\text { Bowie solution for a double ended } \\
\text { crack emanating from a circular } \\
\text { hole }\end{array}$ \\
\hline 7 & $\begin{array}{l}\text { Compact tension specimen, } \\
\text { J.C. Newnan }\end{array}$ \\
\hline 8 & $\begin{array}{l}\text { Compact tension specimen, } \\
\text { Grumann }\end{array}$ \\
\hline $9(a)$ & Axial surface crack in a pipe \\
\hline $10(a)$ & $\begin{array}{l}\text { Axial through wall crack in a } \\
\text { pipe }\end{array}$ \\
\hline $11(a)$ & $\begin{array}{l}\text { Circumferential surface crack in } \\
\text { a pipe }\end{array}$ \\
\hline $12^{(a)}$ & $\begin{array}{l}\text { Circumferential through wall } \\
\text { crack in a pipe }\end{array}$ \\
\hline $13(a)$ & Axial corner crack in a nozzle \\
\hline $14^{(a)}$ & $\begin{array}{l}\text { Axial through wall crack in a } \\
\text { nozzle }\end{array}$ \\
\hline
\end{tabular}

\footnotetext{
(a)Added to CRACKS as part of the work presented in Reference 2 .
} 


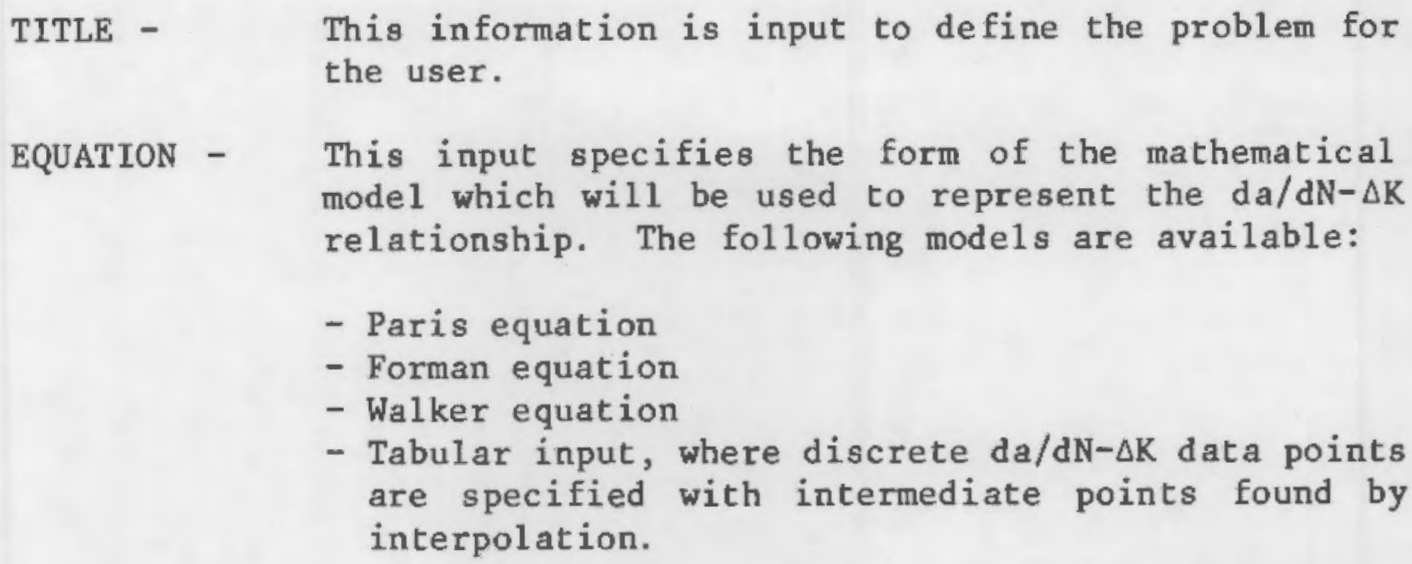

MATERIAL - This input includes the name of the material, the data (coefficients, exponents, etc.) required for the model selected, the fracture toughness $K_{c}$, and the yield and flow stresses. A threshold $\Delta \mathrm{K}$ may also be specified.

LIMITS - This input consists of the initial crack size, and the maximum crack size of practical interest.

ANALYSIS - This section of input deals with the description of the stress intensity factor. This is where the $B_{i}$ correction factors are specified.

LOADS - The maximum and minimum fatigue stresses and the number of cycles for each transient are input here.

SPECTRUM - The order in which the transients occur during operation of the plant are specified here.

Other input information includes an option to select the amount and detail of the output from the program, and an option for an automatic restart capability useful in doing sensitivity analyses. 


\subsection{RESULTS}

As mentioned in the previous sections of this report, the current study was conducted in a manner very similar to the study reported in Reference 2. The following revisions were made to the input data to accomplish our objective:

- The initial crack sizes were reduced to 0.25 inch, roughly 10 percent of the wall thickness.

- Operational transients which have a low probability of occurrence were removed from the load spectrum; in addition the vibration induced loading was no longer included.

- The crack growth rate data from the original work was modified to be less conservative.

- For the dissimilar metal welds a linear stress gradient was introduced. This gradient reduced the stresses at the outside of the pipe wall thickness to less than 15 percent of their inside surface values, while the inside surface stresses remained very nearly the same as in the original study.

Incorporating these revisions into the analysis scheme of the original study produced the results given in Table 8 for the plants and joint locations considered.

While Table 8 is arranged in a manner similar to the tables containing the results in Reference 2, the crack growth life data presented here are somewhat different. The original report gave the number of 40-year plant design lives for a crack to cause a leak and subsequently cause the pipe to rupture. In Table 8 , the number of 40-year lives is the time for a crack (initially smaller than those used in the original study) to grow to about 50 percent of the wall thickness. This is short of the depth to cause a leak, but the period of growth represents most of the 1 ife of the flawed piping. As a result, a direct comparison of the results here and in the previous work is difficult. However, the effect on life of changing each of the input parameters will be discussed in the following subsections.

\subsection{STRAIGHT PIPE}

The crack growth lives required to cause an initially small crack to grow to failure (using the revised input data for ten straight pipe joint locations in St. Lucie-1) are given in Table 8 . The results for circumferential cracks are plotted in Figure 18 or 19 , depending on the wall thickness. As can be seen, these lives are all much greater than one design life, and range from 31 to 63 design lives of 40 years. 
TABLE 8. Results of the Fracture Mechanics Analysis Using the Revised Input Data

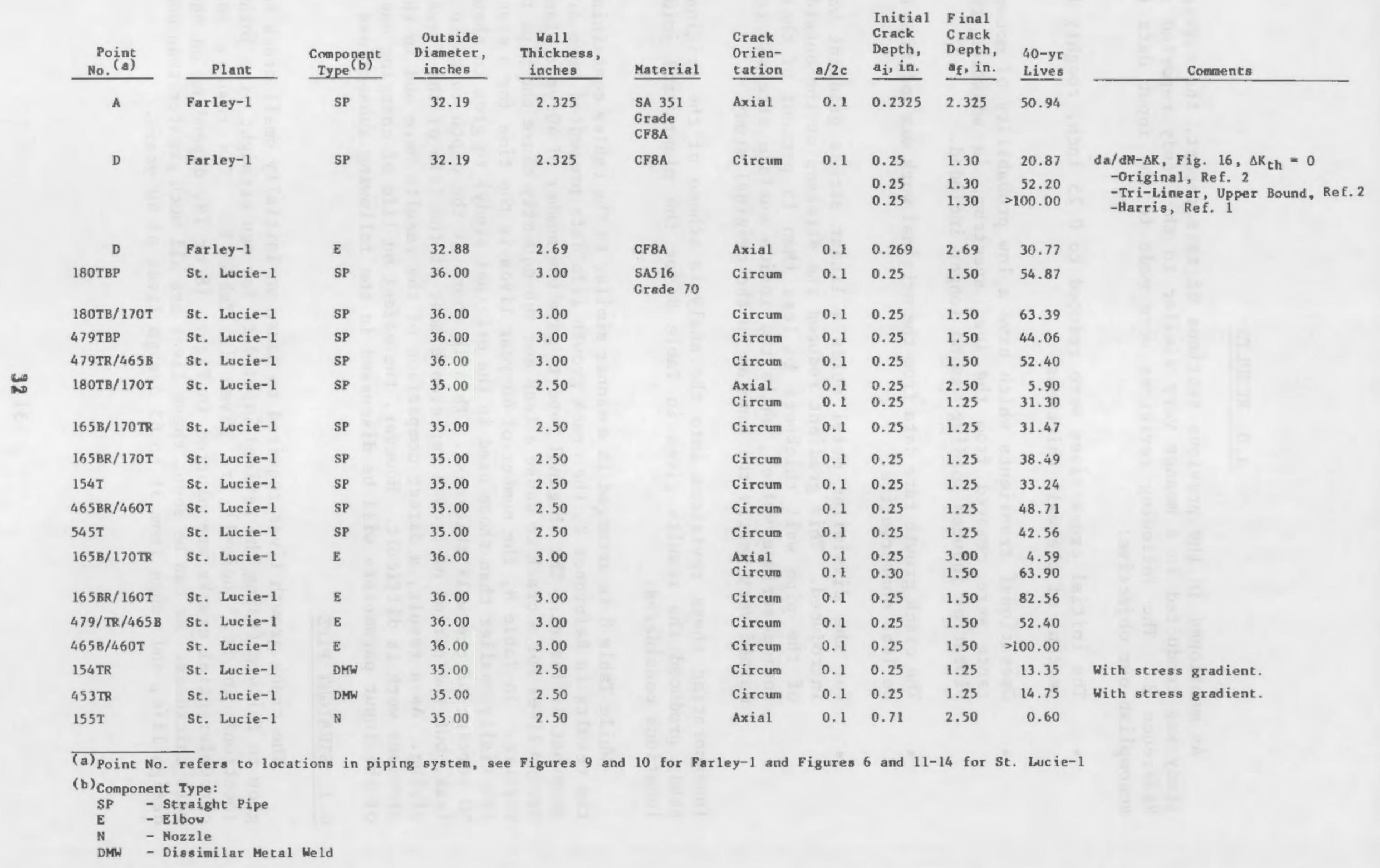




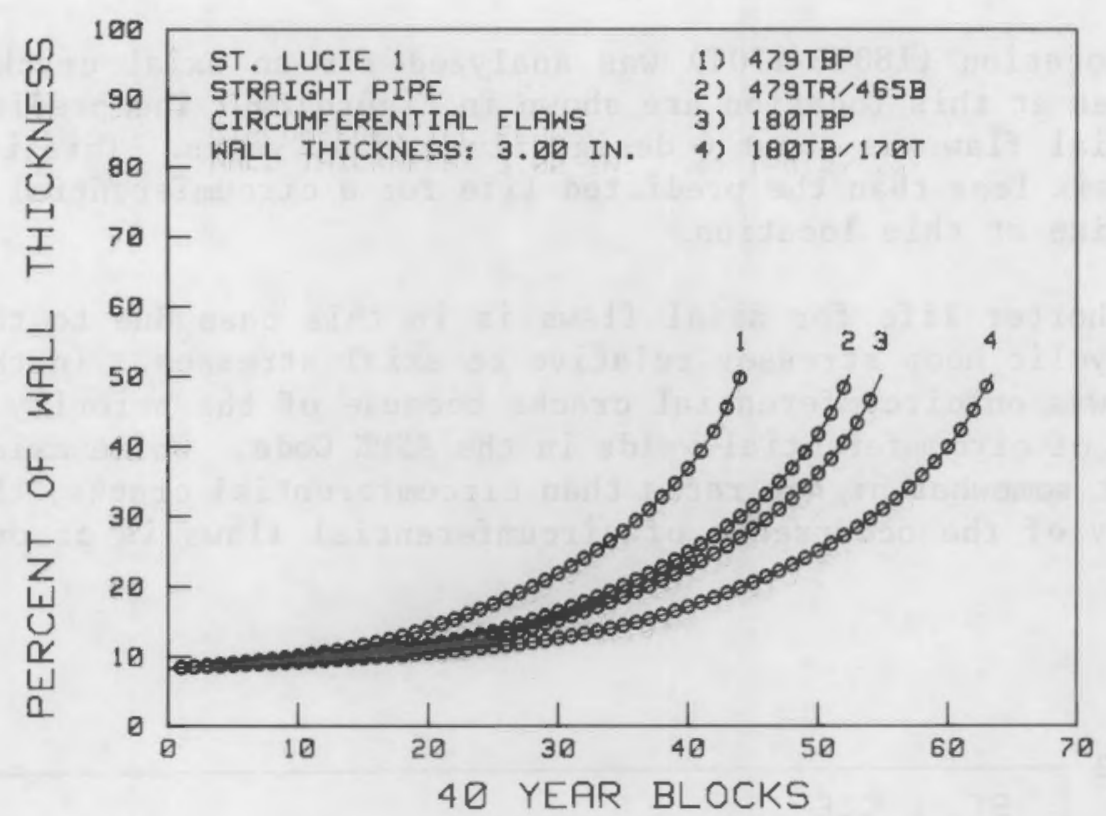

FIGURE 18. Results of the Circumferential Crack Growth Analysis For Straight Pipe, St. Lucie-1, Points 180TBP, 180TB/ $170 \mathrm{~T}, 479 \mathrm{TBP}$, AND 479TR/465B

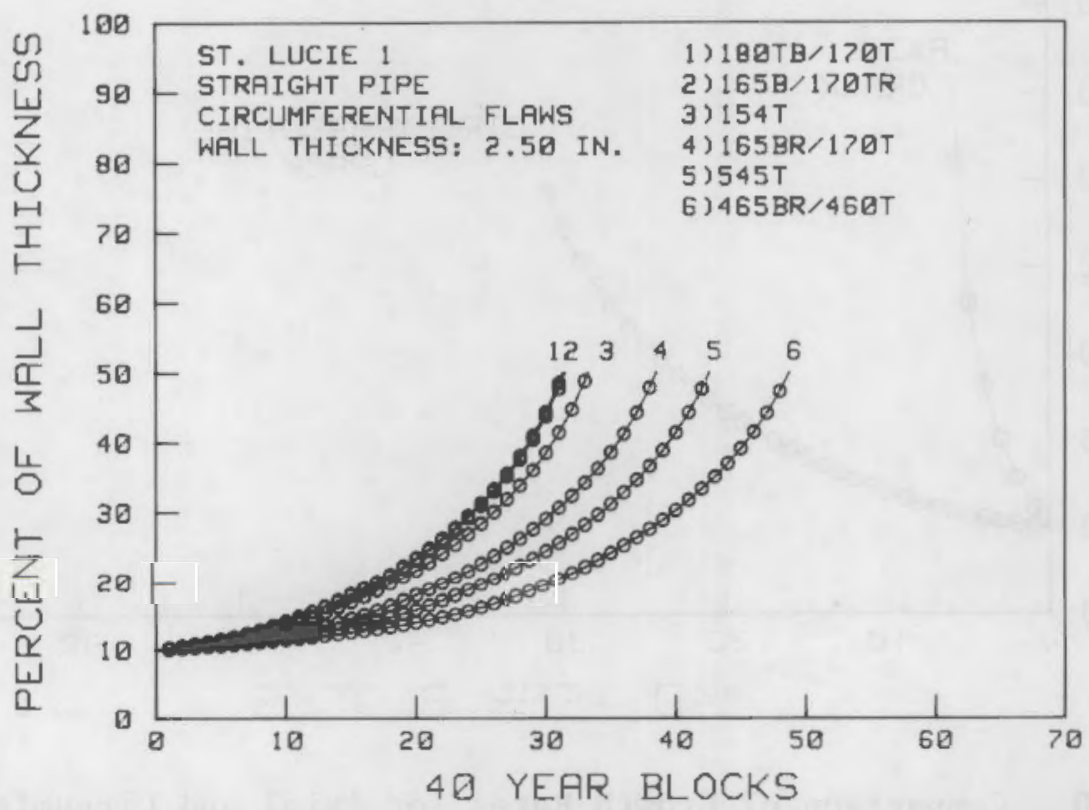

FIGURE 19. Results of Circumferential Crack Growth Analysis For Straight Pipe, St. Lucie-1, Points $180 \mathrm{~TB} / 170 \mathrm{~T}$, $165 \mathrm{~B} / 170 \mathrm{TR}, 165 \mathrm{BR} / 170 \mathrm{~T}, 154 \mathrm{~T}, 465 \mathrm{BR} / 460 \mathrm{~T}$, AND $545 \mathrm{~T}$ 
One location $(180 \mathrm{~TB} / 170 \mathrm{~T})$ was analyzed for an axial crack. Crack growth rates at this location are shown in Figure 20. The predicted life for the axial flaw was about 6 design lives of 40 years. This is about a factor of six less than the predicted life for a circumferential crack of the same size at this location.

The shorter life for axial flaws is in this case due to the higher level of cyclic hoop stresses relative to axial stresses. In this study the focus was on circumferential cracks because of the priority given to inspection of circumferential welds in the ASME Code. While axial cracks may grow at somewhat higher rates than circumferential cracks, the higher probability of the occurrence of circumferential flaws is of overriding concern.

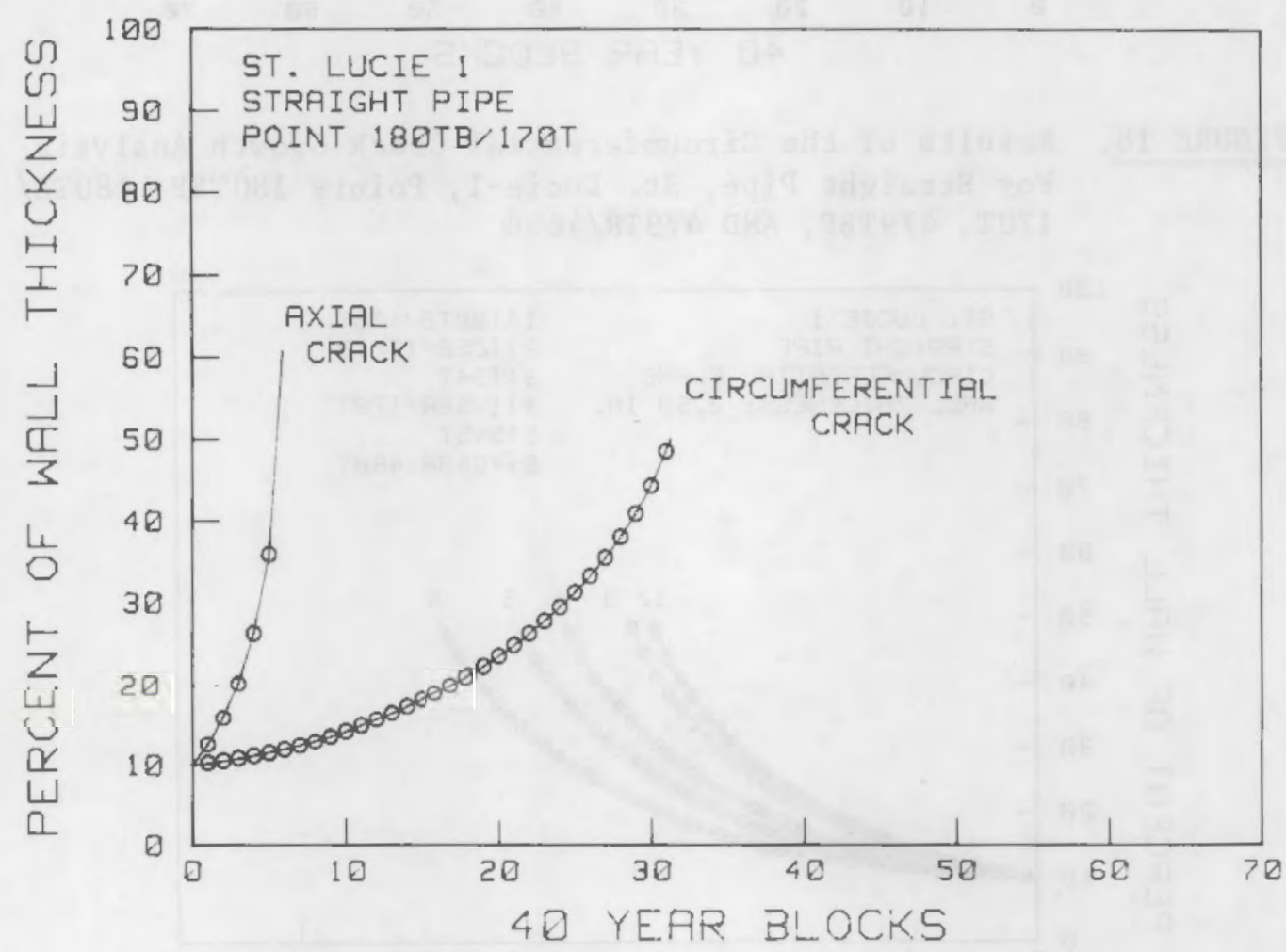

FIGURE 20. Comparison of Growth Rates for Axial and Circumferential Cracks in Straight Pipe, St. Lucie-1, Point 180TB/170T 


\subsection{SENSITIVITY STUDY}

In order to characterize the effect of each individual change of the input items, a sensitivity study was conducted; the results are given in Table 9 and have been plotted in Figure 21 .

The sensitivity study was conducted for straight pipe, since these results are fairly typical for the components examined, and because there is no reason to believe that the trends resulting from changes in the input data will be any different for the other components. In addition, it was expected that the relative magnitudes of the changes in predictd 1 ife would be similar from component to component. As with Table 8 , the results are given in terms of 40 year plant design lives. However, Table 9 shows the number of 40-year lives predicted for a crack to grow to a leak as well as for the crack to grow to 50 percent of the wall thickness $(t)$.

The difference between the lives of cracks growing to 50 percent $t$ and to a leak gives an indication of the crack growth velocity as it propagates through the remaining wall thickness. For the two runs with the original spectrum, this velocity is quite high because of the presence of a large number of vibrational stress cycles in the spectrum, on the order of $10^{10}$ cycles per 40 years. Because there are so many vibration cycles, once the crack grows deep enough that the $\Delta \mathrm{K}$ from the vibration stress exceeds the threshold $\Delta \mathrm{K}$, the growth through the remaining wall thickness is very fast. This is also true of Run No. 2, in which the original spectrum was run with the revised crack growth rate data, taken from Reference 3.

TABLE 9. Results of Sensitivity Studies of Initial Crack Size, Spectrum, Vibration, and Crack Growth Rate Equation on Life (Location 165B/170TR - Straight Pipe, Circumferential Crack, $a / 2 c=0.1$ )

Initial

Run Crack Size

No. $a_{i}, \% t$

$125 \%$

$2 \quad 25 \%$

$3 \quad 25 \%$

$4 \quad 25 \%$

$5 \quad 10 \%$

\begin{tabular}{lcc} 
Spectrum & \multicolumn{1}{c}{$\begin{array}{c}\text { Vibration } \\
\text { Stress }\end{array}$} \\
\cline { 3 - 3 } Original & & Yes \\
Original & & Yes \\
Revised & & No \\
Revised & & No \\
Revised & No
\end{tabular}

No
40-Year

Lives For

\begin{tabular}{cc}
\hline $50 \% \mathrm{t}$ & Leak \\
2.43 & 2.43 \\
5.72 & 5.72 \\
4.3 & 5.33 \\
10.2 & 12.7 \\
31.47 & --
\end{tabular}




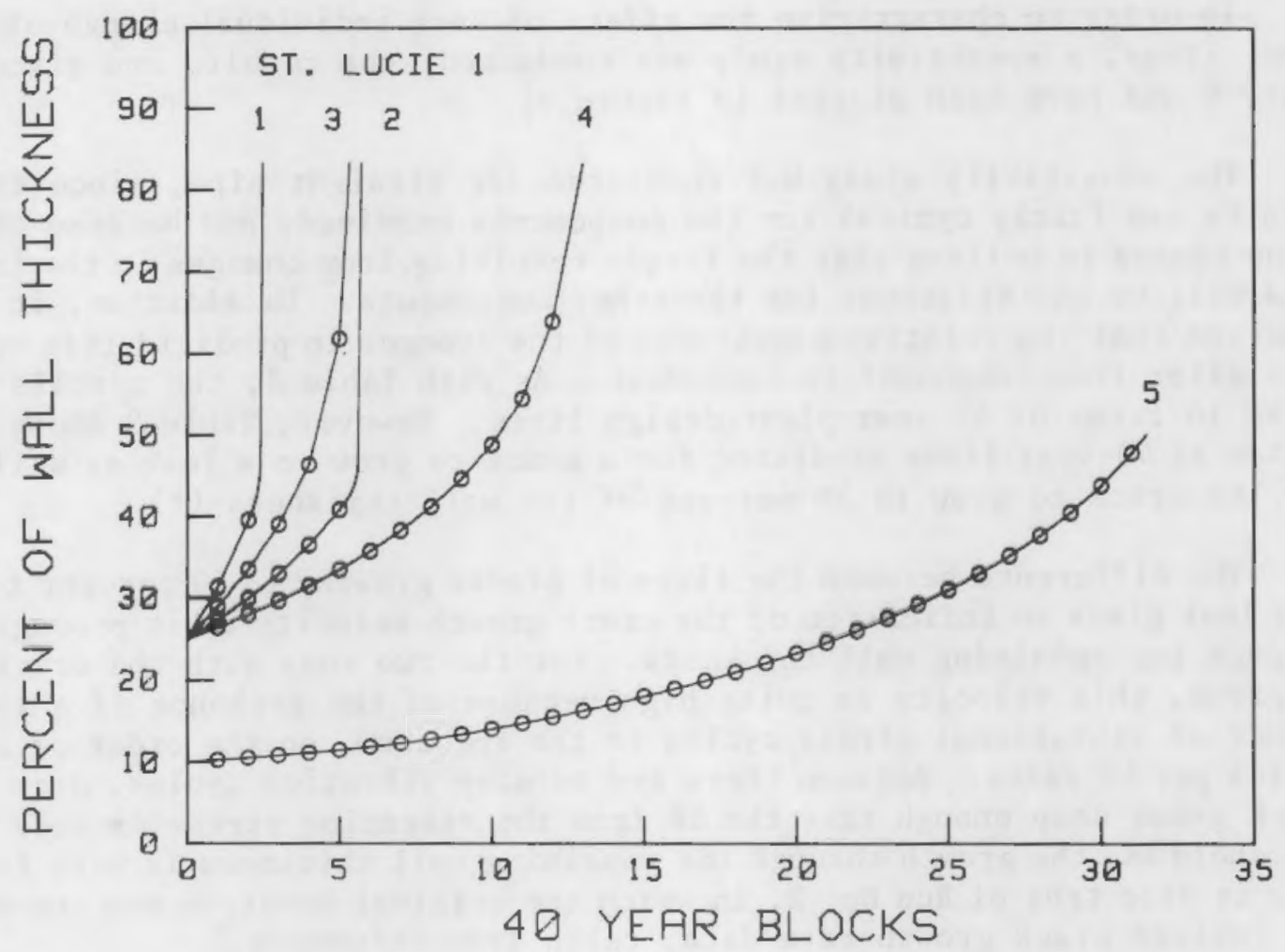

FIGURE 21. Results of the Sensitivity Analysis for Straight Pipe, St. Lucie-1 (Curve Numbers Refer to the Run Numbers of Table 9), Point 165B/170TR

Without a threshold $\Delta \mathrm{K}$, the $\mathrm{li}$ fe would have been extremely short. As a result, a threshold $\triangle \mathrm{K}$ was imposed on the ASME data so that a comparison could be made to show the effect of changing the da/dN data while using the original spectrum. This threshold was the same as that used in the original study $(2.6 \mathrm{ksi} \sqrt{\mathrm{in} .})$. As shown in Table 9 , the increase in life resulting from the change to the ASME $\mathrm{da} / \mathrm{dN}$ curve is more than a factor of 2 .

The effect of eliminating both the transients with a low probability of occurrence and the vibration cycles can be seen by comparing the results of Runs 1 and 3 in Table 9 and Figure 21. For runs 1 and 3 the original $\mathrm{da} / \mathrm{dN}$ data was used. A similar comparison $\mathrm{c}$ an be made for the revised $\mathrm{da} / \mathrm{dN}$ data by comparing Runs 2 and 4 . The increase in life for either case is more than a factor of 2 for the through-wall case and roughly a factor of 
1.7 for the 50 percent $t$ case. Changing both the da/dN data and the spectrum at the same time results in a life increase of a factor of 5 for the through-wall case and 4 for 50 percent $t$ case.

Finally, the effect of reducing the initial crack size on the 1 ife to grow to the 50 percent $t$ crack length is evident by comparing the results of Runs 4 and 5. This comparison was made for only the revised crack growth rate data and spectrum input. The increase in life is roughly a factor of 3.

The results for the Farley-l straight pipe are also contained in Table 8. The straight pipe from the Farley-l plant was included in this study because it provided a common point between the original BCL Cold Leg study (Ref. 2) and the work of Harris et al. (Ref. 3). As shown in Table 8, this pipe in Farley-1 is made of stainless steel while all of the St. Lucie-1 piping components studied here were made of carbon steel. This being the case, the major emphasis was on the effect of the $\mathrm{da} / \mathrm{dN}$ data used in the analysis. Three sets of da/dN data were studied:

- the data used in the original Cold Leg Report

- an upper bound "tri-linear" curve fit to the data used in Reference 2

- the data used by Harris et al. (Ref. 1).

The predicted crack growth lives resulting from the use of each of the $\mathrm{da} / \mathrm{dN}$ data sets are given in Table 8 and have been plotted in Figure 22. The operational load spectrum used in these calculations was the revised spectrum for Farley-1; the original spectrum was not used. In addition, a threshold $\Delta \mathrm{K}$ was not used. As indicated in Table 8 , the predicted lives vary over a range of 5 or more, depending on which da/dN data is used. The present "tri-linear" fit and the Harris straight line fit give predicted lives differing by a factor of three. This difference is not unexpected since the Harris curve was derived as a mean curve over the total range of growth rates, while the present curve was derived as a bounding curve at each particular growth rate. A detailed comparison of the results of References 1 and 2 is contained in Section 5 of this report.

\subsection{DISSIMILAR METAL WELDS}

The lives predicted for two dissimilar metal welds in St. Lucie-1 are given in Table 8. This prediction includes the effect of reducing the initial crack size, revising both the cyclic stress spectrum and the $\mathrm{da} / \mathrm{dN}$ curve, and introducing a through-wall axial stress gradient. The results of a sensitivity study conducted to evaluate the effect of including the through-wall axial stress gradient are presented in Table 10. In addition, the results of the crack growth predictions are plotted in Figure 23. For 


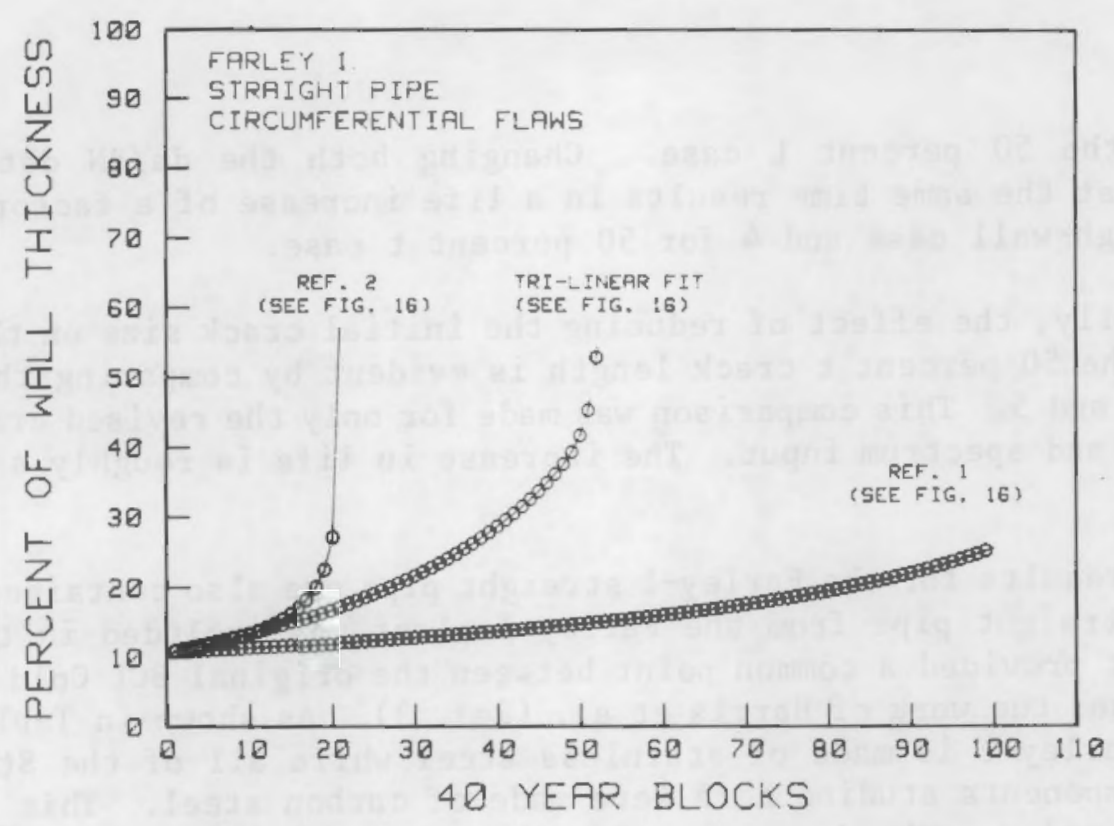

FIGURE 22. Results of the Crack Growth Analysis for Stainless Steel Straight Pipe, Farley-1 (Point D - Ref. 2, Point 13 Ref. 1)

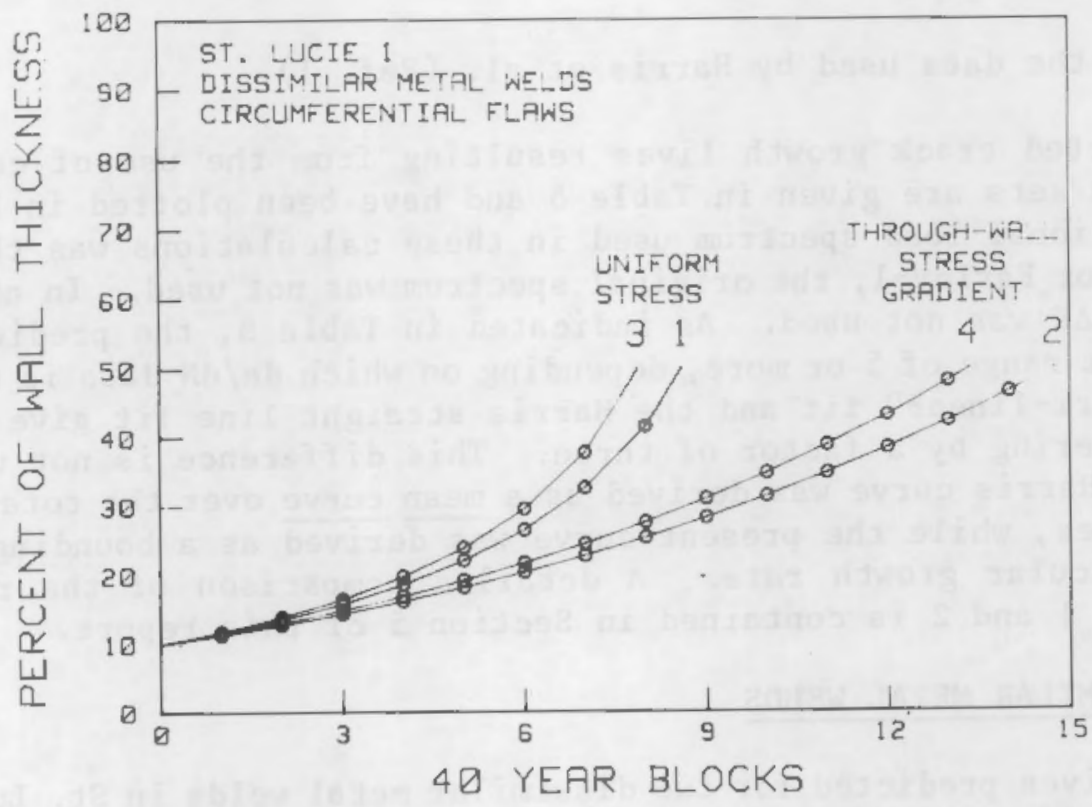

FIGURE 23. Results of the Crack Growth Analysis for Dissimilar Metal Welds, St. Lucie-1, Points 154TR and 453TR 
TABLE 10. Results of a Sensitivity Study to Evaluate the Effect of Including a Through-Wall Stress Gradient for the Dissimilar Metal Welds (Initial Crack Size $=10 \% \mathrm{t}$, Fina1 Crack Size $=50 \% t$ )

\begin{tabular}{|c|c|c|c|}
\hline $\begin{array}{l}\text { Run } \\
\text { No. }\end{array}$ & $\begin{array}{l}\text { Joint } \\
\text { Location }\end{array}$ & $\begin{array}{c}\text { Axial Through-Wall } \\
\text { Stress Gradient } \\
\end{array}$ & $\begin{array}{c}\text { 40-Year } \\
\text { Lives } \\
\end{array}$ \\
\hline 1 & $453 \mathrm{TR}$ & No & 8.59 \\
\hline 2 & $453 \mathrm{TR}$ & Yes & 14.75 \\
\hline 3 & $154 \mathrm{TR}$ & No & 7.88 \\
\hline 4 & $154 \mathrm{TR}$ & Yes & 13.35 \\
\hline
\end{tabular}

both joints the increase in life attributable to the gradient was roughly a factor of 1.7. As in the original study of Reference (2), the results for the cases where no gradient was present were obtained by letting the stresses remain constant through the wall at their maximum values.

The predicted lives for the dissimilar metal welds are about 13 to 15 times the design life of 40 years. Because of the higher stresses at the dissimilar metal welds, these predicted lives are about 25 to 50 percent of the corresponding lives of welds in straight pipe.

\subsection{ELBOWS}

The lives predicted for the St. Lucie-l elbows are given in Table 8 , and results for circumferential flaws have been plotted in Figure 24 . As before, these results reflect the changes in the spectrum, the da/dN data, and the reduction in initial crack size from those of the original study. For the St. Lucie-1 plant, elbow 465/460T had the longest life (of any of the locations analyzed) for a circumferential crack to grow from 10 to 50 percent of the wall thickness. For circumferential flaws, the elbow lives were somewhat greater than those for straight pipe. This is probably due to the increased wall thickness and correspondingly lower stresses at the elbows.

Figure 25 compares the lives for axial and circumferential flaws of the same initial size for elbow point 165B/170TR. The characteristically high hoop stresses in the elbow results in the axial flaw life being about 7 percent of the life for the circumferential flaw. Nevertheless the predicted life is 4.59 times the design life of 40 years. 


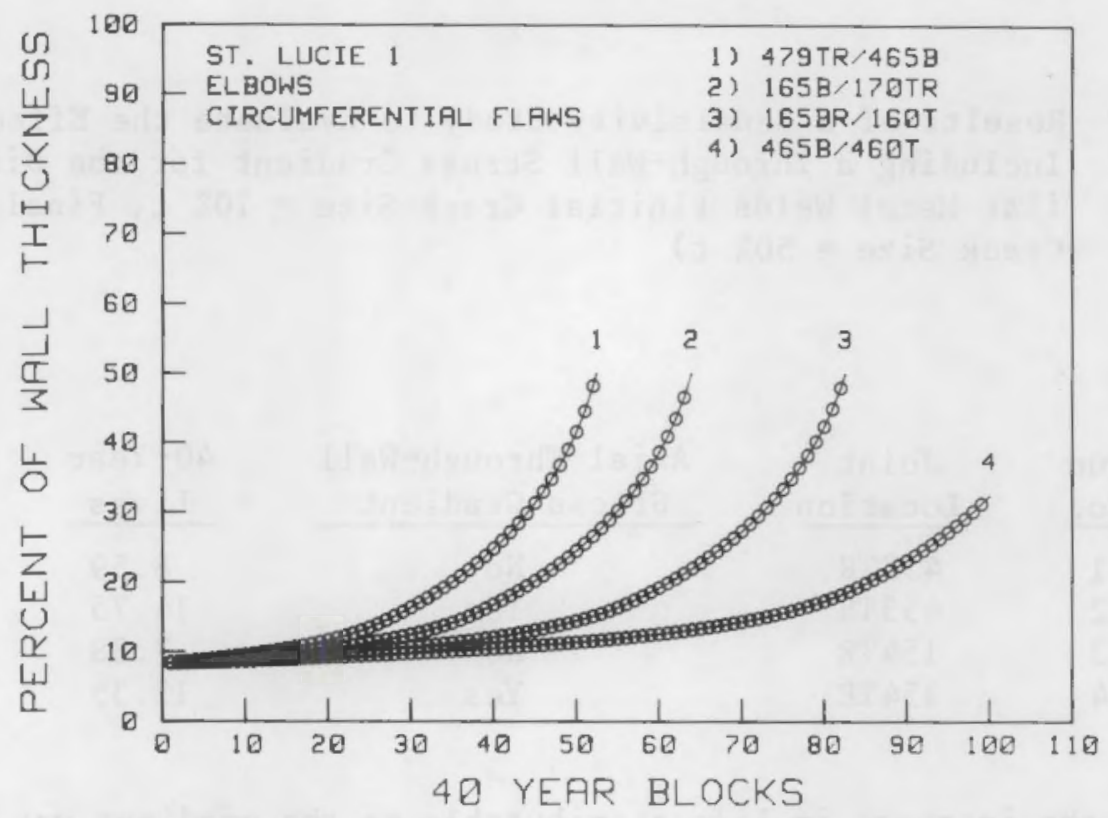

FIGURE 24. Results of the Crack Growth Analysis for Circumferentially F1awed E1bows, St. Lucie-1, Points 165B/170TR, 165BR/160T, $479 \mathrm{TR} / 465 \mathrm{~B}$, AND $465 \mathrm{~B} / 460 \mathrm{~T}$

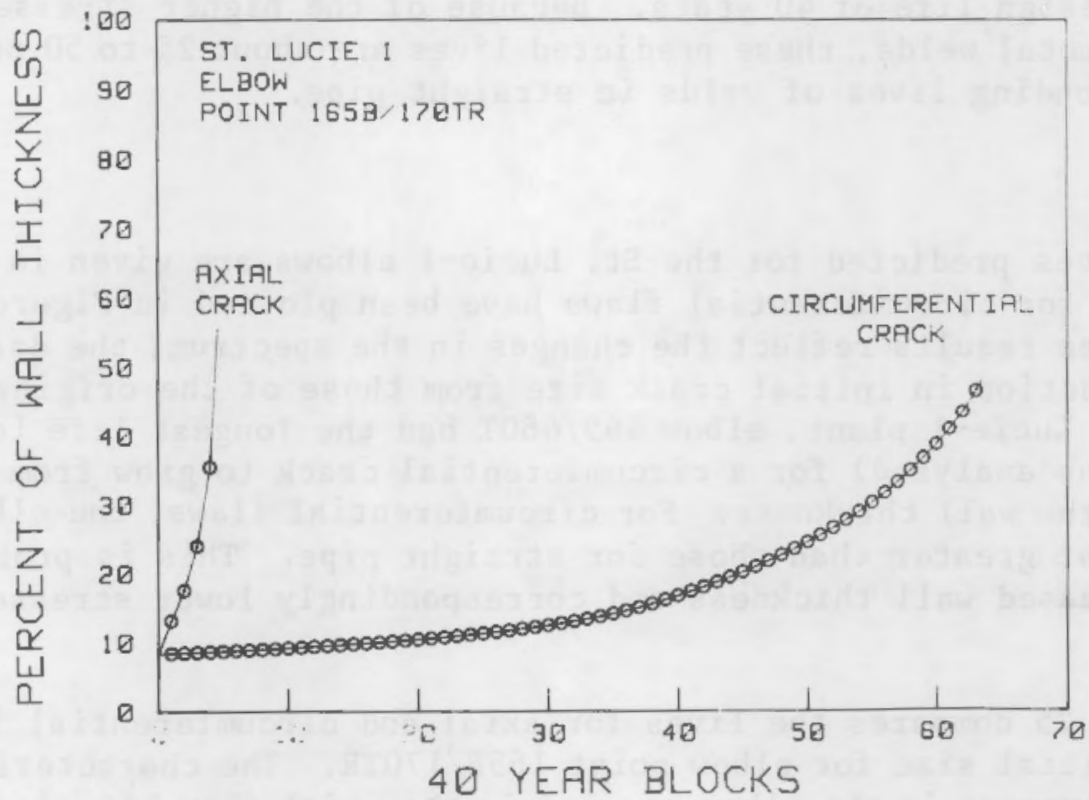

FIGURE 25. Comparison of Growth Rates for Axial and Circumferential Cracks in Elbow, St. Lucie-1, Point 165B/170TR 


\subsection{NOZZLES}

In this analysis, the nozzle corner crack was considered (as a worst case assumption) to be axially orientated relative to the run pipe. However, as with the dissimilar metal welds, a through-wall stress gradient was included in the analysis of the nozzle. The life predicted for the charging inlet nozzle of St. Lucie-l is given in Table 8 and has been plotted in Figure 26. Of the components re-examined in this study, the nozzle was the only flawed component with a predicted 1 ife of less than 40 years. Presumably this can be attributed to the large initial crack size and high stress concentration at this location. Recall from Section 3.2 that the initial crack size for the nozzle was selected from consideration of the nozzle geometry in the vicinity of the crack location. It must also be pointed out that the final crack depth for the nozzle was not limited to 50 percent of the wall thickness as was the case for the other analyses listed in Table 8. In the nozzle analysis the computer calculations were permitted to proceed to wall breakthrough. Since the 1 ife of the nozzle remained considerably less than 40 years, even after some of the conservatism was removed from the original analysis in Reference 2, nozzles are still of concern from the fatigue point of view. Flaws at the location of concern are not readily detected with existing NDI procedures, and the detection of corner flaws as shown in Figure 14 are outside the scope of present code inspection plans for piping.

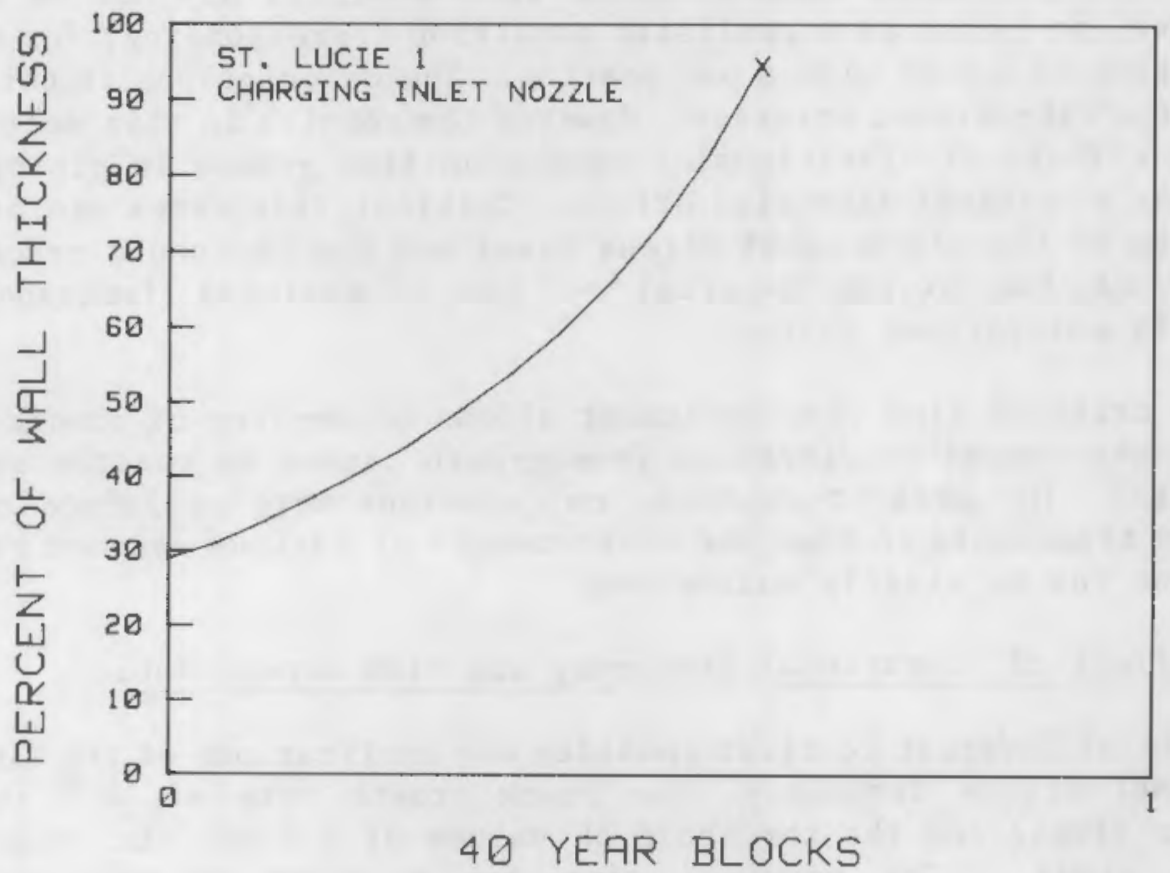

FIGURE 26. Results of the Crack Growth Analysis of the Charging Inlet Nozzle, St. Lucie-1 Point $155 \mathrm{~T}$ 
Cracks have recently been noted at charging inlet nozzles of operating reactors. The probability of large initial flaws at this location should be low, and it is likely that cracks are due to an initiating mechanism such as thermal fatigue. The present analysis does not address thermal fatigue; however, the calculations do clearly show that there are other sources of stress to grow a crack once a crack is initiated. Recent experience as well as the present analyses indicate that greater attention should be given to inservice inspection of branch piping nozzles.

\subsection{VIBRATIONAL STRESS EVALUATION}

The results of the original cold leg integrity study (Ref. 2) showed that even relatively low (e.g., 1.0-ksi) vibrational stresses can have potentially serious consequences on piping integrity. The predicted lives were often limited by vibrational stress leve1s. In the original study, a vibrational stress of $1.0 \mathrm{ksi}$ at 1,000 cycles per minute (cpm) was assumed to be present in all calculations. Study of these crack growth rate predictions suggests that vibrational stresses have an "all or nothing" type of effect. Once a crack grew to a critical depth (this growth being due to the other loading transients), the vibrational stress resulted in a very rapid failure of the pipe at the location of concern.

Lacking data from the reactor system vendors, the original study assumed a 1.0-ksi cyclic stress at $1,000 \mathrm{cpm}$. Subsequent comments from vendors have indicated that although such a stress may not be a common occurrence, it is not an unrealistic condition corresponding, for example, to operation of a pump with a bad bearing. The calculations in this report deleted the vibrational stresses. However the results in this section show that the effects of vibrational stresses on $\mathrm{flaw}$ growth in piping can be treated as a critical flaw size effect. Critical flaw sizes are primarily a function of the vibrational stress level and the threshold crack growth behavior of the piping material -- the vibrational frequency is a relatively unimportant factor.

The critical flaw size treatment allows decoupling of predictions of crack growth caused by vibration from growth caused by reactor operating transients. The present cold leg calculations were performed only for operating transients so that the consequences of various assumed vibration conditions can be clearly delineated.

\subsubsection{Effect of Vibrational Frequency and Flaw Aspect Ratio}

It is of interest to first consider the implications of the $1,000-\mathrm{cpm}$ vibrational stress frequency, the crack growth rate of $10^{-8} \mathrm{in./cycle}$ (ferritic steel) and the threshold $\Delta K$ values of $2.6 \mathrm{ksi} \sqrt{\mathrm{in}}$. used in the original study. The required time for a crack to grow through a significant fraction of the wall of a primary coolant pipe can be 
estimated; for example, the time for 1.0-in. of crack growth at 1,000 cpm and $10^{-8}$ in./cycle is

$$
\begin{aligned}
& \text { Time } \leq \frac{a}{\mathrm{da} / \mathrm{dN}}\left(\frac{1}{\mathrm{f}}\right)=\frac{1.0 \mathrm{in} .}{10^{-8} \text { in. } / \text { cycle }} \times \frac{1}{1,000 \mathrm{cpm}} \\
& \text { Time } \leq 10^{5} \mathrm{~min}(2.3 \text { months })
\end{aligned}
$$

This clearly shows that the calculations will predict rapid failure by vibration once the fatigue threshold is exceeded.

It is also of interest to establish other combinations of vibrational frequencies and threshold crack growth rates that will lead to rapid pipe failure. Rapid failure is viewed as failure in a time period that is brief relative to the ASME Section XI 10-yr inspection interval. Table 11 shows the time to grow a crack $1.0 \mathrm{in}$. for frequencies ranging from 100 to 10,000 cpm $(1.7$ to $1700 \mathrm{~Hz})$ and crack growth rates of $10^{-10}$ to $10^{-6} \mathrm{in./cycle}$.

Table 11 indicates that crack growth rates much below $10^{-9}$ in./cycle are unlikely to lead to significant crack growth. Thus, in developing $\mathrm{da} / \mathrm{dN}$ curves, one needs to establ ish the minimum $\Delta \mathrm{K}$ required to grow a crack at a rate of, say, $10^{-9}$ to $10^{-8} \mathrm{in./cycle,} \mathrm{and} \mathrm{this} \mathrm{value} \mathrm{can} \mathrm{serve} \mathrm{as} \mathrm{a}$ working definition of a threshold $\Delta \mathrm{K}$. Table 11 shows that vibrations at even low frequencies ( $100 \mathrm{cpm}$ or about $2 \mathrm{~Hz}$ ) can quickly give a sufficient number of stress cycles to fail a pipe in a time period less than a 10-year inspection interval.

Calculations have been performed using the crack growth rates of Section 3.2.4. The effects of vibrational frequency, ferritic versus stainless steel, threshold $\Delta K$, and flaw aspect ratio have been considered.

TABLE 11. Assessment of Crack Growth Rates and Vibrational Frequencies

Crack Crowth Rate,

Time for 1.0-in. of Crack Growth, in./cycle

$10^{-10}$

$10^{-9}$

$10^{-8}$

$10^{-7}$

$10^{-6}$

\begin{tabular}{ccc}
\multicolumn{3}{c}{ years } \\
\hline $100 \mathrm{cpm}$ & $1,000 \mathrm{cpm}$ & $10,000 \mathrm{cpm}$ \\
200.0 & 20.0 & 2.0 \\
20.0 & 2.0 & 0.2 \\
2.0 & 0.2 & 0.02 \\
0.2 & 0.02 & 0.002 \\
0.02 & 0.002 & 0.0002
\end{tabular}


Surface defects were assumed to be elliptical with the specific aspect ratios $(a / 2 c)$ of 0.1 and 0.5 . The state of stress through the pipe wall is considered to be uniform, which could approximate stresses for internal pressure or bending moment loads to the pipe. Back surface effects as a function of a/t were included in calculations of crack tip stress intensity fractions. No plastic zone size effects were considered.

A flaw was defined to be of a critical size if it grew through the wall of the pipe in a time that would be considered small when compared to the inspection interval. Specifically, a flaw was defined as critical if its growth rate had a magnitude of $\mathrm{da} / \mathrm{dt} \geq 1.0 \mathrm{in.} / \mathrm{yr}$. In the evaluations below, a pipe wall thickness of 2.5 in. was considered to be typical of a PWR primary cooling loop; thus, the criterion of $1.0 \mathrm{in./yr}$ implies a year or less before an ID surface flaw becomes a through-wall crack.

Figure 27 shows the critical depths for surface flaws for ferritic steel pipe as a function of cycle stress and frequency. The upper bound crack growth curve of Figure 15 was applied with the threshold $\Delta \mathrm{K}$ of $2.6 \mathrm{ksi}$ $\sqrt{i n}$. Once the frequency exceeds $120 \mathrm{cpm}$, there are a sufficient number of cycles accumulated in 1 year at the threshold growth rate to grow the crack the required $1 \mathrm{in./yr}$. At relatively low frequencies, the stress must be increased somewhat to give a sufficient growth per cycle for 1.0 in. of growth a year. Since vibration frequencies will usually exceed $120 \mathrm{cpm}$, it appears that frequency will not govern critical flaw size estimates. Rather, when any flaw growth occurs under vibrational stress, the number of cycles is so large that the flaw will grow at a rapid rate.

Figure 28 shows the effect of flaw aspect ratio and compares a long surface flaw with a half-penny surface flaw. These results were selected to correspond to the original analysis of the St. Lucie cold leg. In the original study, a $\Delta \sigma$ of $1.0 \mathrm{ksi}$ was assumed, for which the critical flaw depths of Figure 28 are 1.2 in. for $a / 2 c=0.1$ and 2.25 in. for $a / 2 c=0.5$. This compares favorably with the results given in 2 which indicated rapid growth of the $a / 2 c=0.1$ flaw once a depth of about 1 in. was attained (Figure 8-1c of Reference 2).

\subsubsection{Critical Flaw Sizes}

Figure 29 shows results for ferritic and stainless steel based on the crack growth curves of this report. Stainless steel appears to be somewhat less sensitive to vibrational stresses (larger critical flaw depths) than ferritic steels. While the estimate of the threshold $\Delta \mathrm{K}$ is slightly lower for stainless steel than ferritic steel, the much slower growth rates for stainless at the threshold results in somewhat larger critical flaw sizes for stainless. 


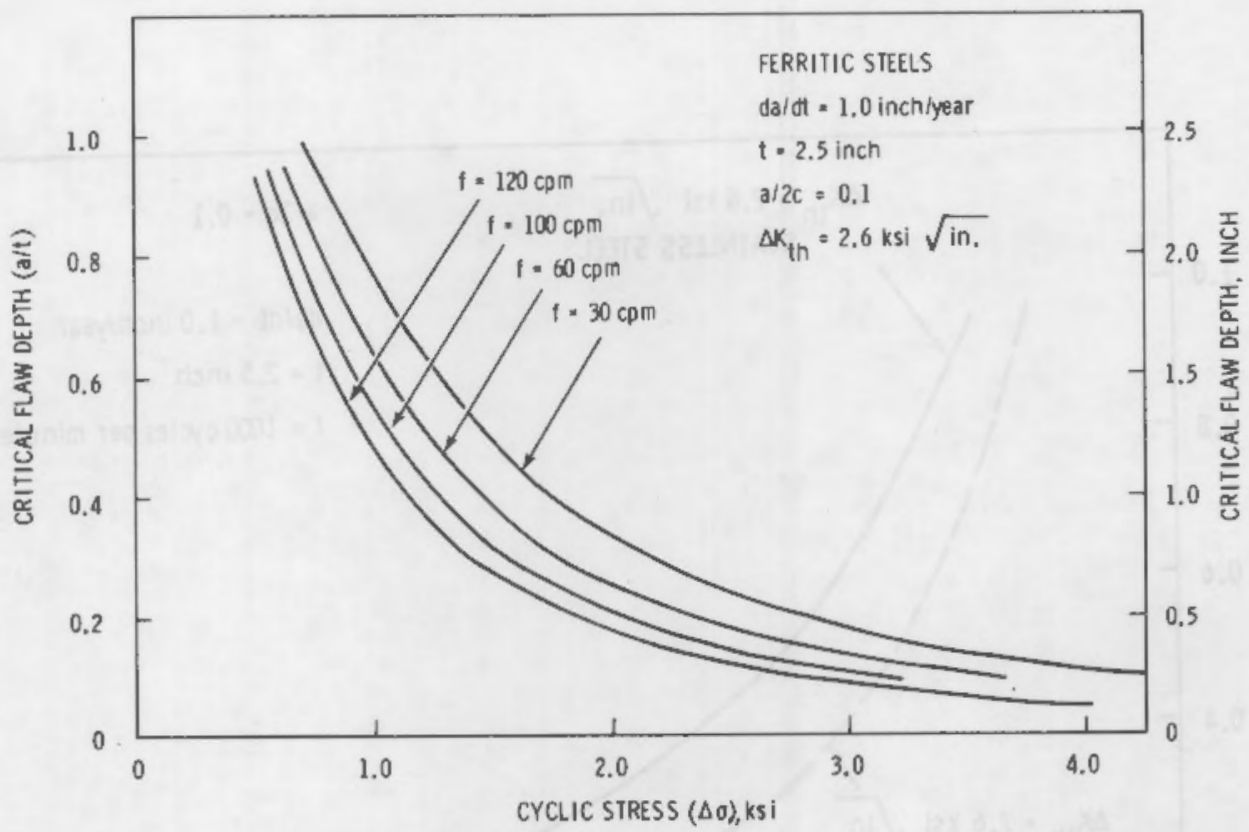

FIGURE 27. Effect of Vibrational Frequency on Critical Flaw Size

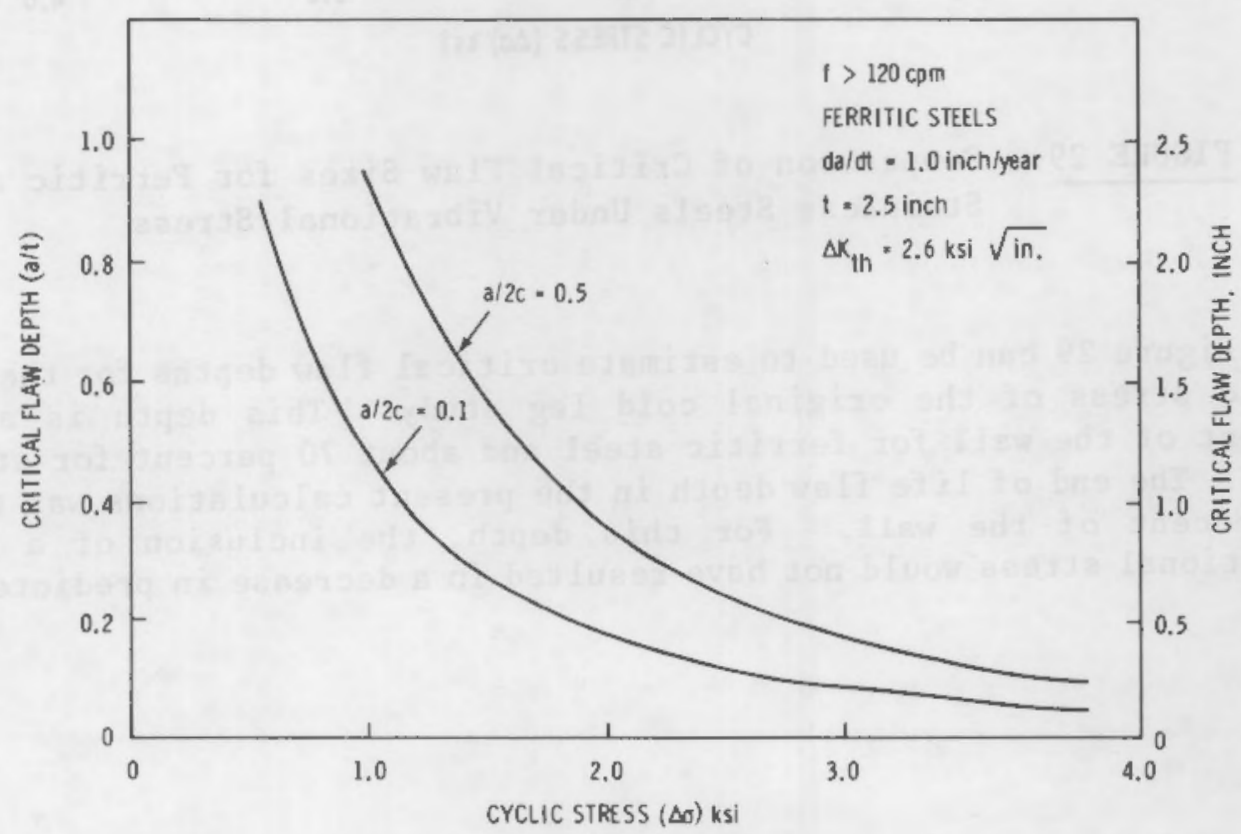

FIGURE 28. Effect of the Aspect Ratio of an ID Surface Flaw on Critical Flaw Size 


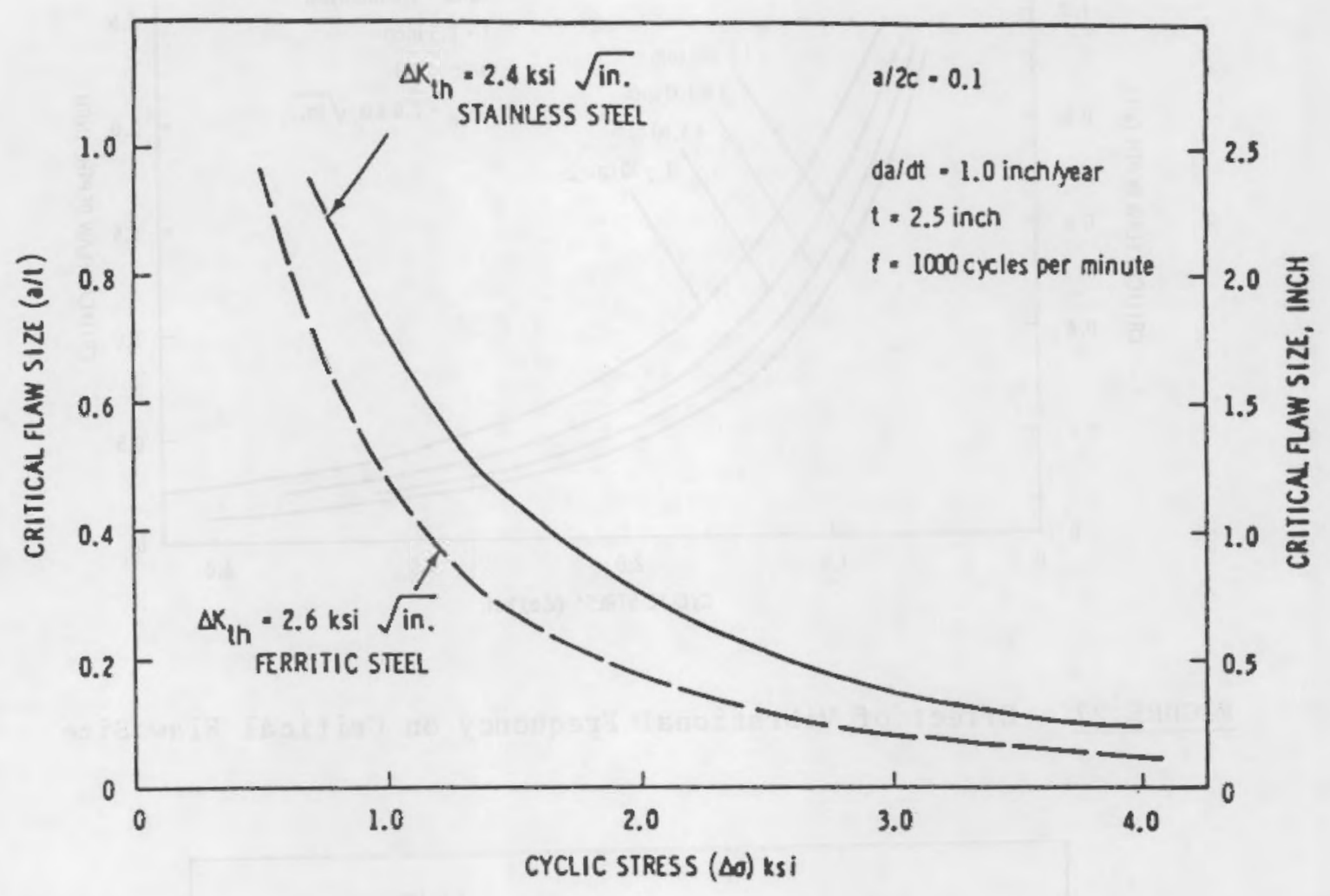

FIGURE 29. Comparison of Critical Flaw Sizes for Ferritic and Stainless Steels Under Vibrational Stress

Figure 29 can be used to estimate critical flaw depths for the $1.0 \mathrm{ksi}$ cyclic stress of the original cold leg study. This depth is about 50 percent of the wall for ferritic steel and about 70 percent for stainless steel. The end of $\mathrm{li}$ fe flaw depth in the present calculations was taken as 50 percent of the wall. For this depth, the inclusion of a $1.0 \mathrm{ksi}$ vibrational stress would not have resulted in a decrease in predicted life. 


\subsection{COMPARISON TO PROBABILISTIC ANALYSIS}

This section discusses a detailed comparison of the present deterministic analysis for the Farley-l plant with the probabilistic analysis given in Reference 1 for the $\mathrm{Zion-1}$ plant. First, the analyses are compared on the basis of the following input parameters:

1) description of component geometry

2) stress levels and stress history

3) fracture mechanics model

4) material properties

5) initial crack size and shape.

A quantitative comparison is then developed by assigning probabilities as measures of the conservatism inherent to the input parameters of the present deterministic analyses. Of primary concern are the initial flaw size and $\mathrm{da} / \mathrm{dN}$ curves, which are the parameters treated probabilistically in Reference 1.

\subsection{DISCUSSION OF INPUT PARAMETERS}

\subsubsection{Description of Component Geometry}

Both the Farley-1 and Zion-1 plants employ nuclear steam supply systems designed by Westinghouse. Recall from Figure 7 that Farley-1 is a three-loop design. Figure 30 shows Zion-1 to be a four-loop design. The cold legs between the two plants appear to be very similar in general configuration. For the purposes of this study, Point D in Farley-1 (see Figure 8) will be compared to Point 13 in Zion-1 (see Figure 30). This location is the juncture between the straight pipe and elbow. The crack was assumed to be in the straight pipe adjacent to the weld because Harris states "at joints where thickness transitions occurred (such as straight pipe run to elbow welds), the stresses in the thinner section were employed." (Ref. 1). Typically, elbows are made with a greater wall thickness than straight pipe.

Table 12 details the dimensions and materials used in the straight pipe sections of the two cold legs.

TABLE 12. Dimensions and Materials Used in the Straight Pipe Sections of the Cold Legs in Farley-1 and Zion-1

\begin{tabular}{|c|c|c|c|}
\hline Plant & Material & $\begin{array}{c}\text { Outside } \\
\text { Diameter, in. }\end{array}$ & $\begin{array}{c}\text { Thickness, } \\
\text { in. }\end{array}$ \\
\hline $\begin{array}{l}\text { Farley-1 } \\
\text { Zion-1 }\end{array}$ & $\begin{array}{ll}\text { SA-351 } & \text { Grade CF8A } \\
\text { SA-376 } & \text { Type } 316\end{array}$ & $\begin{array}{l}32.19 \\
32.26\end{array}$ & $\begin{array}{l}2.325 \\
2.38\end{array}$ \\
\hline
\end{tabular}




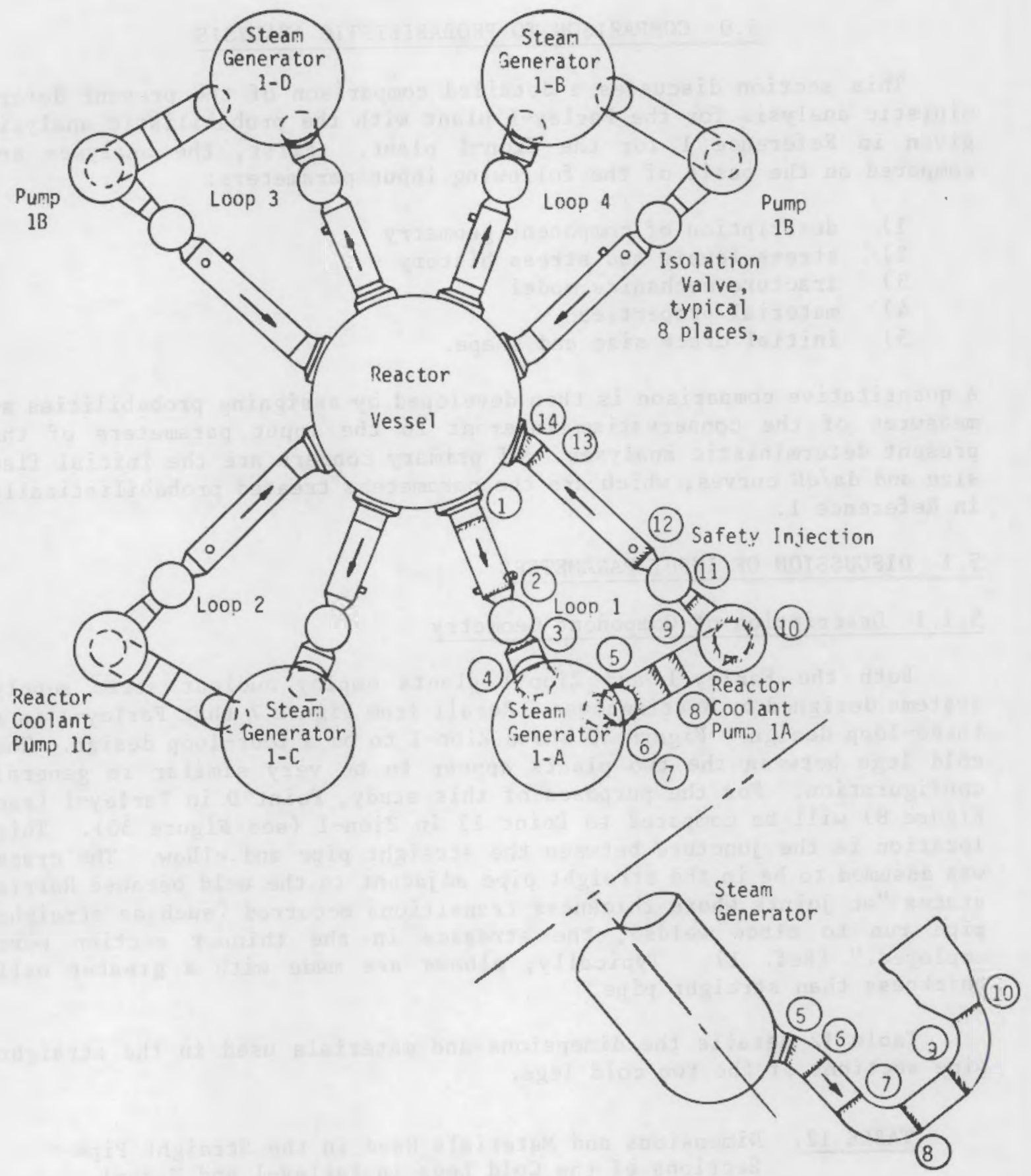

FIGURE 30. Diagram of Primary Piping of Zion-1 Showing Locations of Welds Considered (Ref. 1) 


\subsubsection{Stress Levels and Stress History}

The stress analysis for the primary coolant loop of $\mathrm{Zion-1}$ was conducted by Lawrence Livermore Laboratories and is reported in Volumes 2 and 3 of the nine-volume set of reports describing the Load Combination Program - Phase I. Unfortunately, there is insufficient detail in these volumes to make a cycle-by-cycle comparison with stresses given in the tables of Reference 2. However, a review of the reports and discussions with the authors revealed little difference in the methods and input assumptions used to compute the stresses. Pipe out-of-roundness was not considered in the Zion-l analysis but was considered in the Farley-1 analysis. However, this would not affect the axial stresses which are the focus of the present comparison. Differing viewpoints were taken in dealing with welding residual stresses and piping fit-up stresses. The effect of such stresses are addressed later in this discussion when the effect of mean stress on the da/dN curve is considered. Both the present analysis and the probabilistic analysis as sumed no crack growth caused by vibrational stresses.

A detailed comparison of calculated stress levels was beyond the scope of this study. However, it is likely that differences in calculated stresses should be relatively small and not as important as assumptions about initial flaw sizes and crack growth rate curves.

The cycle counting scheme used by Harris is quite similar to the range-pair counting method. This method apparently resulted in more than one stress cycle for each transient occurrence. The method used by BCL resulted in a single stress cycle for each transient occurrence. However, the Harris approach gives a smaller stress range for each "cycle" in the transient than for the single stress cycle used by BCL.

If one considers that fatigue damage is related to $(\Delta \sigma)^{n} \mathrm{~N}$, where $\mathrm{n}$ is the exponent in the Paris equation (see Section 3.2), then it is not clear whether the BCL cycle counting scheme is more conservative than the Harris approach. The relative conservatism would be a function of the stress ranges and number of cycles. To illustrate, consider a reactor trip transient where the reactor goes to a cold shutdown condition. The stress increases from the steady-state value of $15.09 \mathrm{ksi}$ (see Table 3-36(b) in Reference 2) to $17.43 \mathrm{ksi}$ and then falls to $\sim 0$. The BCL approach took this as one cycle with a range of $17.43 \mathrm{ksi}$. Harris might take this to be one cycle with range of $2.34 \mathrm{ksi}$ and one cycle with range of $15.09 \mathrm{ksi}$. Taking $\mathrm{n}=4$, the damage estimate from the BCL cycle would be $9.23 \times 10^{4}$ while the Harris cycles would yield a damage of $5.19 \times 10^{4}$. For this example, the BCL approach is more conservative. However, one cannot be sure that the BCL approach is always more conservative without more information concerning the Zion-1 stress analysis and implementation of the cycle counting procedure. 


\subsubsection{Fracture Mechanics Mode1}

The fracture mechanics model for crack growth used in Reference 1 permits crack growth in both the length and depth directions with the only constraint being that the crack shape must remain semi-elliptical although the aspect ratio can change. The stress intensity factor was generated using the Boundary Integral Generated Influence Function technique (Ref. 1). This K-solution, developed as part of Reference 1, is much more elaborate than the one-degree of freedom K-solution used by BCL (Ref. 2). The Harris approach is capable of accounting for through-wall stress gradients and the resulting changes in flaw shape (aspect ratio).

The influence function techniques are typically purely elastic. This is a disadvantage for the analysis of cracks in piping, since the loadings can produce gross section stresses on the order of the yield stress for operational transients. The K-solution used in Reference 2 attempts to account for plasticity through a correction applied, essentially to the crack length. In the present cold leg comparison, the applied stresses were relatively low, and plasticity effects should not play an important role.

\subsubsection{Material Properties}

As noted in Table 12, Farley-1 uses SA-351 Grade CF8A for the straight pipe while SA-376 Type 316 is used in Zion-1. Both of these materials are stainless steel and have essentially the same crack growth rates based on the data presented in both References 1 and 2 .

Harris presents his crack growth rate data on a plot of da/dN versus $\mathrm{K}_{\text {eff }}$ where the stress ratio, $\mathrm{R}$, is accounted for in $\mathrm{K}_{\mathrm{eff}}$. The BCL data are presented as $d a / d N$ versus $\Delta K$ for a given $R(R=0.7)$. As noted in Section 3.2 , the conversion of Reference 1 data from $K_{e f f}$ to $\Delta K$ assumed that $R=$ 0.7. The two lines describing the data were shown in Figure 16. The Reference 1 line results in higher crack growth rates up to a $\Delta K$ of about $10 \mathrm{ksi} \sqrt{\mathrm{in}}$. Above that level the Reference 2 line results in the higher growth rates. Since most of the stresses from Reference 2 result in $\Delta K^{\prime} s$ of 10 or greater, the BCL 1 ine results in more conservative life estimates for the same starting crack size. This is clearly demonstrated in Figure 22 .

There appears to be a bias to higher growth rates for the upper bound curve used in the present calculations as compared to the mean curve of the probabilistic analysis. This bias is factored into the quantitative comparison presented below. 
One other interesting comparison is in the threshold $\Delta \mathrm{K}$ values used in

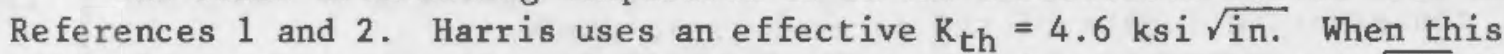

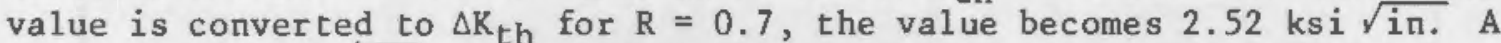

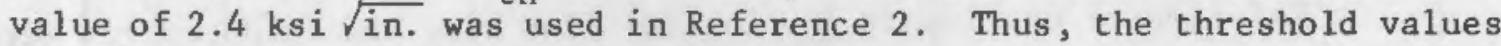
of $\Delta K^{\prime}$ s used in the two studies were very close.

\subsubsection{Initial Crack Size and Shape}

Reference 1 provides a rather detailed explanation and justification for the initial crack distribution used in the analysis. The initial distribution describes the cracks remaining at welds after the preservice inspection. This distribution is modified during the life of the joint only by the crack growth. There is no credit taken for inservice inspection (i.e., $P_{N D}=1$ for all crack sizes). These assumptions are consistent with the approach used in this study. The major difference is that the initial crack aspect ratio assumed here was kept constant; i.e., self-similar crack growth was assumed, while Harris allows crack growth in two directions, i.e., changes in flaw shape.

Reference 1 used the distribution of crack depths suggested in the Marshall report, with the mean depth of 0.246 inches. The crack aspect ratios $(\mathrm{a} / 2 \mathrm{~b})$ range from 0.5 to 0 . The distribution on aspect ratio is described as a "shifted lognormal" distribution. An aspect ratio of 0.1 is apparently a "reasonable" upper limit, although the distribution goes to zero. The mean of the distribution (excluding the 1 percent of the cracks having an aspect ratio greater than 0.1 ) is 0.305 . In formulating the crack size distributions, Harris assumed that the crack depth distribution and aspect ratio distribution were independent.

The initial crack distributions used by Harris have a mean depth of 0.246 inches and a mean aspect ratio of 0.305 with 1 percent of the aspect ratio being greater than 0.1 . The crack geometry considered herein has an initial depth of 0.250 with the fixed aspect ratio of 0.1 . This crack would lie well within the initial distribution of Reference 1.

\subsection{QUANTITATIVE COMPARISON}

Both the deterministic and probabilistic analyses predict that flaws will grow slowly for the cyclic stresses that are predicted at the location of interest in the cold leg piping. The conclusions are stated in quite different terms as follows:

Deterministic - The postulated initial flaw will grow to be a throughwall, leaking crack only after 55 design lives of 40 years.

Probabilistic - The probability of a leak during the 40-year design life is about $3.5 \times 10^{-8}$. 
These two conclusions will be compared by assigning probabilities to the conservative inputs of the deterministic analysis.

In Reference 1 the inputs for initial flaw size and $d a / d N$ curves were prescribed as probability distributions. The other inputs describing stress levels, crack-tip stress intensity factors and component geometry were treated as deterministic. The comparison to be performed here ignores possible differences the deterministic inputs of Reference 1 and the inputs of the deterministic calculations of this report -- or assumes that the differences cancel each other.

\subsubsection{Initial Flaw Probability}

Figure 31 shows the probabilities of having a flaw of a given depth and an aspect ratio that were assumed in Reference 1. These probabilities are conditional on there being a flaw in the weld. The probability of there being a flaw was estimated to be 0.1 .

The state space of Figure 31 shows both crack depth and length. The probability of a flaw existing in each cell is indicated in the cell. The reduced probability of a flaw after preservice inspection is indicated in parenthesis. For the difficult-to-inspect cast stainless steel, one can see that little benefit was predicted in Reference 1 for preservice inspection. The bold line shows the beginning-of-life flaw size (depth of 10 percent $t$ and aspect ratio of 0.1 ) used in the deterministic analysis of this report.

In the lower right corner of each cell there is a number that indicates a relative measure of crack tip stress intensity factor for the size of flaw corresponding to the cell. The shaded cells show those cells with a greater stress intensity factor than the beginning-of-life flaw assumed in the deterministic flaw growth calculations of this report.

The probability of a flaw being more severe than the 10 percent $t$ flaw of the deterministic calculation is obtained by adding the probability numbers for all the shaded cells. This probability is 0.26 . Since only one weld in ten will have any flaw, the probabilistic analysis of Reference 1 had a 0.026 probability of having a more severe flaw than the 10 percent $t$ flaw assumed in the present calculations.

\subsubsection{Growth Rate Probability}

In Reference 1 the crack growth rate $d a / d N$ was taken to have a lognormal distribution about the mean value curve of Figure 16 . This distribution is plotted in Figure 32, and shows the probability that the crack growth rate will be a given factor $\left(\mathrm{c} / \mathrm{C}_{50}\right)$ greater than the mean. This plot will be useful here in associating a probability of occurrence with differences in crack growth rates. 


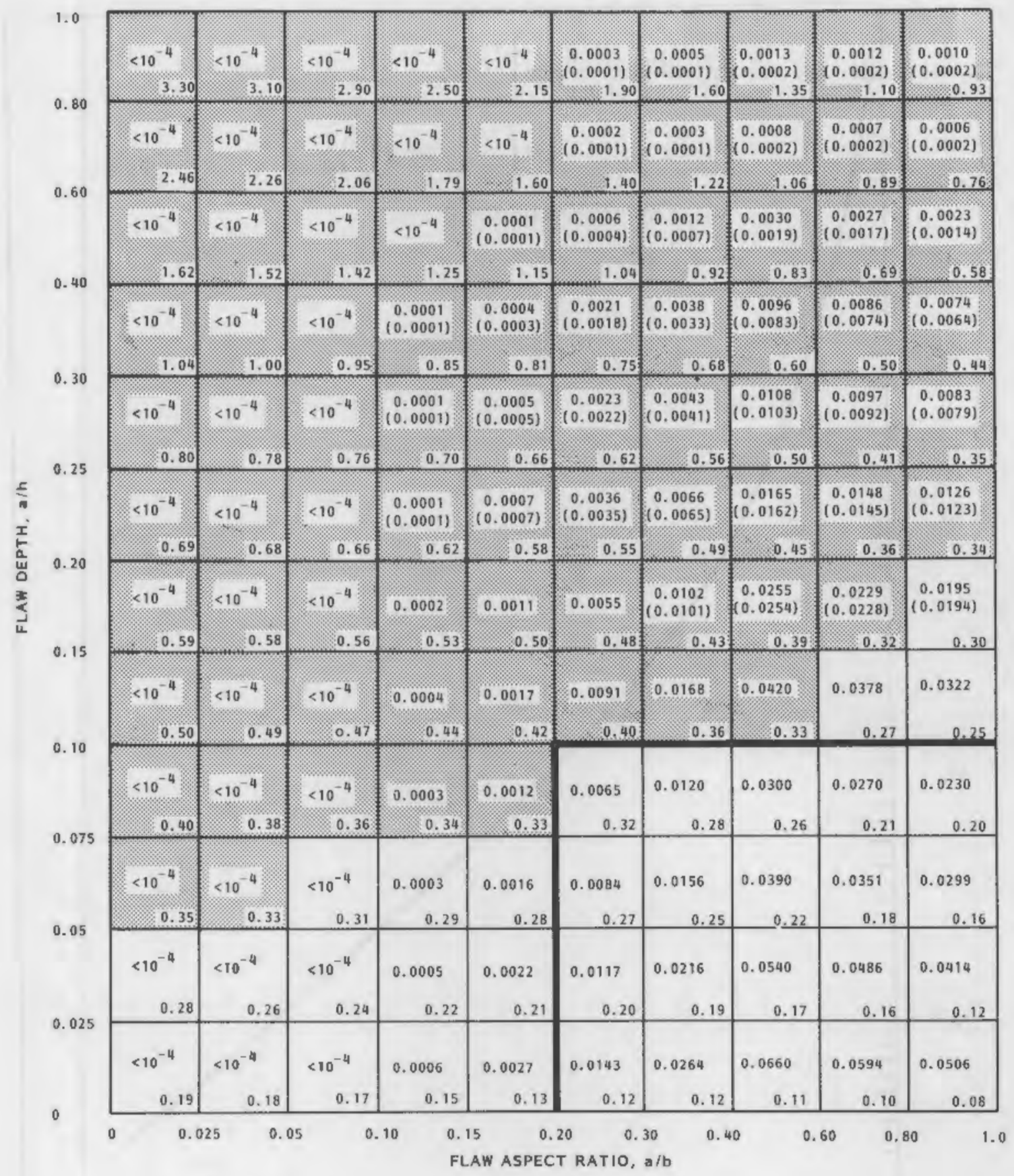

LEGENO

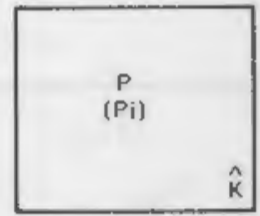

$P=$ PROBABILITY OF CRACK WITHOUT INSERVICE INSPECTION $P \mathbf{P}=$ PROBABILITY OF CRACK WITH INSERVICE INSPECTION $K=$ RELATIVE VALUE OF STRESS INTENSITY FACTOR $\mathbf{a}=$ CRACK OEPTH $2 b=$ CRACK LENCTH $h=$ WALL THICKNESS

FIGURE 31. Conditional Probability of Crack Existing in Various Regions of State Space 


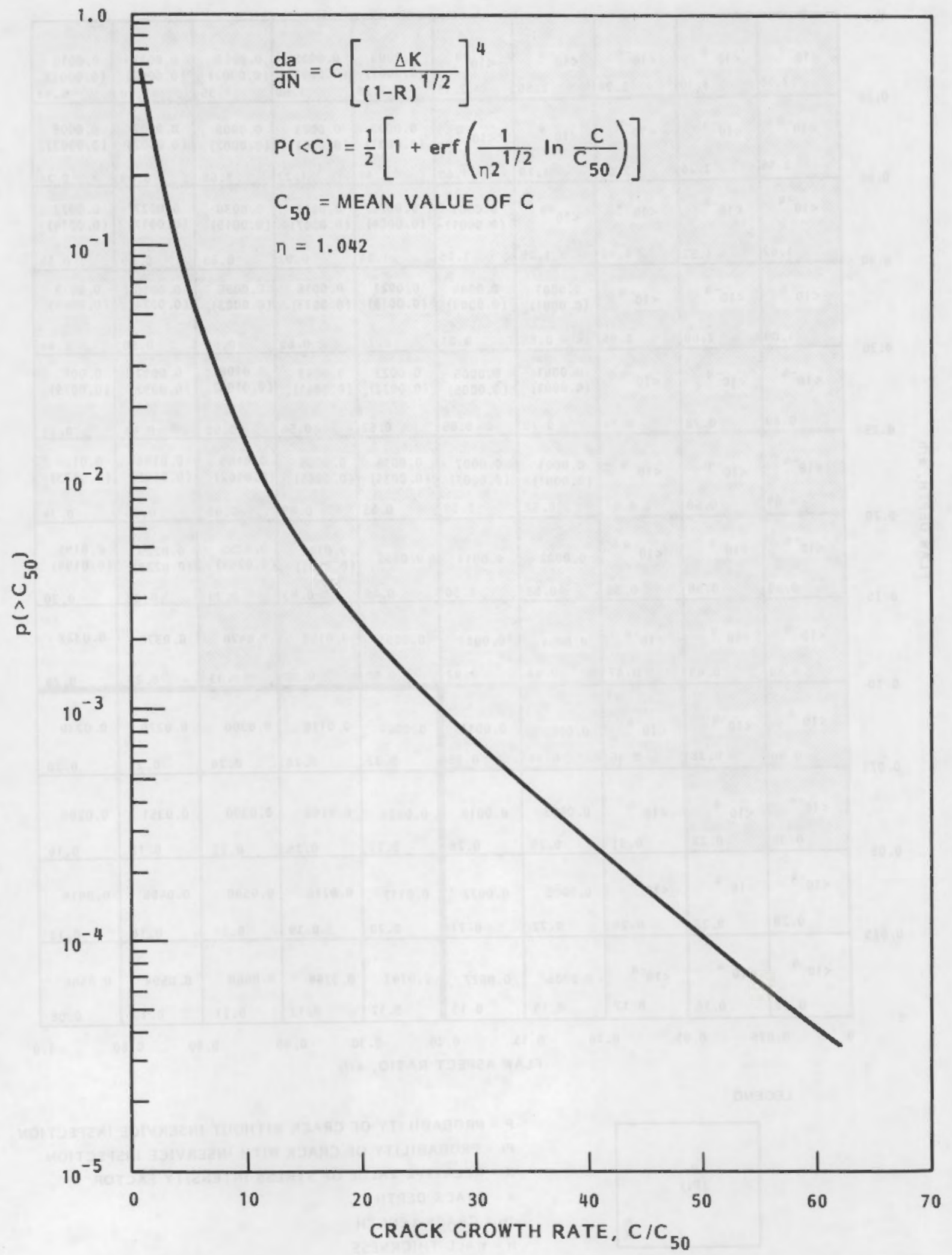

FIGURE 32. Probability Distribution on Crack Growth Rate Coefficient C 
In the deterministic calculations, the 1 ife was predicted to be 55 design lives of 40 years. As noted previously, this prediction included a more conservative fit of the growth rate data than that used for the mean curve of the probabilistic calculations. As indicated in Section 4.2, the mean curve of Harris (Ref. 1) gave a growth rate about one-half that of the tri-linear upper bound curve used here. It has been further noted that the probabilistic model did not consider the effect of residual and fit-up stresses on mean stress. Since crack growth in Reference 1 was attributed mainly to the startup/shutdown cycle, the implied value of $R$ was 0.0 rather than the conservative value of 0.7 used in this report. This difference in $R$ can be used to compute relative crack growth rates through the $K_{e f f}$ parameter. In this way, the difference between $R=0$ and $R=0.7$ implies a factor of about 10 in crack growth rates.

Thus, the deterministic calculations need to be adjusted by a factor of 10 (e.g., $R$ effect) times 3 (mean vs upper bound curve fit) for comparison with the probabilistic results. Thus, adjusting for differences in conservatism, the predicted 1 ife at joint D becomes $55 \times 30=1,650$ design lives of 40 years. This deterministic prediction of a very long life would be expected to correlate with a very low failure probability.

\subsubsection{Leak Probability}

Upper and lower bounds will be estimated for the leak probability implied by the deterministic calculations. It will be assumed that a leak (i.e., through-wall flaw) can occur if either a flaw larger than the postulated flaw is present or if the postulated flaw grows at a greater rate than calculated.

Table 13 lists flaw depths from $a / h=0.10$ to 0.95 along with two associated probabilities. The probability $P_{1}$ is the probability that a more severe flaw is present, while $P_{2}$ is the probability that the flaw of depth a/h will grow at a sufficient rate to leak in one design life. As shown in Table 13, the probability of a very large flaw is very low, and the probability of a rapidly growing small flaw is also very low.

Bounds on the probability of a leak in the 40-year design life were estimated from the $P_{1}$ and $P_{2}$ values of Table 13. These bounds were as foll ows :

Upper bound on Failure Rate, $P_{1}+P_{2}\left(0.1-P_{1}\right)-$ Assume that all flaws greater than $a / h$ will fail, and that all flaws less than $a / h$ grow as fast as the $a / h$ flaw.

Lower Bound on Failure Rate, $P_{1} \times P_{2}$ - Assume that all flaws greater than a/h grow at the same rate as the a/h flaw and that all flaws less than $a / h$ have a zero probability of failure. 
TABLE 13. Probabilities Associated with Inputs to Deterministic Analysis of Joint D of Farley-1

\begin{tabular}{c}
$\begin{array}{c}\text { Flaw Depth } \\
\text { a/h }\end{array}$ \\
\hline 0.10 \\
.15 \\
.20 \\
.25 \\
.30 \\
.40 \\
.50 \\
.60 \\
.70 \\
.80 \\
.90 \\
.95
\end{tabular}

\begin{tabular}{l}
$P_{1}$ (Probabilite \\
Occurrence \\
More Severe \\
\hline $3 \times 10^{-2}$ \\
$1 \times 10^{-2}$ \\
$6 \times 10^{-3}$ \\
$3 \times 10^{-3}$ \\
$1 \times 10^{-3}$ \\
$5 \times 10^{-4}$ \\
$2 \times 10^{-4}$ \\
$5 \times 10^{-5}$ \\
$1 \times 10^{-5}$ \\
$4 \times 10^{-6}$ \\
$1 \times 10^{-6}$ \\
$4 \times 10^{-7}$
\end{tabular}

$P_{2}$ (Probability of Growing to a Through-Wa1l F1aw) $6 \times 10^{-13}$

$4 \times 10^{-12}$

$5 \times 10^{-11}$

$4 \times 10^{-10}$

$5 \times 10^{-9}$

$3 \times 10^{-7}$

$8 \times 10^{-6}$

$2 \times 10^{-5}$

$8 \times 10^{-5}$

$4 \times 10^{-4}$

$3 \times 10^{-3}$

$2 \times 10^{-2}$
Probability of Leaking in

the 40-yr Design Life

\begin{tabular}{|c|c|}
\hline $\begin{array}{c}\text { Upper Bound } \\
\mathrm{P}_{1}+\mathrm{P}_{2} \times\left(0.1-\mathrm{P}_{1}\right) \\
\end{array}$ & $\begin{array}{c}\text { Lower Bound } \\
\mathrm{P}_{1} \times \mathrm{P}_{2} \\
\end{array}$ \\
\hline $3 \times 10^{-2}$ & $2 \times 10^{-14}$ \\
\hline $1 \times 10^{-2}$ & $4 \times 10^{-14}$ \\
\hline $6 \times 10^{-3}$ & $3 \times 10^{-13}$ \\
\hline $3 \times 10^{-3}$ & $1 \times 10^{-12}$ \\
\hline $1 \times 10^{-3}$ & $5 \times 10^{-12}$ \\
\hline $5 \times 10^{-4}$ & $1 \times 10^{-12}$ \\
\hline $2 \times 10^{-4}$ & $2 \times 10^{-9}$ \\
\hline $5 \times 10^{-5}$ & $1 \times 10^{-9}$ \\
\hline $2 \times 10^{-5}$ & $8 \times 10^{-10}$ \\
\hline $4 \times 10^{-5}$ & $2 \times 10^{-9}$ \\
\hline $3 \times 10^{-4}$ & $3 \times 10^{-9}$ \\
\hline $2 \times 10^{-3}$ & $8 \times 10^{-9}$ \\
\hline
\end{tabular}


Table 13 was scanned to identify the least upper bound and the greatest lower bound, and the following estimate of the probability of leak in the 40-year design life was obtained:

$$
10^{-8}<P_{\text {leak }}<10^{-5}
$$

This estimate is consistent with the leak probability of $3.5 \times 10^{-8}$ from Reference 1, which is relatively close to the lower bound estimated here. The quantitative estimates of Table 13 show that a low probability of failure can be associated with the deterministic flaw growth calculations of this report. Also, the quantitative estimate of failure probability is consistent with the value obtained from the probabilistic fracture calculations of Reference 1 . 


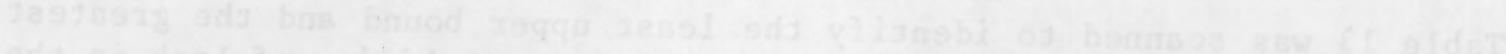
15020

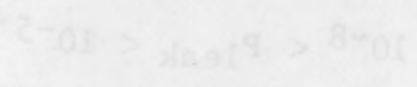

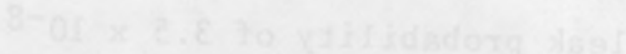

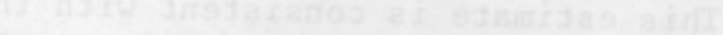

-

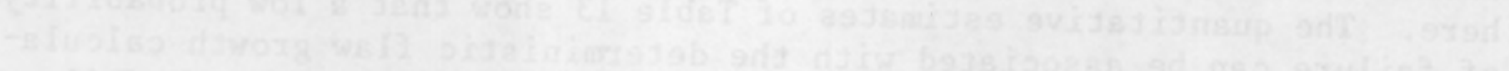
Cratain

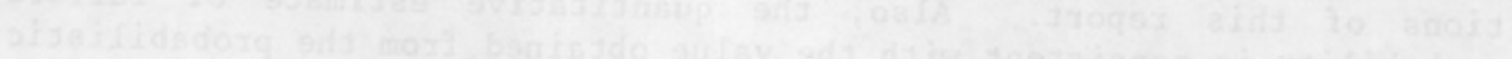
- 


\subsection{CONCLUSIONS}

The principal conclusions of this study are:

1. Changing the input parameters as described herein greatly increased the predicted crack growth lives as compared to the results of Reference 2.

2. The smaller initial flaw sizes and the deletion of the vibrational transient had the greatest effect on increasing crack growth lives; changes in the crack growth rate curves and deletion of lowprobability transients had a lesser effect.

3. The life of the charging inlet nozzle of St. Lucie-1 was still less than one design life, indicating this is a fatigue-critical location, even for normal operation.

4. The lives for welds with circumferential flaws ranged from 13 to 100 design lives, and the lives for welds with axial flaws ranged from 4 to 50 design lives.

5. Results of the deterministic calculations of this study are consistent with the low failure probabilities of Reference 1.

6. The inclusion of vibrational stresses is equivalent to decreases in the critical end-of-life flaw size.

7. Including the effects of the DMW (dissimilar metal weld) gradient increases the calculated life by a factor of about 1.7. 


\subsection{REFERENCES}

1. D.O. Harris, E.Y. Lim, and D.D. Dedhia, "Probability of Pipe Fracture in the Primary Coolant Loop of a PWR Plant, Volume 5: Probabilistic Fracture Mechanics Analysis", NUREG-CR-2189, Vo1. 5, August 1981.

2. M.E. Mayfield, T.P. Forte, E.C. Rodabaugh, B.N. Leis, and R.J. Eiber, "Cold Leg Integrity Evaluation", NUREG/CR-1319, 1980.

3. Rules for Inservice Inspection of Nuclear Power Plant Components, Section XI, Division 1, 1980 Edition.

4. W.H. Bamford, "Technical Basis for Revised Reference Crack Growth Rate Curves for Pressure Boundary Steels in LWR Environment", ASME J. of Pressure Vessel Technology, Vo1. 102, pp. 433-442, November 1980.

5. R.M. Engle, CRACKS III, Version 1, Air Force Flight Dynamics Laboratory,. Wright-Patterson AFB, July 10, 1975. 



\section{DISTRIBUTION}

No. of

Copies

\section{OFFSITE}

385 U.S. Nuclear Regulatory Commission

Division of Technical Information and Document Control 7920 Norfolk Avenue Bethesda, MD 20014

U.S. Nuclear Regulatory Commission

Division of Reactor Safety Research

7920 Norfolk Avenue

Bethesda, MD 20014

W.F. Anderson

U.S. Nuclear Regulatory Commission Office of Nuclear Regulatory Research Mail Stop 1130-SS

Washington, D.C. 20555

R.E. Johnson

U.S. Nuclear Regulatory Commission Generic Issues Branch

Mail Stop 268 Phillips Bldg.

Washington, D.C. 20555

J. Muscara

U.S. Nuclear Regulatory Commission Office of Nuclear Regulatory Research Mail Stop 1130-SS

Washington, D.C. 20555

G. Weidenhamer

U.S. Nuclear Regulatory Commission Office of Nuclear Regulatory Research Mail Stop 1130-SS

Washington, D.C. 20555

R.C. Cipolla

Aptech Engineering Services

795 San Antonio Road

Palo Alto, CA 94303
W.J. Shack

Irgonne National Laboratory

9700 South Cass Ave.

trgonne, IL 60439

J.M. B loom

Babcock \& Wilcox Company

Alliance Research Center

P.0. Box 835

Alliance, $\mathrm{OH} 44601$

W.A. Van Der Sluys

Babcock \& Wilcox Company

Alliance Research Center

1562 Beeson Street

Alliance, $\mathrm{OH} 44601$

G.M. Wilkowski

Battelle Columbus Laboratories $505 \mathrm{King}$ Ave.

Columbus, $\mathrm{OH} 43201$

P.C. Paris

Del Research Corporation

7730 Caronde let

Suite \#408

St. Louis, M0 63105

T.J. Griesbach

Electric Power Research Institute

Nuclear Safety Analysis Center

3412 Hillview Avenue

Palo Alto, CA 94303

D.M. Norris

Electric Power Research Institute Nuclear Systems and Materials Dept. 3412 Hillview Avenue

Palo Alto, CA 94303 
T.U. Marston

Electric Power Research Institute Nuclear Systems and Materials Dept. 3412 Hillview Avenue

Palo Alto, CA 94303

C.E. Buchalet

Framatome

Tour Fiat/Cedex 16

92-084 Paris La Defense

FRANCE

L.J. Chockie

General Electric Company

Nuclear Energy Business Operation

175 Curtner Avenue, M/C 363

San Jose, CA 95125

S. Ranganath

General Electric Company

175 Curtner Avenue, M/C 775

San Jose, CA 95125

S. Yukawa

General Electric Company

Materials \& Processes Laboratory

One River Road, Bldg. 55, Rm 113

Schenectady, NY 12345

F.L. Becker

J.A. Jones Applied Research Co.

P.0. Box 217097

Charlotte, NC 28221

C.K. Chou

Lawrence Livermore National Lab

700 East Avenue

Livermore, CA 94550

H.H. Woo

Lawrence Livermore National Lab

7000 East Avenue

Livermore, CA 94550
B.R. Maccary

Consultant

9306 Over lea Drive

Rockville, MD 20850

M.E. Mayfield

Materials Engineering Associates

9700 B Palmer Highway

Lanham, MD 20706

E. Debarba Northeast Utilities Service Co. P.0. Box 270

Hartford, CT 06101

M. Kupinski

Northeast Utilities Service Co.

P.D. Box 270

Hartford, CT 06101

P.C. Riccardella

Nutech In.

6835 Via Del Oro

San Jose, CA 95119

J.G. Merkle

0ak Ridge National Laboratory

P.0. Box Y

Oak Ridge, TN 37830

D.0. Harris

Science Applications, Inc.

5 Palo Alto Square

Suite 200

Palo Alto, CA 94304

W.H. Bamford

Westinghouse Electric Corp.

P. 0 . Box 355

Pittsburgh, PA 15230 
No. of

Copies

\section{ONSITE}

40 Pacific Northwest Laboratory

W. E. Anderson

M. C. C. Bampton

S. H. Bush

R. A. Clark

S. R. Doctor

G. B. Dudder

C. W. Goodrich

P. G. Heasler

P. H. Hutton

K. I. Johnson

G. J. Posakony

G. P. Selby

F. A. Simonen (20)

T. T. Taylor

A. M. Sutey

Technical Information (5)

Publishing Coordination SH (2) 


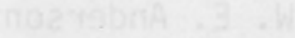

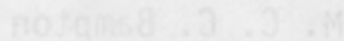

$19249=14=2$

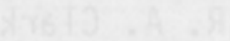

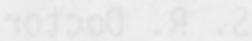

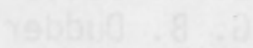

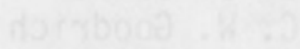

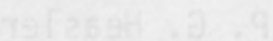

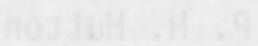

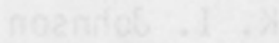

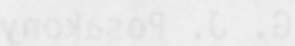

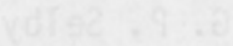

Q10.2.

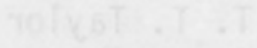

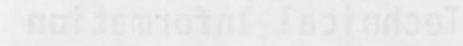




\begin{tabular}{|c|c|c|c|}
\hline \multirow{3}{*}{\multicolumn{2}{|c|}{ 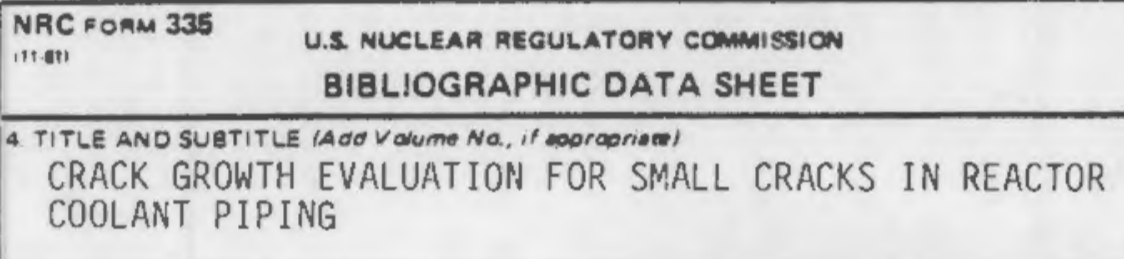 }} & \multicolumn{2}{|c|}{$\begin{array}{l}\text { 1. AEPOAT NUMEER (A supned oy OOC) } \\
\text { NUREG/CR }-3176 \\
\text { PNL }-4642\end{array}$} \\
\hline & & \multicolumn{2}{|l|}{ 2. (Levere olenk) } \\
\hline & & \multicolumn{2}{|c|}{ 3. RECIPIENT'S ACCESSION NO. } \\
\hline \multicolumn{2}{|c|}{$\begin{array}{l}\text { 7. AUThorisi } \\
\text { F.A. Simonen, M.E. Mayfield, T.P. Forte, D. Jones }\end{array}$} & \multicolumn{2}{|c|}{ 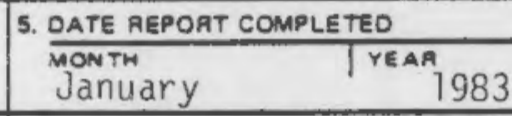 } \\
\hline \multicolumn{2}{|c|}{ 9. PERFORMING ORGANIZATION NAME AND MAILING ADORESS (Inelucie Zio Code) } & \multicolumn{2}{|c|}{ DATE REPOAT ISSUED } \\
\hline \multirow{2}{*}{\multicolumn{2}{|c|}{$\begin{array}{l}\text { Pacific Northwest Laboratory } \\
\text { Richland, Washington } 99352\end{array}$}} & \multicolumn{2}{|c|}{\begin{tabular}{l|l} 
MONTN & TYEAA \\
Apri1 & 1983 \\
\end{tabular}} \\
\hline & & \multicolumn{2}{|c|}{ 6. (Leme wenk) } \\
\hline & & \multicolumn{2}{|l|}{ 8. (Levere brenk) } \\
\hline \multirow{2}{*}{\multicolumn{2}{|c|}{ 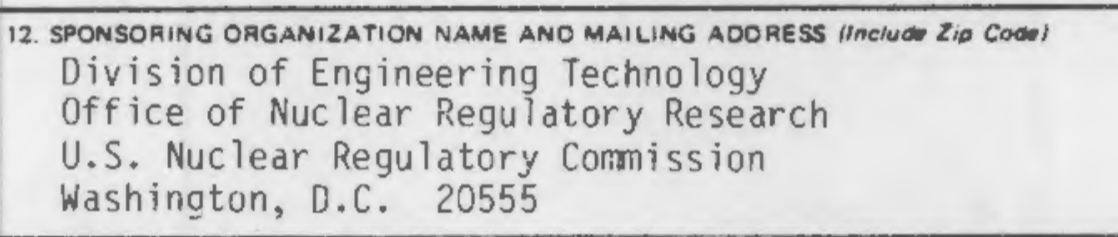 }} & \multicolumn{2}{|c|}{ 10. PROJECT/TASK/WORK UNIT NO. } \\
\hline & & \multicolumn{2}{|l|}{ 11. FIN NO. } \\
\hline \multicolumn{4}{|l|}{ 13. TYPE OF PEPORT } \\
\hline \multicolumn{2}{|l|}{ 15. SUPPLEMENTAAY NOTES } & \multicolumn{2}{|l|}{ 14. (Levere alank) } \\
\hline \multicolumn{4}{|c|}{ 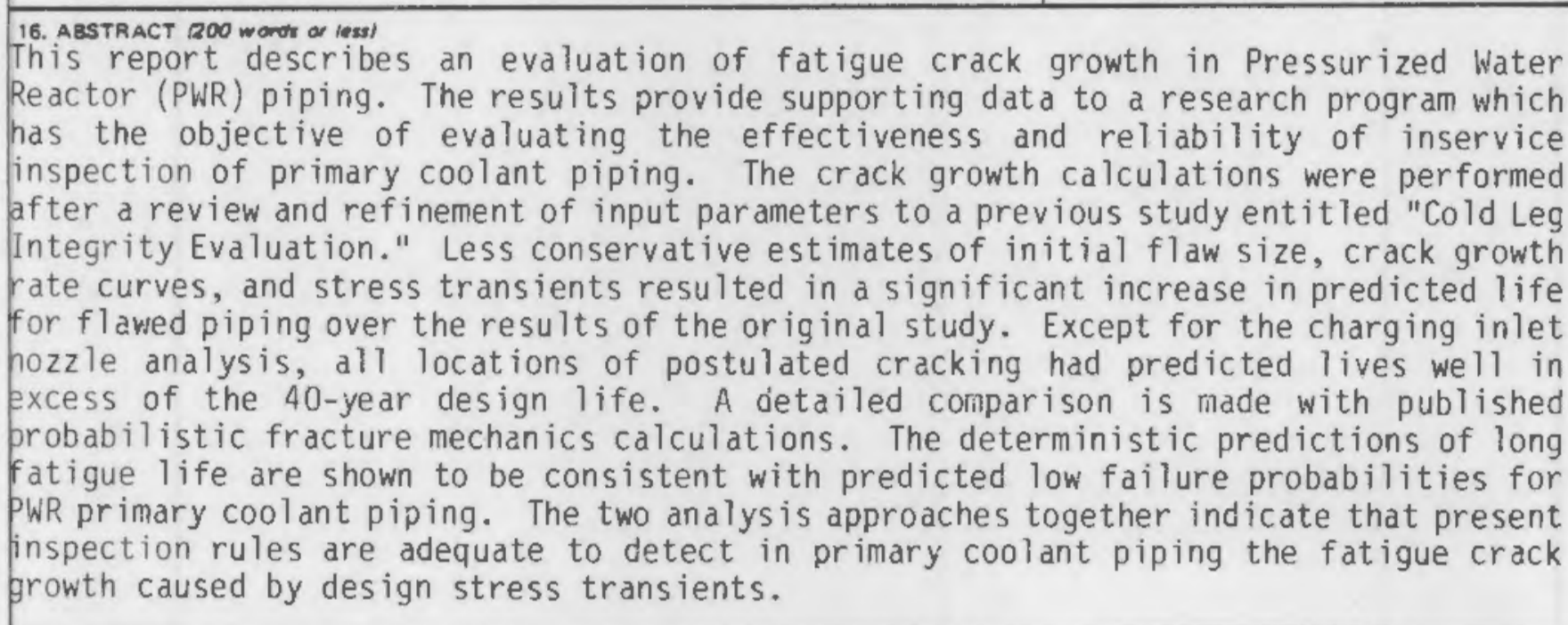 } \\
\hline \multicolumn{4}{|c|}{ 17. KEY WOROS ANO DOCUMENT ANALYSIS 17G OESCAIPTORS } \\
\hline \multicolumn{4}{|c|}{ 176. IDENTIFIERS:OPEN-ENDEO TEAMS } \\
\hline \multirow{2}{*}{$\begin{array}{l}\text { 18. AVAILABILITY STATEMENT } \\
\text { Unlimited }\end{array}$} & \multirow{2}{*}{\multicolumn{2}{|c|}{ 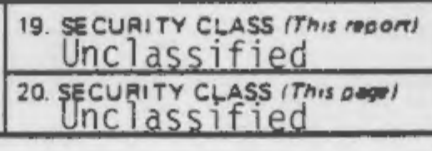 }} & 21 NO. OF PAGES \\
\hline & & & $\begin{array}{l}\text { 22. PAICE } \\
\mathrm{S}\end{array}$ \\
\hline
\end{tabular}




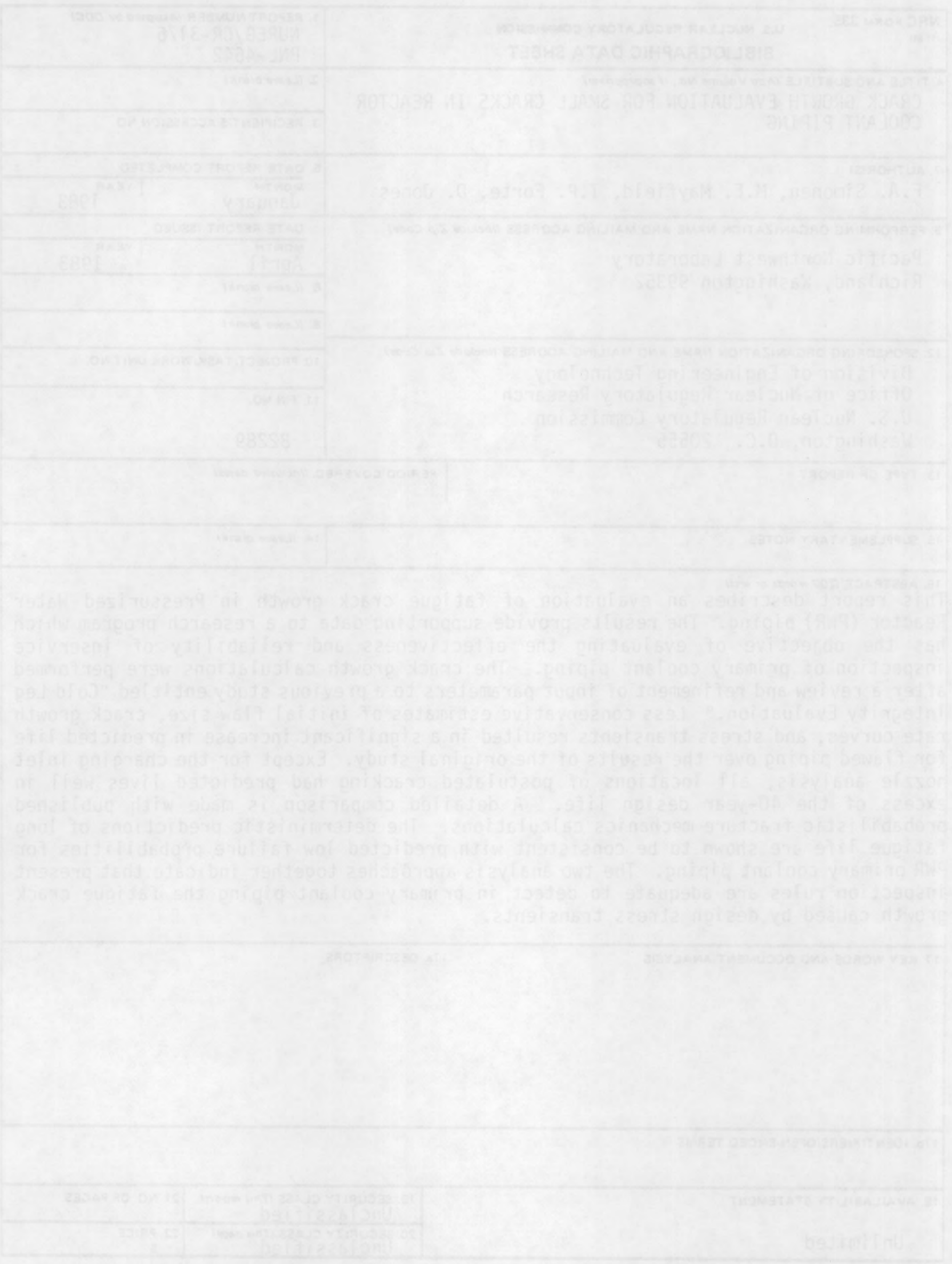

